\title{
Urban Dialysis : \\ [re]invigorating urban vitality using adhocism
}

by

\section{Mei Ling Chow}

A thesis submitted to the Faculty of Graduate and Postdoctoral Affairs in partial fulfillment of the requirements for the degree of

Master of Architecture

in

Master of Architecture Professional

Carleton University

Ottawa, Ontario

(C) 2012

Mei Ling Chow 
Library and Archives

Canada

Published Heritage

Branch

395 Wellington Street

Ottawa ON K1A ON4

Canada
Bibliothèque et

Archives Canada

Direction du

Patrimoine de l'édition

395 , rue Wellington

Ottawa ON K1A ON4

Canada
Your file Votre référence

ISBN: 978-0-494-91512-7

Our file Notre référence

ISBN: $978-0-494-91512-7$
NOTICE:

The author has granted a nonexclusive license allowing Library and Archives Canada to reproduce, publish, archive, preserve, conserve, communicate to the public by telecommunication or on the Internet, loan, distrbute and sell theses worldwide, for commercial or noncommercial purposes, in microform, paper, electronic and/or any other formats.

The author retains copyright ownership and moral rights in this thesis. Neither the thesis nor substantial extracts from it may be printed or otherwise reproduced without the author's permission.
AVIS:

L'auteur a accordé une licence non exclusive permettant à la Bibliothèque et Archives Canada de reproduire, publier, archiver, sauvegarder, conserver, transmettre au public par télécommunication ou par l'Internet, prêter, distribuer et vendre des thèses partout dans le monde, à des fins commerciales ou autres, sur support microforme, papier, électronique et/ou autres formats.

L'auteur conserve la propriété du droit d'auteur et des droits moraux qui protege cette thèse. $\mathrm{Ni}$ la thèse ni des extraits substantiels de celle-ci ne doivent être imprimés ou autrement reproduits sans son autorisation.
In compliance with the Canadian Privacy Act some supporting forms may have been removed from this thesis.

While these forms may be included in the document page count, their removal does not represent any loss of content from the thesis.
Conformément à la loi canadienne sur la protection de la vie privée, quelques formulaires secondaires ont été enlevés de cette thèse.

Bien que ces formulaires aient inclus dans la pagination, il n'y aura aucun contenu manquant. 


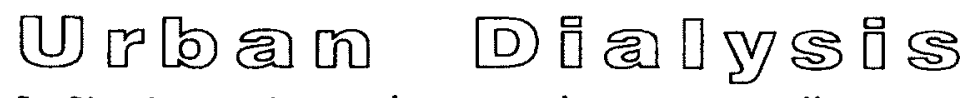
[re]invigorating urban vitality using adhocism

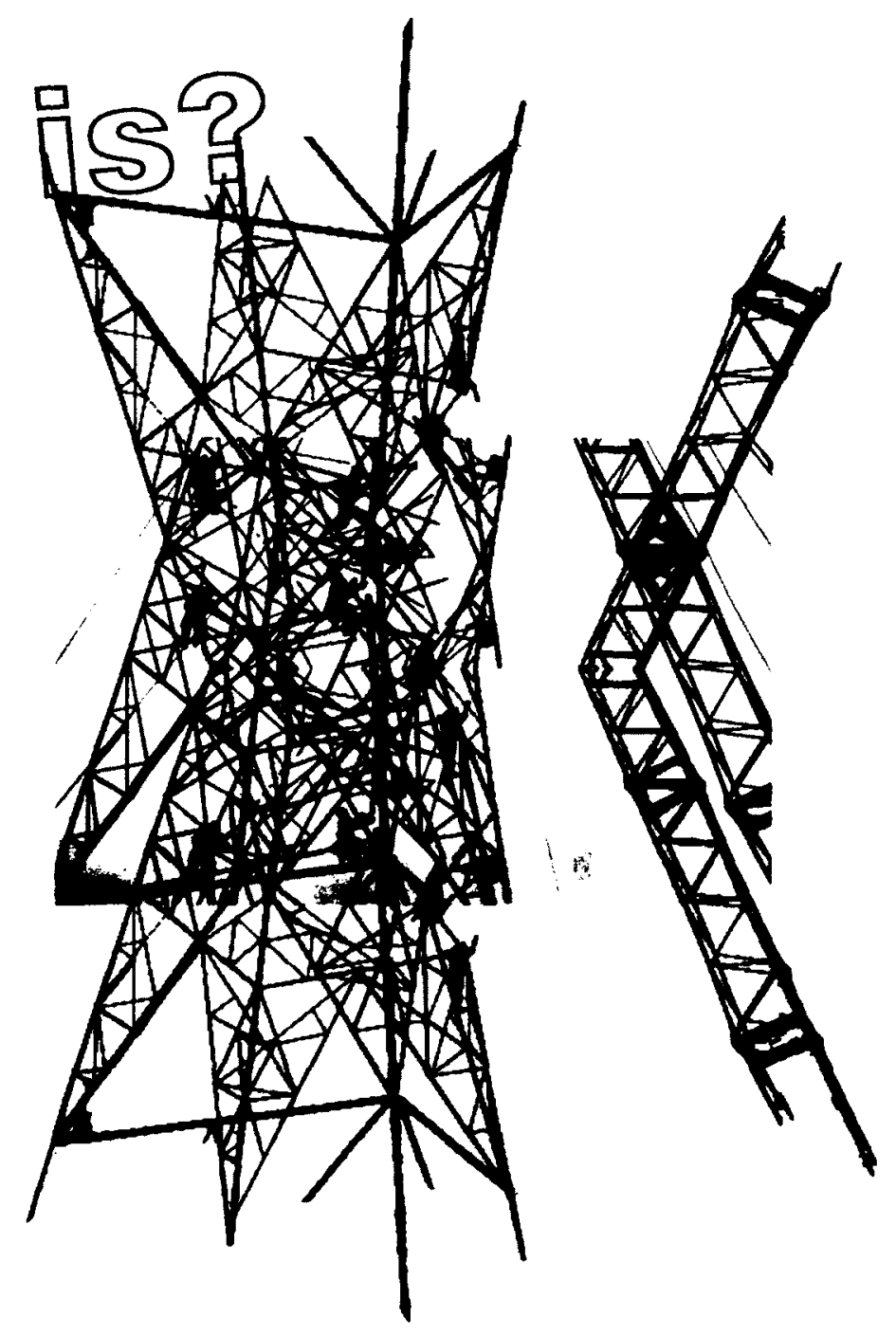




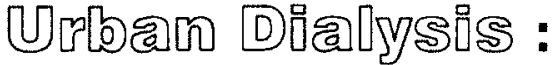 \\ [re]invigorating urban vitality using adhocism}

by Mei Ling Chow

A thesis submitted to the Faculty of Graduate and Postdoctoral Affairs in partial fulfillment of the requirements for the degree of

Master of Architecture in

Master of Architectural Studies

Carleton University

Ottawa, Ontario

(C) 2012

Mei Ling Chow 


\section{Acknowledgement}

The successful completion of this thesis would not have been possible without the following people.

Thesis Advisor

Roger Connah's support has been tremendous, he not only guided my efforts he also embraced my ideas and directed me to related paths.

\section{Cheer-leading Angels}

My family has been my cheer-leaders and my emotional guardian angels all through this year long process. I deeply thank my mame, papa, saklo Dickson, muimui Kennis, and Maggie for their love and constant support.

\section{Laughter Angel}

I am very grateful for all the stories and jokes my mother-in-law shared with me as well as her humorous and inventive way of carrying on our conversations, she helped take a lot of thesis stress away.

\section{Friends \& fellow students}

I thank my friends and fellow thesis studio classmates for all the discussions and encouragement.

The two Michaels

Thank you goes to my husband Michael and my nephew Michael for taking care of all the chores at home so I could focus on my thesis 24-7.

\section{Ad hoc Angel}

This angel shared the good times and the bad throughout this challenging process. He is the person who made me coffee every morning, the first reader of every passage, my assistant editor, personal manservant, a constantly bothersome questioner, occasional packmule, partner in social adhocism and the biggest contributor (after me) to the success of this thesis my husband Michael.

My sincerest thank you to all of the people l've mentioned; I would not be where I am today without their help. 


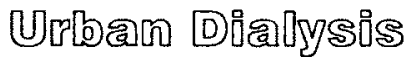

[re]invigorating urban vitality using adhocism 


\section{Abstract}

The changes in the ecology of the urban fabric within cities - without careful application in maintaining or promoting vibrant and livable neighbourhoods - can lead to a notable decrease of the quality of life in communities. Two of the primary problems of providing publicly available active areas within cities are the issues of finance and time constraints. Under these conditions how can architecture, normally an expensive and long process, help when the problems are cost and time? Could an ad hoc architecture approach turn the problems to opportunities and allow spaces and structures that can be built quickly and inexpensively? Would ad hoc architecture, as we see it, continuously evoke user curiosity, imagination and interest, or would it be a mere distraction as city goers and users pass by? How can adhocism improve the vitality of a community that needs [re] invigoration? We will call this process 'urban dialysis' and for this inquiry we will investigate an ad hoc application - as an architectural condition and as a tool - to reinvigorate community vitality by adding spaces and structures for socially relevant, imaginative activities. We shall explore the notion of a solution that adheres to affordability, urgency, nongeneralization and improvisation. Eventually the question posed is: Can adhocism be a useful lasting operation within architecture, and of lasting value to the community? 
"Ad hoc's complex articulation pleases the mind and allows it to comprehend and coordinate a much wider range of experience."

Jencks, Charles. Adhocism: the case for improvisation. 1972

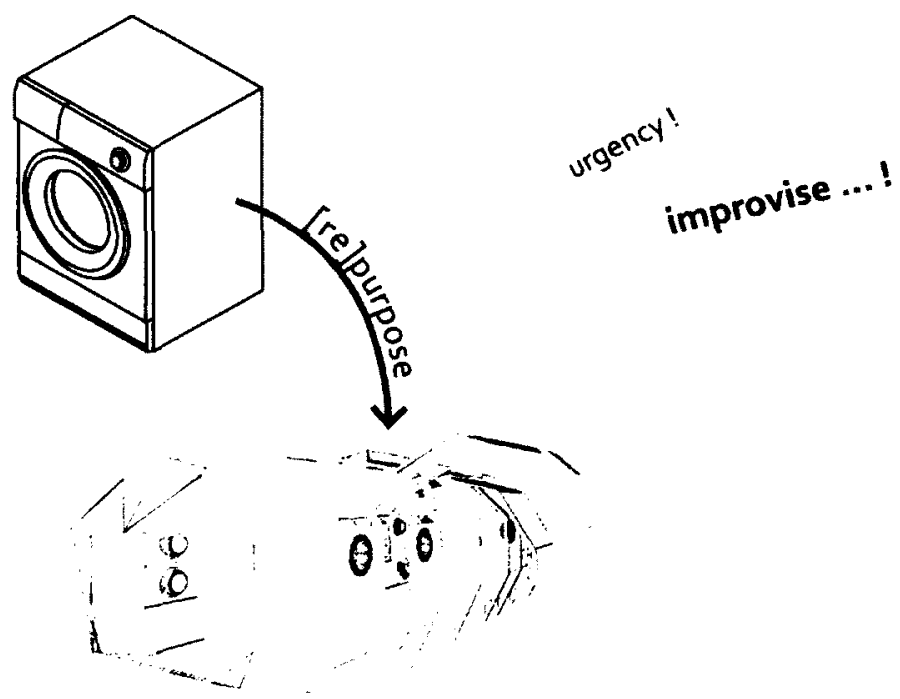




\title{
Contents
}

\begin{abstract}
Glossary $\ldots \ldots \ldots \ldots \ldots \ldots \ldots \ldots \ldots \ldots \ldots \ldots \ldots \ldots \ldots \ldots$

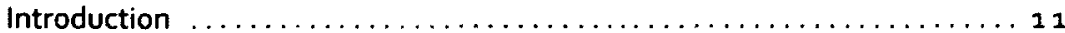

(1)

1 - What is Urban Dialysis? . . . . . . . . . . . . . . . . 23

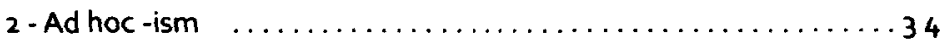

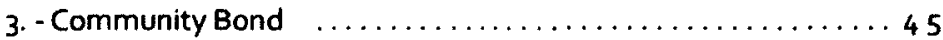

Portfolio | Case study .......................... 56

Reconfigurable + mobile multifunction envelope $\ldots \ldots \ldots \ldots \ldots 5^{8}$

Community-based transformable + mobile music studio $\ldots \ldots \ldots 61$

Utilizing composite components for children playground .......64

Social project on a city-owned failing structure ..........67

1 - Design methodology ....................... 73

2 - Proposal $\rightarrow$ S-613::Art + Play $\ldots \ldots \ldots \ldots \ldots \ldots \ldots \ldots \ldots$

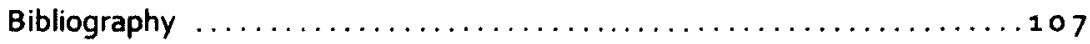

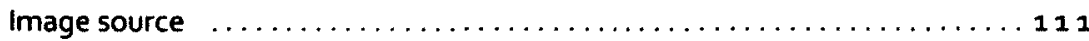




\section{Glossary}

\section{Adhocism}

Adhocism is a process of materialization [shift in meaning] using predefined heterogeneous or homologous subsystems I parts that are [re]purposed from elsewhere and [re] appropriated into a new, immediate and specific purpose - the clearly distinguishable variety of subsystems that are assembled in their own order are what set adhocism apart from non-sense randomness.

Autopoietic

An autopoietic organization constitutes a closed domain of relations specified only with respect to the autopoietic organization that these relations constitute, and thus it defines a space in which it can be realized as a concrete system, a space whose dimensions are the relations of production of the components that realize it. /m/

Autopoiesis

... means "self", ("creation, production"), literally "selfcreation" and expresses a fundamental dialectic between structure, mechanism and function. The term was introduced in 1972 by Chilean biologists, Humberto Maturana and Francisco Varela. $/ \mathrm{m} /$ 
Community

A body of people having common rights, privileges, or interests, or living in the same place under the same laws and regulations. $/ w /$

Community collaboration

Being collective or corporate within an organized society or common people. $/ \mathrm{w} /$

Dialysis

Health: A process by which dissolved substances are removed from patients body by diffusion. / w/

Improvisation

An unplanned expedient. /w/ Non-generalization

Idea/s having non-general / unique individual application. / w/ Programming/program

The relationship between the function and the actual use of

a given set of spatial relationships, building programs and/or building typologies. / $/ \mathbf{p}$

[Re]appropriate

Being suitable [again], adapt [again]. /w/ [Re]invigoration

Quality of being active or spirited or alive and vigorous [again]. / $w /$

|p/ Porter, Tom. Archispeak: an illustrated guide to architectural terms. Routledge, 2004.

|r Williams, Raymond. Keywords: a vocabulary of culture and society. Oxford University Press, 1985.

/w/ Webster's Online Revised Dictionary, 1913. <http://www.websters-online-dictionary.org/>. 


\section{Subsystem}

A self-contained system within some larger system. /w/

Unused

Not habituated; unaccustomed; being idle or inactive. / $w /$ Urban dialysis

Urban dialysis is a proposed methodology/practice/process that uses adhocism - a way of thinking, decision making, acting, and [re]appropriating materials - to improve vitality in an urban community.

Urban dialysis machine

When social interaction is combined with [re]invigorating a space using adhocism.

Urgency

Pressing importance requiring speedy action. $/ w /$ Vernacular architecture

A traditional language of building, usually of unknown authorship, constructed from local materials to suit their native setting, indigenous dimate, and specific local needs. $/ p^{\prime}$

/p/ Porter, Tom. Archispeak: an illustrated guide to architectural terms. Routledge, 2004.

/w/ Webster's Online Revised Dictionary, 1913. <http://www.websters-online-dictionary.org/>. 


\section{Aims}

Urban Dialysis proposes to explore an active - user improvisation - ad hoc approach in architecture to [re]invigorate an urban community; later we will refer to the design proposals as urban dialysis machines. We will explore the following components:

Ad hoc approach - a process of urgency, improvisation, nongeneralization in design and decision making;

[Re]appropriate - engaging the unused; including actions, space, materials, buildings, communication, knowledge and people;

Community Bond - shaken, not stirred, a re-invigoration of the community, a removal of toxicity. 


\section{Introduction}

"... architecture is about designing conditions, rather than conditioning designs..."
(1) Tschumi, Bernard. Architecture in/Of Motion. NAi publishers, 1997. p. 21.
We can see, hear, smell and feel that man continues to [re] shape the urban fabric, from the zig, zag, zip and zoom of the city core to its' soft and sleepy suburbs. Strategies of urbanization, the necessity of growth, and the increasing demands for living spaces bring about new landscapes. The quality of communities however, is declining as new developments take over the ecology of the urban fabric. We witness constant failures to maintain vibrant and livable neighbourhoods. How do we realize urban needs? Surely a viable community needs a collection of healthy neighbourhoods with support in the way of residences, jobs, businesses, and community structures; neighbourhoods that facilitate activities for youth, single adults, young couples, children, parents, senior citizens and the community as a whole. Are we not in need of an Urban Dialysis? Do we not need procedures to increase vitality using social and architectural objects that realign the community through redefining the activity spaces?

While community invigoration can be slowly achieved over time through an architectural revitalization of the urban area, every community should be understood as a living ecology that could benefit from an immediate, improvised \{spatial, social, material, activity\} adaptation. When decisions are made under pressure of time, how can appropriate needs be answered with imaginative, original solutions? How can we, for example, repurpose the unused or 
under utilized? Perhaps one answer is the ad hoc. Our examination of the ad hoc approach to architecture must then show how well it is aligned to take on these urgent urban roles.

- Refer to Case Study [p. 57]

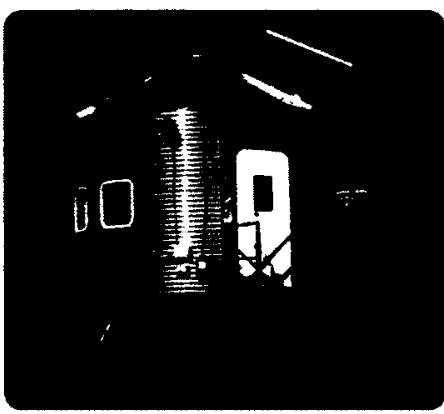

M.I.K.E.

One of the vehicles for the Connecting Communities program at the Kohler Arts Center, it was designed for travel to different communities throughout the country.

(c) $/ / 1$

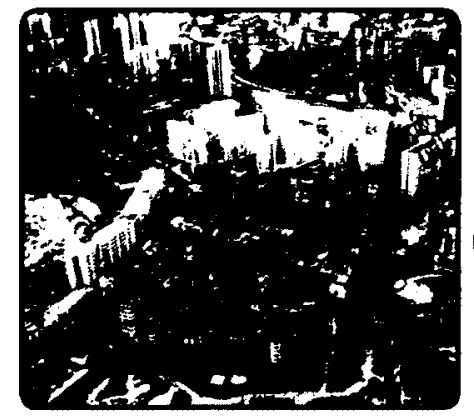

九场紫

Photography of Kowloon Walled City before it was demolished in 1993; it was a city of improvisation.

(c) $/ / 2$
The community-based transformable, mobile music studio and stage named M.I.K.E. - Music Integrated Kiosk Environment - shows community invigoration through the application of an ad hoc architectural approach. Located in Wisconsin at the Kohler Arts Center, it provides an immediate mobile social space for children and teenagers in the local community through the interaction of different uses of this music kiosk. The ad hoc approach to this multi-program music space is the repurposing of a grain bin; a specific piece of architecture with another purpose than its intention which has resulted in non-generalized design in assembly and style. Put together by local at-risk teens and students from a nearby technical college, it engages community collaborative efforts. •

The adaptive nature of the ad hoc approach to architecture allows the space and structures to [re-]evolve in time to reflect their environmental surrounding, local culture and historical context. Hong Kong's Kowloon Walled City [re]evolved over a 46 year time period as continuity of ad hoc madness up until it was demolished in 1993. It strongly reflected the needs and lifestyle of the community as they purposely configured and re-configured their private residences and 


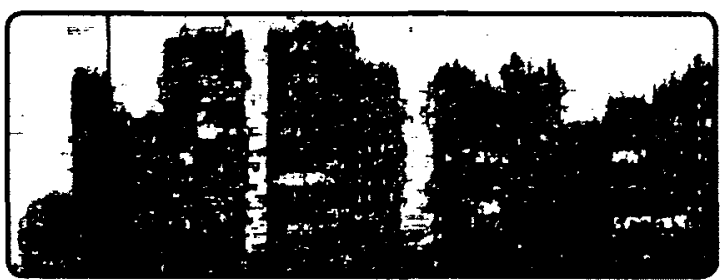

Walled city section. Illustration. By Kazumi Terasawa [寺潘一美] o $\| 3$ public social spaces. This 6.5 acre urban settlement has a rich history and different changes dating from 960 A.D. through to 1993 . Originally a salt trading outpost, it transformed into a walled fort centuries later and then this settlement was excluded from British control after Hong Kong was taken over from

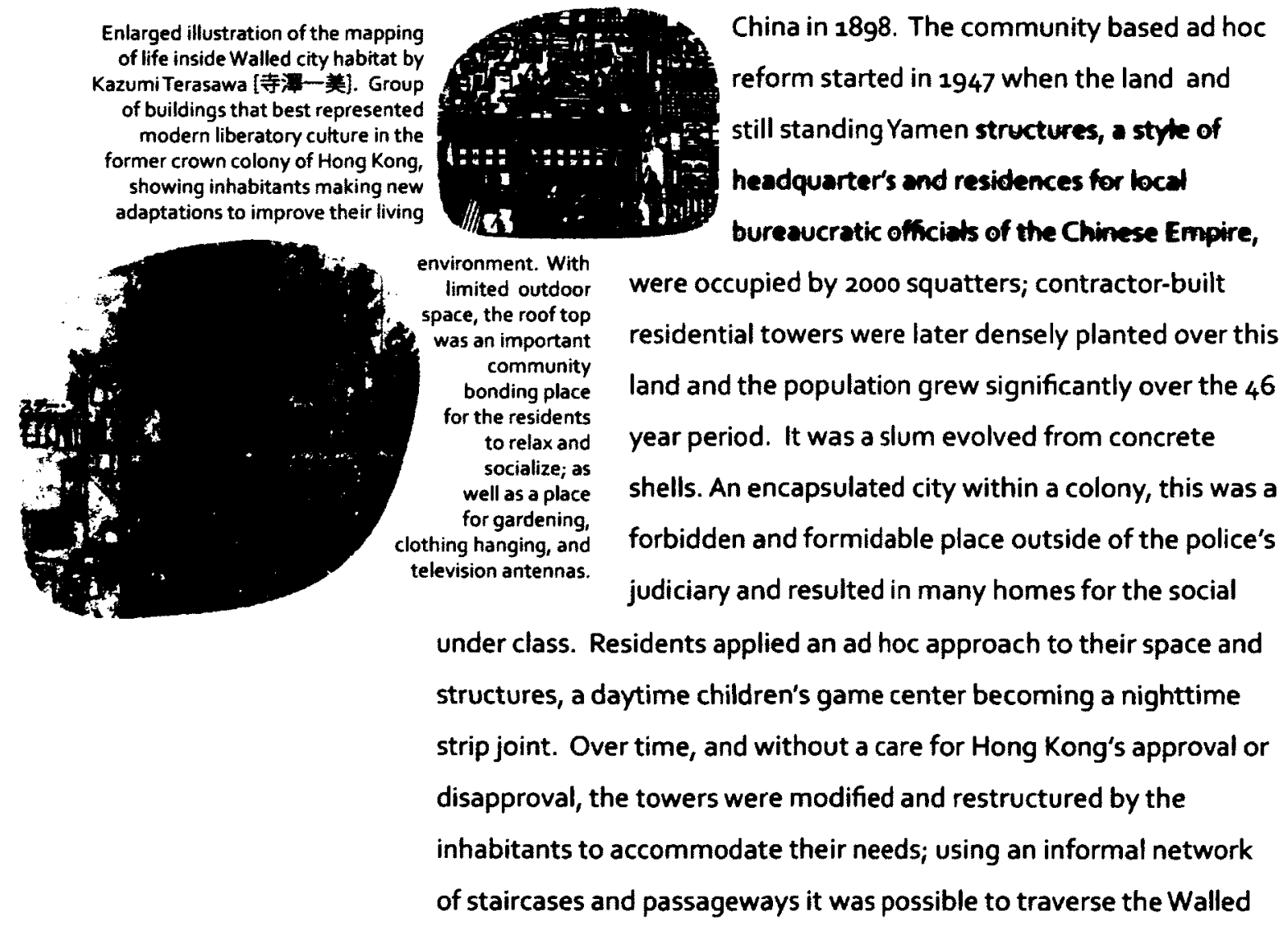


City from north to south without once touching the ground. ${ }^{2}$ The section drawn by a team of Japanese researchers mapped a glimpse of the lives and activities in relation to the inhabitants and their surroundings. While the Walled city was considered a slum, a longtime criminal haven, and one of the most densely populated areas on earth $\left(1,255,000 \mathrm{~km}^{2}\right.$ in 1993$),{ }^{2}$ residents inside were [re]invigorating their living community by improving what they could through their own efforts and control.

With this in mind, we will begin to propose the following as a working design methodology for urban dialysis:

o) delight for the community [ad hoc delight]

$$
\text { ↔ }
$$

1) breaking the rules [ad hoc thinking]

2) community collaborative design and/or construction [wit of ad hoc] 3) materials [re]appropriation [ad hoc resources improvisation] 4) providing or [re]appropriating public space for common good

In keeping with the adhocism approach, this methodology will opt for a loose combination of guidelines rather than a set of strict rules. This methodology invites two conditions; that delight is required and at least two of the four guidelines in any measurable proportion must be included in a combination that results in an urban dialysis design. For our convenience, we will call this methodology flexibleX 3 - [flexible times three guidelines] meaning a loose combination of guidelines.

Lambot, Ian. Ciry of Darkness: Life In Kowloon Walled City. Watermark, 1993. Goddard, Charles. "The Clearance." In City of Darkness: Life In Kowloon

Walled City. Watermark, 1993. 208-211.. 


\section{o) delight for the community [ad hoc delight]}

Delight in this circumstance implies the urban dialysis implementation should provide a source of happiness or a feeling of satisfaction for the community. Delight in design can comes in many forms. It may be functional, interactive, simply esthetically pleasing, or the ad hoc delight from unexpected recognition; delight can connect with our visceral body and mind within the experiential space in and out of the urban dialysis machine.

Delight can put a smile on someone's face, it is the creation and maintenance of positive feelings. Studies show that our body reacts to activated muscle groups that reflect the experiencing emotion. A smile on the face will trigger the body to release serotonin, dopamine and other positive indicators. A smile that not only utilizes the muscles of the mouth but also those of the eyes. These are known as Duchenne smiles. It is considered a smile of real happiness ${ }^{3}$, and displays of emotional states have been shown to be infectious. Based on a theory by zoth century German philosopher Theodor Lipps, efforts to understand the process of an affective state that matches the other's emotional display has developed into the field of study known as emotional contagion. ${ }^{4}$ This field of study proposes that body responses to the experience of emotion and facial displays of emotion affect not only the individuals feeling the particular

3 Dimberg. U., Thunberg, M., Elmehed, K. "Unconscious Facial Reactions to Emotional Facial Expressions." Psychological Science. 2000. <http://apsychoserver.psych. arizona.edu/JJBAReprints/PSYC50IA/Readings/Dimberg_Thunberg_Elmehed_2000 Psych_Science.pdf >

4 Hess, U. \& Blairy, S. "Facial Mimicry and Emotional Contagion to Dynamic Emotional Facial Expressions and Their Influence on Decoding Accuracy". International Journal of Psychophysiology. 2001. <http://psych.colorado.edu/ -tito/sp03/7536/ Hess\%26Blairy_2001.pdf> 
emotions it can also have a physical and emotional effect on those individuals who are seeing displays of physical responses to emotion. A simpler explanation for the aspects of emotional contagion we are interested in and more common phrase states: Smile and the world smiles with you.

\section{1) bending the rules [ad hoc improvise thinking]}

\section{8}

2) community collaborative design or construction

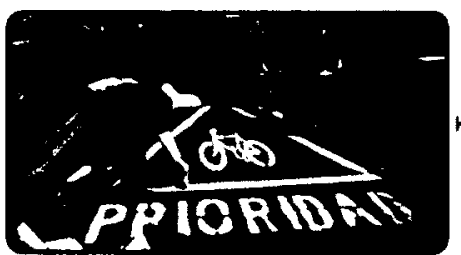

Mexico city "guerrilla" bike lane project - a self- initiated group called Make Your City Collective - an example of the community design model that use self-reliance and self-determination to promote the self-help model.

(Q) $/ / 4$
Make Your City Collective a citizen's group involved in a Mexico city 'guerrilla' project - Wikicarril, a bike lane campaign - took action because of the government's repeated unjust delays in implementing the 2007 pledge for $300 \mathrm{~km}$ of non-motorized infrastructure across the city by 2012. While many bike lanes throughout the city had been designated a lack of government funding for non-motorized transportation resulted in limited official action taking place. Using a popular Mexican crowdsourcing site fondeadora.mx , Make Your City Collective fund raised 13,500 pesos (about $\$ 1000$ ) in four days for paint supplies and equipment. In November 2011 invitations through the social networking sites of Facebook and Twitter went out to participate in the $5 \mathrm{~km}$ project. Cycling organizations joined in, others brought there families, about 80 volunteers came out and help painted the unauthorized bike path over an eight hour period. 
The route painted purposefully ended in front of the Mexican national congress as a message to the federal government to increase funding for non-motorized transportation infrastructure. ${ }^{5}$

This was not to suggest illegal activities in the city should be rewarded, but rather the story is encouraging citizens to the rewards of taking calculated risks when the action may call for rule bending. Rule bending was not the sole urban dialysis element of this Mexico city 'guerrilla' bike lane project either, it also required a considerable collaborative effort and promoted a common good. Furthermore the recognition of the collaborative and public nature of the project was inherent in it's name Wikicarril, chosen "because it was made through voluntary participation and is open to everyone, like the online encyclopedia, Wikipedia“ ${ }^{6}$. The citizens realized the immediate needs to take action, using available resources imaterials, people, and space] around them to claim an environment that it is rightfully theirs - all of these actions to sustain their right as citizens, and to transcend the governmental bureaucratic delays are ad hoc spirit in thinking, action, and implementation. The action fulfilled the ad hoc spirit as expressed by Charles Jencks because, "a purpose immediately fulfilled is the ideal of adhocism; it cuts through the usual delays caused by specialization, bureaucracy and hierarchical organization." 7

5 Smith, Riley. Celsias. Updated 14 December 2011.<http://www.celsias.com/ article/wikis-are-normally-online-wikilane-streets-literal/>. Cited Feb 2012.

6 Webster, George. CNN, "Road to Rio: Green activists paint guerrilla cycle land." Updated 01 December 2011. <http://www.cnn.com/2011/12/01/world/americas/wikilanemexico-city/index.html>. Cited Feb 2012.

7 Jencks, Charles. Adhocism: the case for improvisation. New York: Doubleday \& Co., 1972. p.15. 


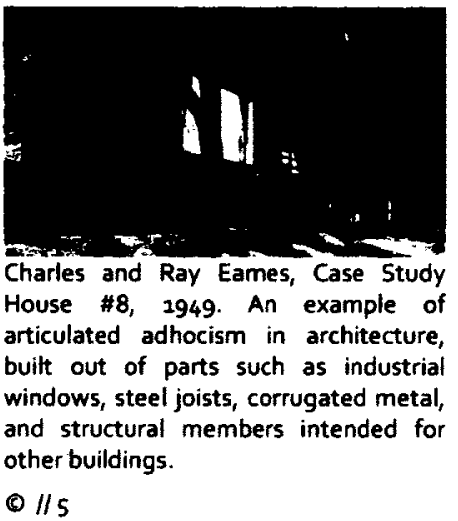

7 also refer to case study

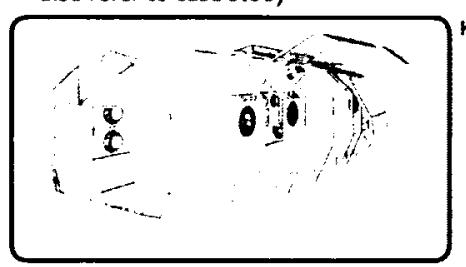

Design by 2012Architecten architectura firm in Netherlands, MSS had travelled across the Netherlands and was used as multi-functional unit; it has been an espresso service bar, back stage and concert kiosk, and architect's site office.

(c) 116

\section{3) materials [re]appropriation [resources improvisation]}

Using materials that are available right away but were not intended for the purpose, Charles and Ray Eames designed their case study house using ready-made parts from a catalogue that were intended for industrial use. Case study house \#8was used as the couple's home-studio and a prototype for the Case Study House program, organized by John Entenza's Arts \& Architecture magazine, to reflect the complex urban life style of a designer and artist household. The architectural articulation in adhocism is largely dependent on the clearly distinguishable ready-made parts. MSS [Miele Space Station] architectural mobile kiosk was made out of utilized unwanted front-loading washing machines that are commonly used in European households. The design not only addresses the issue of waste overload, but also show a consistent relation of parts assembled aesthetically and functionally.

\section{4) providing or [re]appropriating public space for common good}

In discussing a public space for common good in architecture, we can reference the only complete surviving treatise of classical architecture - De Architectura (Ten Books on Architecture in English) a series written by Roman architect and engineer Vitruvius. His wide ranging interest and writings on architecture spanned not only styles, forms, methods and history but equally addressed the elements of quality of architecture and other empyreal topics. According to Vitruvius the ethos of architecture was that the social relevance of the work distinguished the quality of the space, not the form nor 
$\neg$ also refer to case study \#4

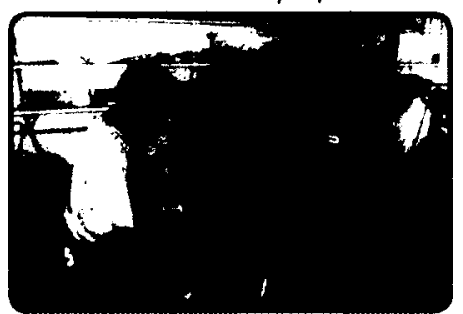

Designed by M12studio the shed provides an opportunity for young adults to develop new skills while also recycling used bicycles.

(c) $1 / 7$ the craftsmanship of the work. Professor Indra Kagis McEwan's study of Vitruvius as a writer and critical thinker listed three items of importance in the treatise's claim of proper architectural execution: firmitas (strength), utilitas (use), and venustas (beauty). ${ }^{8}$ In the translation by Morris Hicky Morgan, Vitruvius: book 1.3.2, the utilitas of the building is satisfied "... when the class of the building is assigned to its suitable and appropriate exposure...". Book I - chapter 4, Vitruvius' description of the site of the city is that it be healthy to the citizens. Vitruvius has made a clear point that the use and location of the building and the city are dependent on how these spaces work for people and how they serve the people's needs. 9

When a space is experienced by the public or a community, a delight can be spread to a large number of people to enliven a community. Therefore allowing architecturally-defined public space to welcome different positive social activities can bring life to a space and [re] invigorate the surrounding community. When such space and it's benefits is shared among large numbers of people both in and out of the immediate community, that space is also providing a common good to people. Coleman Center for the Arts and Culture's Bicycle Shed is an example of a [re]invigorating ,[re]appropriated public spacefimage\}. What used to be a city-owned failing and abandoned structure is now a bicycle-recycling workshop for young adults under the age of seventeen. The workshop is in regular

8 McEwan, Indra Kagis. Vitruvius: Writing the Body of Architecture. MIT press, $2003, .233-234$

9 Vitruvius, Pollio. The Ten Books on Architecture. Trans. Morris Hicky Morgan. Cambridge: Harvard University Press. Press. 1914.< http://www.perseus.tufts.edu $>$, cited November 2011. 
operation, is run and staffed by local volunteers, it promotes and [re] appropriates technical skills in the neighborhood, provides young adults in the community a place to share common interests by [re] purposing used bicycles and it is for these reasons an excellent example of public space for common good.

A return to the MSS kiosk will allow an examination of its ability to reconfigure non-program space to satisfy different pragmatic concerns thereby providing multifunctional space to serve different needs, which is a key aspect of public space with loosely defined purposes. Since the resulting structures are small in scale, it permits change without major difficulties. The kiosk's mobility and multifunctional aspects allowed it assist in increasing economic vitality in different communities; another indicator of positive impact. The Mexico city "Wikicarril" bike lane project is a useful example of [re]appropriating public space for the people's common good. The previous vehicle-only road is a rule bending [re]appropriation to prioritize use for citizens who ride bicycles.

Urban dialysis design can be a system spread through out the city, such as the Mexico city bike lane "guerrilla" project, a mobile project such as the MSS kiosk, a stationary structure such as Coleman Center for Arts and Culture bike shed, or any combination of the three. The intent of urban dialysis is to add vitality for reinvigorating a community by creating lively social conditions in an urban context. 


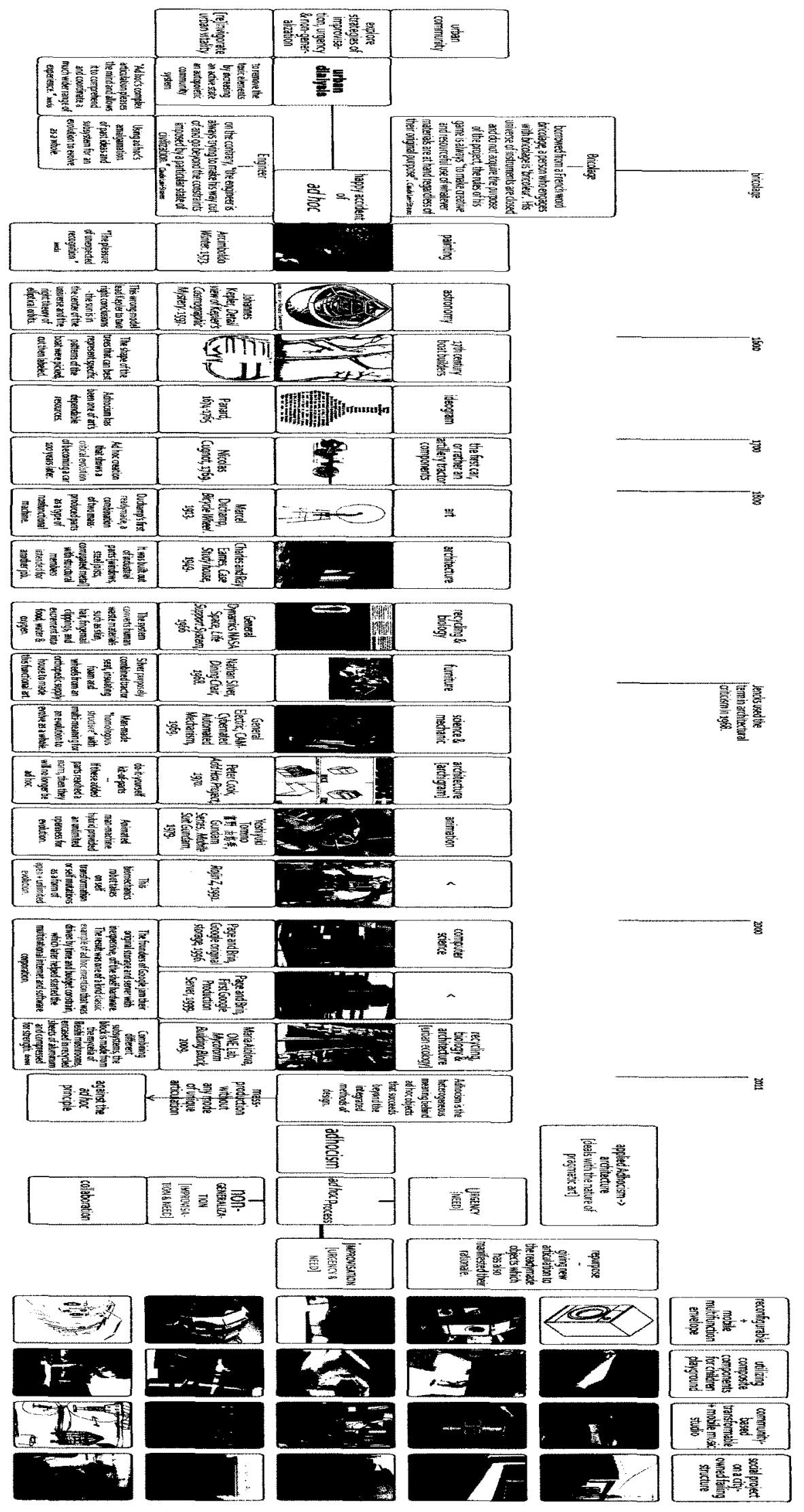


Dialysis: a process by which dissolved substances are removed from the patient's body ${ }^{10}$

(Urban) Dialysis: a process by which toxic elements are removed from the urban fabric within cities.

\section{Urban [Re]Invigoration}

Machine: "A combination of persons acting together for a common purpose, with the agencies which they use; as, the social machine". ${ }^{11}$

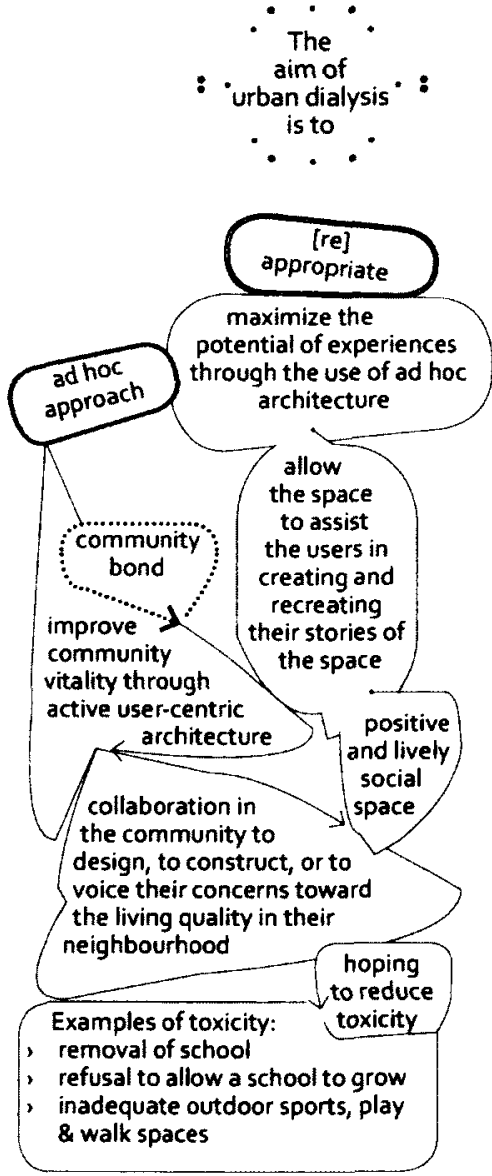

- The " aim dialysis * - is to.

\section{[re]} tial of experiences chitecture allow the users ir stories of community vitality through ctive user-centric and lively social collaboration in design to construct, or to voice their concerns toward the living quality in their neighbourhood hoping toxicity removal of school inusal to allow a schoo 8 walk spaces
In the proposed concept of Urban Dialysis, the people of a neighborhood are an integral aspect of a larger system that keeps the vitality running; the people's interaction with the space is when social interaction is created between the space, the people and the program - the experience, the use, and the components that create the space. When architecture is used in a public space and acts as a generator to create and sustain [non-one off events] social activities, we can consider it as one of the agencies of the social machine. When social interaction is combined with [re]invigorating a space using adhocism, we can considered it an urban dialysis machine. Urban dialysis is a methodology/practice/process that uses adhocism - in a way of thinking, decision making, acting, and [re]appropriating materials - to improve vitality in an urban community.

When [re]invigoration in a community is determined by the people's interaction with the space, then the creation of the space becomes a vital aspect of how people are interacting within it. The uses, functions, and goals intended to meet needs or desires as expressed in a space or structure is known as the program. When there are 


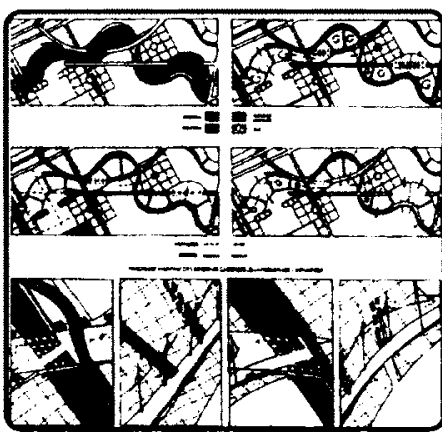

Superimposition montage diagrams of Parc de la Villette by Bernard Tschumi showing the different layers of superimposed elements of design in the park, this technique helped to advance the use of programming.

(c) $1 / 8$ no prior intentions for a space then the architectural term applied is non-programming. Bernard Tschumi coined three terms to describe "the intentional combination of building progammes or archtypes, especially those that seem inextricably incompatible" as cross-programming, dis-programming, and trans-programming. ${ }^{12}$ Cross-programming is where interchangeable functions that are not associated with each other occur in a space at different times, and one or more of these functions are at not intended for the spatial configuration. The conversion of a church into a bowling alley or a warehouse into residential condos are well-known examples of cross-programming. Dis-programming is the juxtaposing of more than one function together in order to undo one another - when any given physical aspect of the architecture is being transformed or reconfigured to change the program of the space. Trans-programing has been described as applying "to the relationship between the function and the actual use of a given set of specific spatial relationships and/or building typologies. This will often take the form of an overlay of a secondary use on the primary spatial function" ${ }^{23}$, a regularly constructed example being a mall within an airport.

The Mexico city "guerrilla" bike lane project showed that the citizens demand turned into action to address how part of the public space should be used. While the bike lane project is more related to urban planning than architecture, it demonstrates an ad hoc

12 Tschumi, Bernard. Architecture and disjunction. MIT Press, 1996. 204-205. 13 Porter, Tom. Archispeak: an illustrated guide to architectural terms. Routledge, 2004. p. 200. 
re-appropriation of public space with trans-programming

functionality. The citizen's group have not banned vehicles from the lane rather they prioritized the lanes primary right of way to nonmotorized transportation and allowed for a secondary use by motor vehicles. The Walled city residents regular alteration of a daytime children game center into a nighttime adult strip joint showed that different programs in the same space, at different times throughout a day, can meet the needs of the community and opportunities of such a space. While potentially disturbing to many, this particular switch between functions is a superb example of cross-programing.

French academic, Henri Lefebvre wrote that "knowledge falls into a trap when it makes representations of space the basis for the study of 'life', for in doing so it reduces lived experience." ${ }^{14}$ Lefebvre believes that the space and the objects in the space are the backdrop of knowledge, whereas people who use the space and how they use

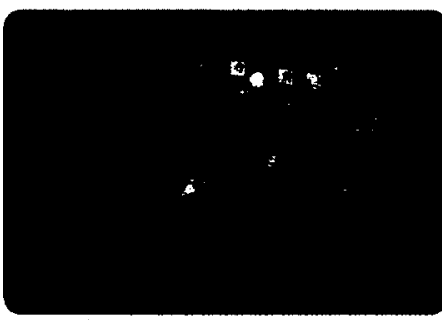

Bernard Tschumi's vue aerienne (aerial view) diagram - 1985 - for Parc de la Villette showing the superimposition of three layering system: points (in red) in the order of a grid, lines (light blue) and surfaces (dark blue) through the site.

$0 / 19$ the space are the subjects of the knowledge. This backdrop can be understood from Bernard Tschumi's design of 'Folie'.

Parc de la Villette was a significant reconstruction in the city of Paris, a 55 hectare parcel of land with intricate composition of crossprogramming and dis-programming space and architecture. The park was built on a former industrial site and contains multifunctional programs such as the science museum, art center, and theme gardens as well there are 35 'Folie' (folly in English, but described by Tschumi

14 Lefebvre, Henri. The production of space. Trans. Donald Nicholson-Smith. Wiley-Blackwell, 1991. p.230. 


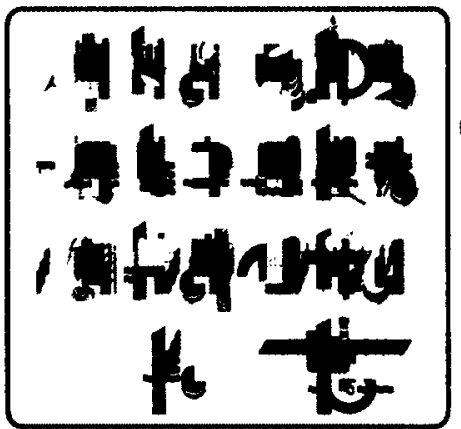

"La Case Vide" 1985, 'Folie' were painted in red, scattered around Pare de la Villette, intended to be no-meaning and can be used for different purposes or treated solely as artistic sculptures.

(c) //10 as madness) distributed through out the park. Clearly, each 'Folie' was designed with non-program in mind and no specific purpose; they are the representation of the space that are merely the backdrops in the park, even when viewed as a whole the 35 are to act as navigational aids through the park. The Parc de la Villette and its 'Folie' were intended as a frame for cultural interaction, but while revered by some the park is also reviled by others. Projects for Public spaces has it listed as one of the worst parks in the world and claims the park "... is a dull landscape that substitutes absurd sculpture and disproportionately scaled structures for playfulness and variety. Once the novelty of the structures wears off, there is little to sustain one's interest or imagination ..." 15 While the PPS may have missed the intent of the 'Folie' designs their concerns raise an issue; does the park actually act as a frame for interaction thereby addressing the lived experience'?

This concern leads to similar questions. If Urban Dialysis is to focus on the needs and desires of the people to interact with their public spaces, ie focus on the "lived experience", we must ask: In order to design the background, should architects study how people can and will interact with the space instead of studying only the space? Is the interaction of people and public space to create different experiences important to the atmosphere of the community? Can Urban Dialysis push the boundaries of the design and construction process to expand their interaction? Is interaction important to the vitality of the community?

15 Project for Public Spaces. "Hall of Shame". <http://www.pps.org/great public_spaces/one?public_place_id=369>. Cited Feb 2012. 


\section{Urban dialysis :: engage actions}

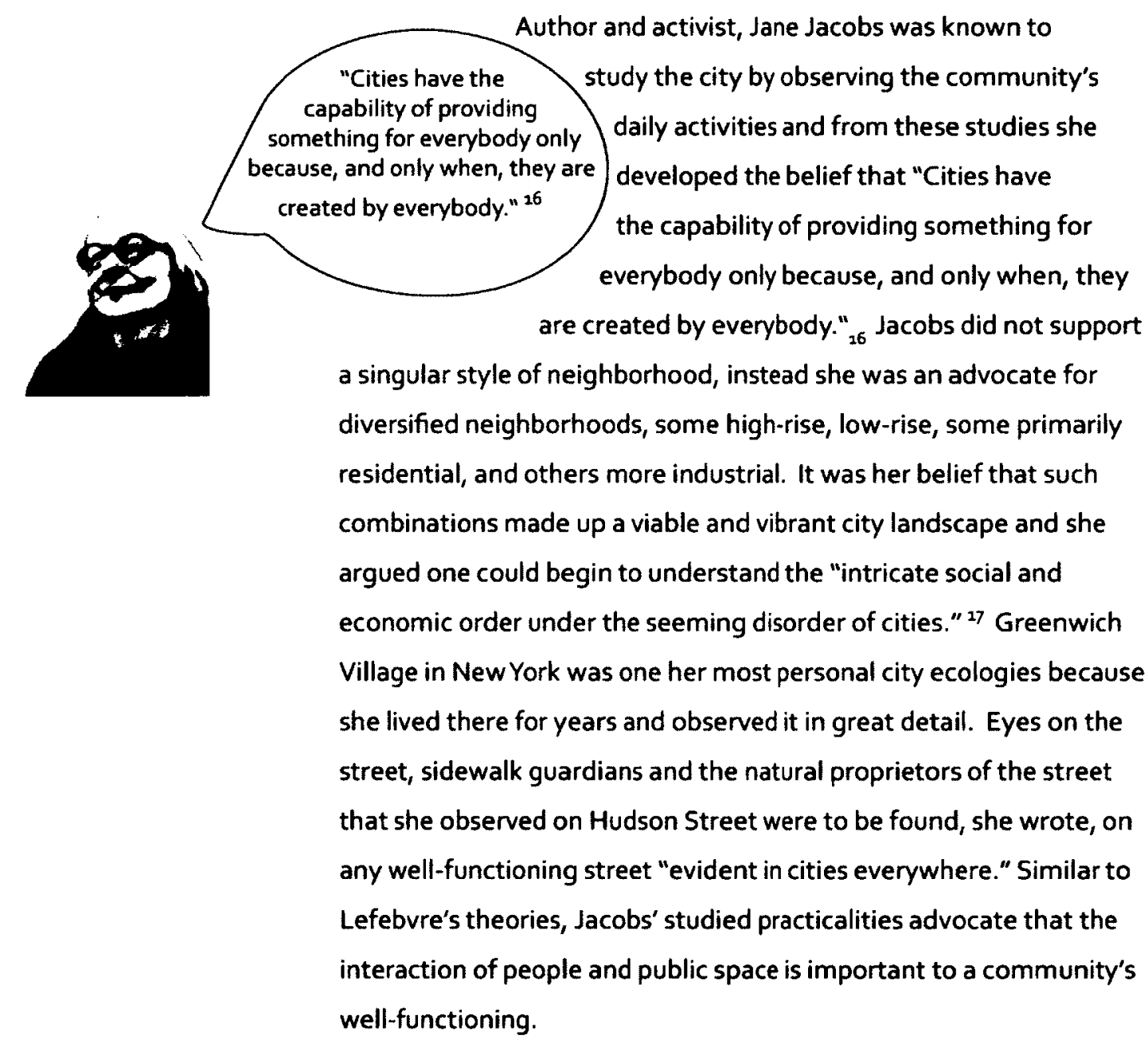

Noted architectural professor, historian, author and theorist,

Alberto Perez-Gomez states that "... architecture communicates the

1617 Jacobs, Jane. The death and life of great American cities. Vintage Books, 1992. 15 
possibility of "recognizing" ourselves as complete, in order to dwell poetically on earth and thus be wholly human." ${ }^{18}$ If we accept this, then shouldn't the 'lived experience' be central to the practice of architecture? If the aims of urban dialysis are to improve community vitality through timely active user-centric ad hoc architecture, to maximize the potential of experiences through the use of costeffective resources [re] appropriation, to allow the space to assist the users in creating and recreating the stories of the space; and to increase the active state of a continuous multiplicity of activity in an urban area; then how does Urban Dialysis address the lived experience'?

\section{Community invigoration :: a park with cross and trans- programming activities}

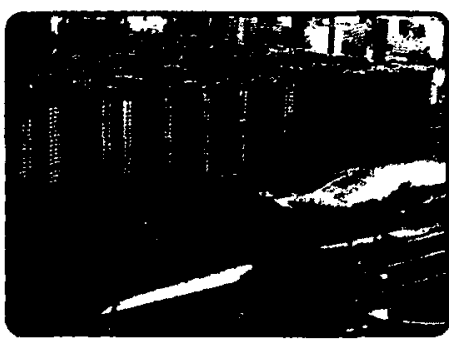

Aerial photo of LaiChi Kok park and Mei Foo private housing estate in Hong Kong.

(1) //21
In the case of an extreme high density city such as Hong Kong, a government report for mid 2010 estimated a population density of $6540 / \mathrm{km}$ sq. What kind of public and social space do they have for the residents in such a high density area? We can look at Mei Foo private housing estate in Hong Kong. The development, aimed toward middle-income families, is a 99 tower complex consisting of 13,500 apartments, completed in 8 stages between 1965 and 1978. ${ }^{19}$ The area has several schools, medical clinics, salons, newspaper kiosks, supermarkets, shopping arcades, restaurants and food markets in the lower levels of the residential towers. Mei Foo is a

18 Perez-Gomez, Alberto, "Hermeneutics as Discourse in Design", Design Issues, Vol. 15 No. 2, Design Research (Summer, 1999), pp.71-79

19 Chan, Chi Kau. Community Development and Management of Private Sector Housing Estates in Hong Kong. Diss. University of Hong Kong, 1995. 74-88. 


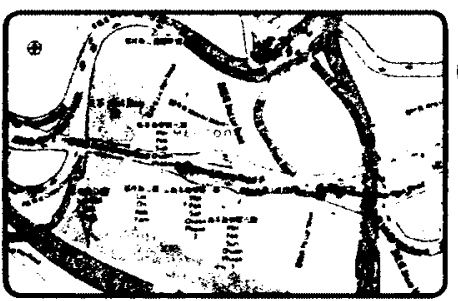

Map of Lai Chi Kok park and Mei Foo private housing estate with Kwai Chung Road running through East and West.

(c) $/ / 2$

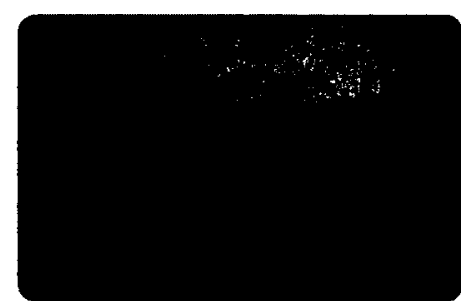

LaiChi Kok park provides a primary source of public and social spaces for the residents in Mei Foo private housing estate in Hong Kong.

(c) $/ 13$ transportation hub. One of city's main bus terminus is located under the Kwai Chung Road underpass. There is a Mass Transit Railway (MTR) interchange station between the Tsuen Wan Line and the West Rail Line, two of the most important light rail lines in the territory. It is bisected by a six-lane inner city corridor, Kwai Chung Road, linking two major cities of Kowloon and Tsuen Wan, interweaving with various source of transportation including double decker buses, minibuses, and taxis. ${ }^{20}$

The Lai Chi Kok Park is located along the West and South parameter around the estate, stretching along the Kwai Chung Road. The park, mainly built on reclaimed land, is equipped with different outdoor and indoor activities for groups of all ages; a children's playground, public swimming facilities, an indoor sports center, an outdoor running facility, a traditional Chinese garden, basketball courts, squash courts, soccer fields, tennis courts and a skate park. The swimming facilities consist of 3 training pools, two children's pools, one diving pool and two main pools. The skatepark is the biggest and most visited by both amateur and professional skateboarders in Hong Kong. Designed with two half pipes - a ramp used in extreme sports - and several quarter pipes, single rails and fun boxes.

This is an extreme high density neighbourhood with a population density of 3817.3 person per hectare ${ }^{21}$, even so the needs and wants of the users are well represented in public spaces. The significance

20 Yu, Pui Kwan. A Study on Quasi-public Space in Large Scale Private Residential Development, case in Hong Kong. Diss. University of Hong Kong, 2007. 27-65. $21 \quad$ Yu, Pui Kwan. 30. 
of the highly utilized public transportation systems are well woven into the neighbourhood but it is important to note the systems serve the people not take over the public spaces. In North America communities are often negatively impacted by the overriding transportation demands of private motorized vehicles.

\section{[Re]appropriation as a form of toxicity removal}

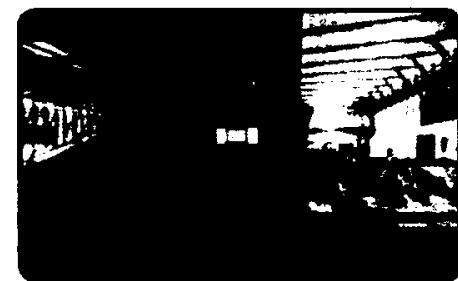

urban dialysis stretches farther out then just space; the unused of materials, space, buildings, communication, action, knowledge, waste .... In this picture, the ground floor of Hong Kong \& Shanghai Bank Headquarters by Norman Foster, who has accidentally designed an ad hoc settlement space in his steel and glass building located in the busiest business district of Hong Kong. At the time during my research visit in Dec 2011 it was [re]appropriated by protesters who have lived in their improvisational homes for months.

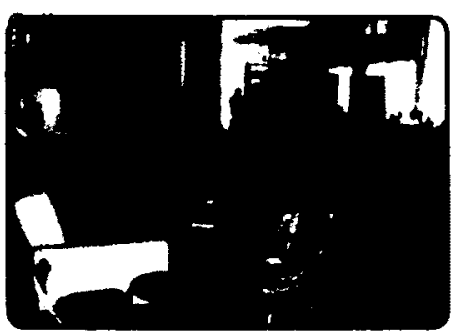

Interior view of the improvised settlement as seen in Spring 2012.

o //14b
The notion of [re]appropriation for urban dialysis stretches farther out then just space; the unused of materials, space, buildings, communication, action, knowledge, waste, and the list goes on. In order to separate the notion of [re]appropriation, elements of continuity need to be thrown in. They include, but are not limited to, some of the elements that have been aligned with sustainability in our environment, economy and social systems: reuse, repurpose, engage, impact, and harvest.

Buildings are considered the second greatest contribution to a increasing carbon footprint. "The building sector contributes up to 30 percent of global annual green house gas emissions and consumes up to 40 percent of all energy." 22 Architects and designers are facing the ongoing struggles between the accolades of architectural innovation and moral imperative towards the application of sustainability. Furthering the divide is the architecturally narrow focus on object sustainability which does not address the issue of scale, in size or quantity. These issues are pushing architects as a whole to embrace a new sensibility of architecture.

22 "Buildings and Climate Change: Summary for Decision-Makers." United Nations Environment Program. 2009. 


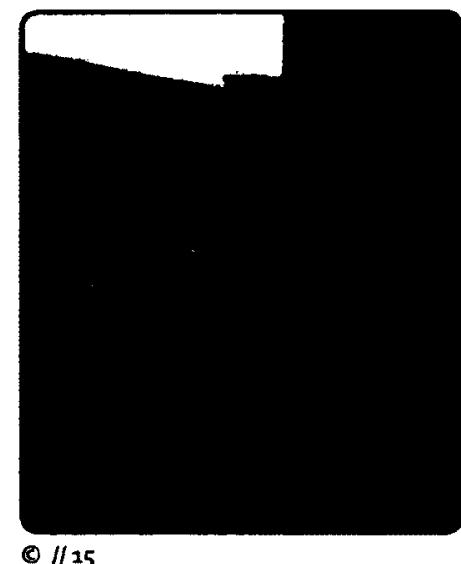

2012Architecten architectural practice based in Rotterdam, Netherlands, has often utilized used and excess materials which are not conventional building materials. They also are vocal advocates of this practice though items such as their book Superuse: constructing new architecture by short cutting material flows, the websites superuse.org \& www.recyclicity.org, a half-hour televised feature in ezdesign as well as numerous international conference appearances. Their motto is re-search (in any potential waste and regional materials), re-design (using ready-made materials), and re-build (collection of appropriate materials and sometimes the process can be experimental). ${ }^{23}$ They have created a community bond and interaction not just in their projects but also in their open-source database. 2012Architecten initiated an online database that welcome exchange of ideas and knowledge from the readers and contributors of how and what materials can be best utilized and [re]purposed. This opposition to rules; their thinking outside of convention and building with diverse available materials share the sensibilities of adhocism.

\section{[Re]appropriate :: space and building --> knowledge and people} Donovan Rypkema, principal of PlaceEconomics and conservation activist, points out that new construction is about a 50-50 split on labour and materials cost, whereas restoration and renovation can be as much as $75 \%$ labour for every dollar spent you get twice as much

232012 architecten. <http://2012architecten.nl/about/>. Cited Nov 2011. 
local employment, and use about half the resources. This affects a local economy on two levels, the direct impact of increased local construction employment and the secondary impact of increased local spending by the construction workers. Renovation uses twice as much labour, and half as much material as new construction. Thus when dealing with financially constrained projects there is considerable benefit in renovation and preservation.

If we accept Rypkema's claims that replacement construction imposes a significant and unnecessary financial burden on a neighbourhood we can understand how public spaces in these redesigned neighbourhoods could be underfunded. This leads to the question, are the acts of building vibrant livable urban communities within cities and increasing population density in an urban areas by building residential high-rises in opposition? While high rises accommodate more people on a smaller footprint; creating a healthy community needs social, cultural, and recreational space as well as places for education - it is these animated, though often underfunded, public spaces that are creating community bond. With these issues in mind it make sense for a community to reuse, restore and renovate existing abandoned space or unused space for the purposes of community [re] invigoration. 


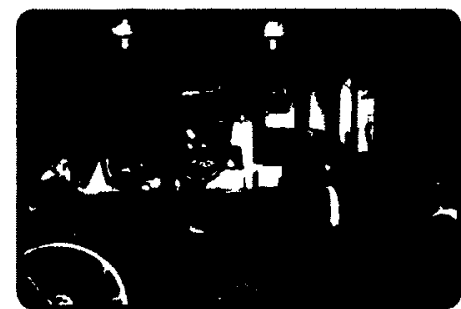

Underfunded community supported program utilized otherwise abandon space. Bicycle shed interior highlighting the basic necessity of space needed to run the bicycle-recycling workshop. o 1116

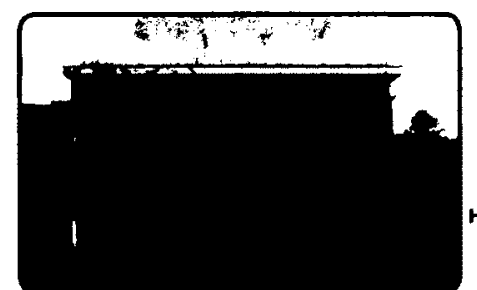

The failing city-owned structure was fixed for a community supported young adults bicycle-recycling workshop.

(c) $/ 17$
Coleman Center for Arts and Culture in Alabama utilized an abandon and failing city-owned structure for a community supported young adults bicycle-recycling workshop. The rehabilitated space not only provided an immediate solution for the bicycle-recycling program, it also reduced the cost of construction for the community center. Ad hoc design improvisation in this project involved the use of low-tech exterior bench, water barrel collector, little mundane things used in and around the workshop; which all provided wonderful opportunities for the community volunteers to bond. These small measures are aspects of the nitty-gritty ad hoc approach that might be neglected during a larger scale project. While the building process might be a one-off community bond, the workshop offers a continuous nourishment for young adults in the community, and reduce resources consumption. This community-based rehabilitation project and it's ongoing functions also fits in the idea of reducing toxicity, thus improving community vitality. This provides further weight to the urgency of repurposing and improvising on the use of existing resources, which includes space in the environment. The design outcome is non-generalized when we can add something new to the used; as such it is the crossroads of need, immediacy, improvisation and [re]appropriation that advocates for an urban dialysis architectural response. 


\section{What is ad hoc?}

With these examples in mind we should then explore in some depth the notion of the ad hoc. Architect Charles Jencks wrote "Adhocism is the heterogeneous meaning behind ad hoc objects that succeeds beyond the integrated methods of design." ${ }^{24}$ Seen this way, ad hoc is an acting process that deals with the needs for immediate action which are done purposefully - this is the spirit of adhocism - and because of this open-nature, ad hoc can be applied in any context of design, creation, thinking and decision. Timing is important in the act of ad hoc, it can be applied to many areas of design and practice and is generally applied to small-scale projects or a portion of a large project that have a quick completion in view. The desired ad hoc action shall cut through any process of controlling organization that may retard the progress of action. While the Latin root of ad hoc is translated as 'for this' Charles Jencks defined adhocism as " a principle of action having speed or economy and purpose or utility ... it involves using an available system or dealing with an existing situation in a new way to solve a problem quickly and efficiently." While Jencks coined the term in 1968 the unnamed basis for the word had long been incorporated in areas of art, design, architecture, engineering, computer science, and everyday decision making.

24 Jencks, Charles. Adhocism: the case for improvisation. New York: Doubleday \& Co., 1972. 


\section{What is adhocism?}

We now extend ad hoc $;$ adhocism is a process of materialization [shift in meaning] using predefined heterogeneous or homologous subsystems / parts that are [re]purposed from elsewhere and [re] appropriated into a new, immediate and specific purpose. The clearly distinguishable variety of subsystems that are assembled in their own order are what set adhocism apart from nonsensical randomness.

Adhocism becomes a physical form that is largely bound by the heterogeneity collection of parts put together, while using a quick wit of thinking as the catalyst for improvisation. Thus, one can apply ad hoc thinking to improvise the use of a predefined parts in a new assemblage that will be defined as adhocism. However, one can also apply an ad hoc action to a non-ad hoc outcome; for example a small social group forming immediately for specific purpose, where only their decision and action were ad hoc in approach.

Many practices have their own languages, just like architecture, so do computer programming, fashion design, graphic design, and other art, design and engineering fields of profession. In adhocism these other languages are often plagiarized and plundered due to the quick thinking to make a timely decision; whether on materials or design decisions. The choice of materials are ready-made parts or subsystems that were intended for other purposes; quite often they are waste or used since they might be the only materials available immediately ${ }^{25}$

25 Jencks, Charles. Adhocism: the case for improvisation. New York: Doubleday \& Co., 1972. 


\section{Adhocism :: Which came first the chicken or the egg?}

Using Charles Jencks again," Adhocism has general and loose approach to a problem rather than a tight and systematic one". ${ }^{26}$ One of the early example of adhocism noted by Jencks was a story of 17 th century boat builders used trees in the forest for materials. The shape of the trees that can best represent specific patterns of

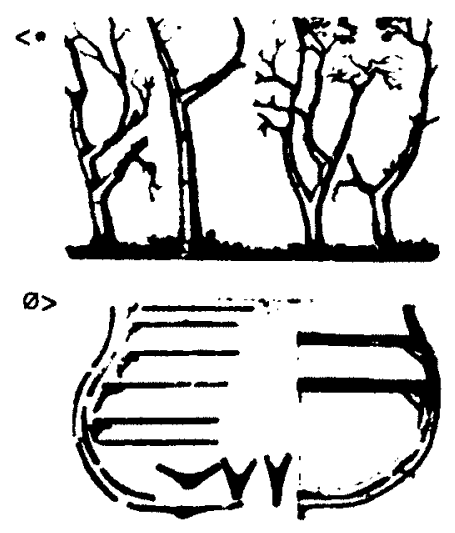

(c) $/ 118$ the boat were picked, cut then labeled. $\langle\bullet, \theta>$ The general and loose approach here is the selection of the subsystem; as described by Jencks, it was not customized for boat constructions and resulting scraps. The unrefined and raw quality of the subsystem has suggested its 'openness' to many possibilities and can be used for many other reasons. Equally it also has its 'limitation'. One may wonder at the difference between this hand picked subsystem and the modern day engineered lumber. The latter is a general material made for nonspecific purpose, while the former was an immediate adaptation of the tree's shape into a highly specific structural member of a ship.

The earliest ad hoc perhaps began with man's creation of objects of necessity, using ready made materials available at hand. Before the term adhocism, there was 'bricolage', borrowed from a French word, it means "a basic form of recycling that involves the opportunistic adoption and reuse of existing materials and structures for other purposes." 27 A person who engages with 'bricolage' is a 'bricoleur',

26 Jencks, Charles. Adhocism: the case for improvisation. New York: Doubleday \& Co., 1972.

27 Porter, Tom. Archispeak: an illustrated guide to architectural terms. Routledge, 2004. p. 19 


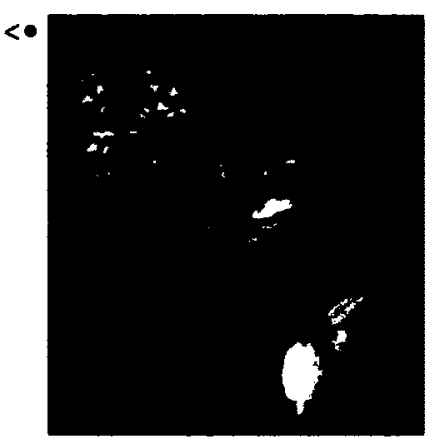

Giuseppe Arcimboldo "Winter", 1563 Mannerist painter rejected the rational, harmonious approach that were adopted by most Renaissance art, and favor ambiguity, virtuosity, and elegance.

o // 19 and as noted by anthropologist Claude Levi-Strauss in his book "The Savage Mind" - "... bricoleur is someone who works with his hands... he does not subordinate the used materials under raw materials (ie, the engineered materials), his universe of instruments are closed and do not acquire the purpose of the project, the rules of his game is always 'to make creative and resourceful use of whatever materials are at hand regardless of their original purpose ${ }^{\prime \prime}{ }^{28}$ In general the bricoleur and adhocist share some very similar characteristics. Thouth, adhocism is more the shift in meaning for predefined subsystems or parts that are [re]purposed from elsewhere and [re]appropriated into a new, immediate and specific-purpose assemblage that separate itself from a nonsense randomness. The adhocist uses a readily available collection of distinctive subsystems willfully melding and molding them together to create an unexpected, non-generalized, usable whole instead of subsuming the parts into a unified whole whose meaning overrides the subsystems.

\section{Ad hoc delight :: unexpected recognition}

Delight in adhocism is the surprise and unexpected recognition materialized from the ad hoc assemblage of heterogeneous parts / subsystems. The delight from the shift of meaning is what makes adhocism memorable; it has been applied in art, science, architecture, language, and almost everywhere else. The measure of delight is subjective, whether the surprise can makes us smile, be repells us, or

28 Claude Levi-Strauss, The Savage Mind: The nature of human society. Oxford University Press, 1996. 16-19. 


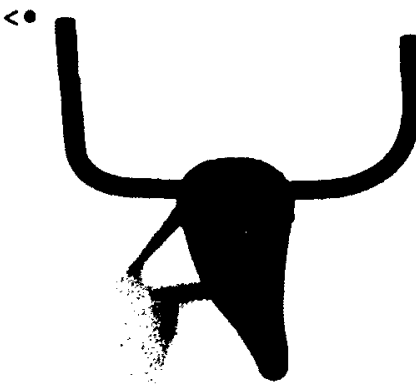

Pablo Picasso "Bull's head". 1942 (9) $/ / 20$

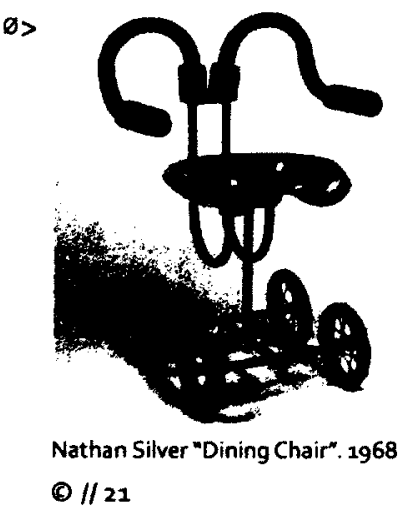

confuses us; it will be memorable one way or the other. From 16th century Mannerist Giuseppe Arcimboldo to 2oth century Cubist Pablo Picasso we can observe ad hoc wit; a shift of meaning, the layered interpretation, element of surprise and unexpected juxtaposition between an artistic work's figure and ground. <•

Arcimboldo's "Winter" is an amalgamated head of subsystems of a tree in winter season, one of the four seasons in the series, which consists of tree trunk for the face, broken branches, leaves on the head and so on. His precursive surrealistic works were his own distinctive style, they absolutely were non-generalized back in the 16th century and even today people are startled yet delighted by these works; all for the wit, his style of painting, the level of details and passion that included in these masterpieces. ${ }^{29}$ Picasso simply used a bicycle seat and handle bars, subsystems of a bike, and oriented them so that the completed piece resembles a "Bull's head". This whimsical shift of meaning from a bike seat to a bull's head provides the unexpected delight. <•

Nathan Silver's "Dining Chair" is an ad hoc delight in both representation and function. The chair is assembled with heterogeneous subsystems of a tractor seat, wheels from an orthopedic supply, and insulated foam components. The shift of meaning from the parts were the past memory of the seat from

29 Ferino-Pagden, Sylvia. Museum, Vienna: National Gallery of Art . $<\mathrm{http}: / \mathrm{www}$ nga.gov/exhibitions/2010/arcimboldo/arcimboldo brochure.pdP. 2010. 
farming vehicle and the wheels from medical supply context that are now used in the context of a household daily use furniture. The functional ad hoc wit lays on the comfort of the tractor seat and the orthopedic wheels for interrupted movement on a brick floor; while the visually unexpected recognition of the ram's horn from the curved handles was a happy accident of the ad hoc construction. ø>

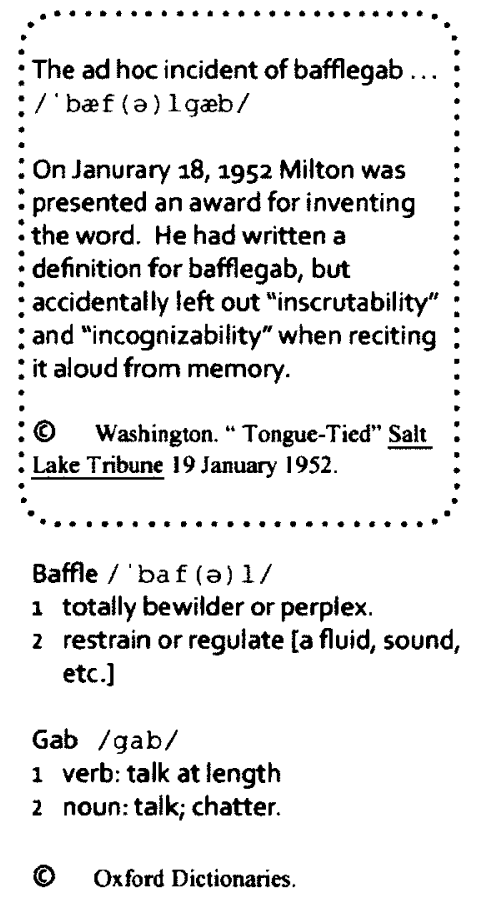

Ad hoc in not limited to artistic visual and physical aesthetics but can be applied in other fields with an equal measure of delight. Dr. Helen McNeil, "Literature" section contributor in Nathan Silver's "The Adhocist Sensibility", believed that"many such ad hoc words and phrases add to the resources of language and are gradually are absorbed by it. Others are strictly temporary .... and still others impoverish language by being less expressive than the words they may drive out." 30 Twenty years before the publication of "Adhocism" the assistant general counsel for the United States Chamber of Commerce, Milton A. Smith, coined the ad hoc term bafflegab to criticize the Office of Price Stabilization for the complex governmental language it used in one of its price orders. Smith defined the linguistically absorbed and still utilized word as a "multiloquence characterized by consummate interfusion of circumlocution or periphrasis, inscrutability, and other familiar manifestations of abstruse expatiation commonly utilized for promulgations implementing Procrustean determinations by governmental bodies." 31

\footnotetext{
30 McNeil, Helen. "The Adhocist Sensibility". In Adhocism: the case for improvisation. New York: Doubleday \& Co., 1972. 147.

31 Quinion, Michael. "World Wide Words". Updated 2012. < http://www.worldwidewords.org/weirdwords/ww-baf1 .htm> Cited January 2012
} 
This Adhocism section began with a Purist version of a common riddle meant to make us question our assumptions and because of last minute serendipity it ends with the Adhocist variation.

Q. Which came first?

A. The chicken or the egg. ${ }^{32}$

\section{Adhocism :: architecture}

Adhocism is not an architectural style such as Renaissance, Modernism, or Deconstructionism that has been widely explored by architects who design mega structures. Because of its ad hoc nature, Adhocism tends to be more often used in small to housescale architecture. In architecture, adhocism is an approach that disassociates itself from form or aesthetic; it focuses on the process of immediacy for a specific purpose, witful thinking, and improvisation in the use of materials and resources. There are a few adhocism characteristics that are similar to vernacular architecture, they both use locally available materials and are sometimes their design and construction is of unknown authorship.

Adhocism is expressed through using parts available to hand. They are generally regional materials or parts from other objects. Adhocism in architecture began when people created a pragmatic space using any materials on hand. They are commonly known as shed or shelter-a simple small footprint single-storey structure

32 Silver, Nathan. "Adhocism part two". In Adhocism: the case for improvisation. New York: Doubleday \& Co., 1972. 198. 


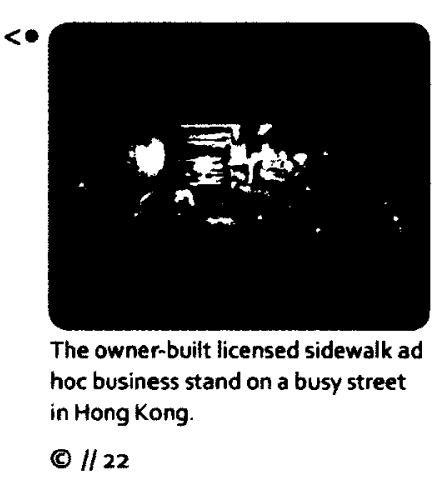

(c) $1 / 22$ consists of walls and roof to keep the person inside dry from the rain and heat from the sun - a practical solution of adhocism. ${ }^{33}$ Sometimes, this shed or shelter will be used as home for some people, or business solution in other cases. <• The owner-built licensed sidewalk-ad hoc fruit stand was one of the many located on a busy street in Hong Kong in an urban neighborhood filled with residential towers, fresh food markets, a variety of restaurants and shops. They provided a quick business solution to local residents and helped stabilized vitality on the street. These kind of ad hoc stands are still very popular today and can be seen in all different part of the world used for different practicalities. We will go on to explore how this practical adhocism in architecture is the inspiration behind the urban dialysis machine.

When there are ad hoc sheds built side by side and front to back together as a group, we refer to them as shanty town, a squatter or slum settlement. Let us also call them ad hoc settlements. Often constructed with scrap materials found on the streets or junk piles, such as corrugated metal for the roof, plywood and card board for the walls, electrical wires as clothes lines, and so on. These materials were arranged in a semblance of order, and while they don't need to look pretty they do have their own aesthetics. These settlements have unknown authorship and were built with local material to suit their native setting and climate; thus they identify as both ad hoc

33 Jencks, Charles. Adhocism: the case for improvisation. New York: Doubleday \& Co., 1972. p. 112. 


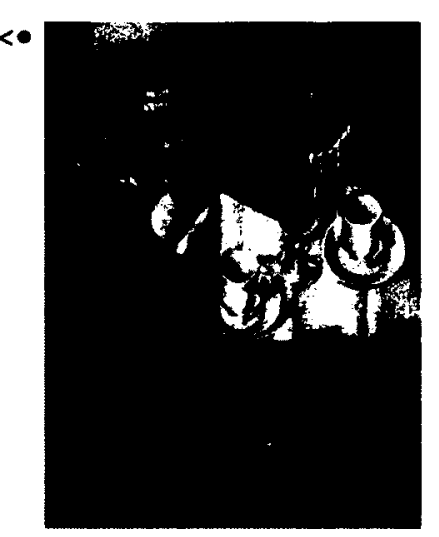

Juan Gris' "Breakfast" . 1914 01123 and vernacular architecture. Earlier in the chapter, we observed MSS station, a structure which utilized regional washing machine parts; it will be equally safe for us to also identify this as urban, ad hoc, vernacular architecture. Ad hoc materials for buildings are not restricted to materials that we already know to be construction supplies, as long as the materials are available immediately and met what is required for the purpose we should consider their use.

\section{Adhocism in architecture :: heterogeneous collage}

Another aspect of adhocism in architecture is the extended definitions in the material language - the intentional and regular use of unusual, ready-made parts. The heterogeneity assemblage of materials in architectural adhocism are like collages in 3-dimensional form. Collage is a word derived from French "coller", to glue. Primary used in visual art and invented by Cubist artists in the 2oth century, collages are made from an assemblage of different flat materials glued onto canvas. Juan Gris' "Breakfast" clearly has differentiable objects whether they are from newspaper, painted table or tea cups..$^{34}$ <- The superimposition of layered depictions in collages are similar to architects' representational drawings of ad hoc parts. Archigram - a group of visionary architects with mainly unbuilt projects from 1961-1974 - sourced their architectural language "from comic books, technologies, spaceware, computer nets, soap bubbles and even the flexing tentacles of an octopus." 35 Peter Cook's archigram

34 Lowry, Glenn. MoMA Highlights: 325 works from The Museum of Modem Art. New York: The Museum of Modern Art, revised 2004, p. 76.

35 Jencks, Charles. Adhocism: the case for improvisation. New York: Doubleday \& Co., 1972. p. 83. 
B>

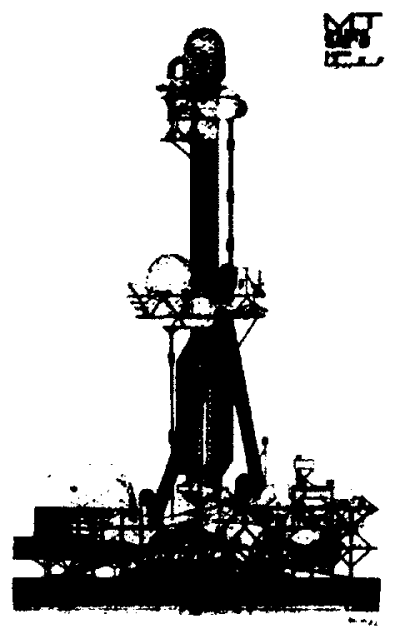

Peter Cook, Archigram. "Entertainments Tower Project", 1963. It was designed for Taylar Woodrow Design Group and also known as Montreal Expo'67 Tower project.

(c) $1 / 24$

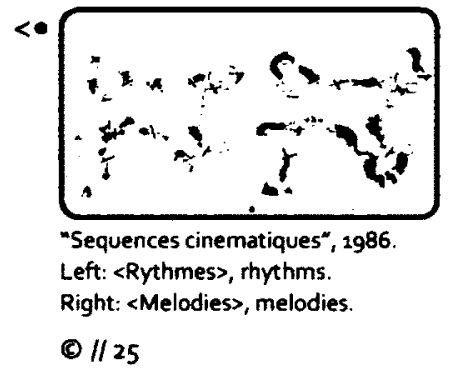

project "Entertainments Tower Project" (also known as Montreal Expo'67 Tower project) shows in it's architectural representation drawings depictions of distinguishable and layered heterogeneous parts representing different architectural programs consisting of conventional sub-languages of different disciplines that were at it's time not commonly utilized in architecture. $\emptyset>$ For example, the geodesic nets to represent circulation, the geodesic dome to denote large auditorium and exhibition spaces, the pneumatic tubes to mean vertical movement, and the elliptical pods to imply individual hotel rooms ${ }^{36}$ Heterogeneous parts purposefully put together convey not only their own meaning but also the meaning of the whole whether it be in collage, representational drawings or ad hoc space. It is for this reason that adhocism is not an nonsensical, purely random, collection of objects.

\section{Adhocism in architecture :: urban park space}

In relation of resolving the complexity of architectural organization and urban public social space, we can again look at Bernard Tschumi's methodology as directly applied in his design of Parc de la Villette.

<- Using the technique of montage he deconstructed the history of the site by layering a series of abstracted analytical diagrammatic systems, which allowed them to have conflicts, to be subtracted and fragmented. On one node, the conflict reflects the unsettling memory and context of the site, and people's preconceived idea of

36 17-18.
Sadler, Simon. Archigram: Architecture without Architecture. MIT Press, 2005. 


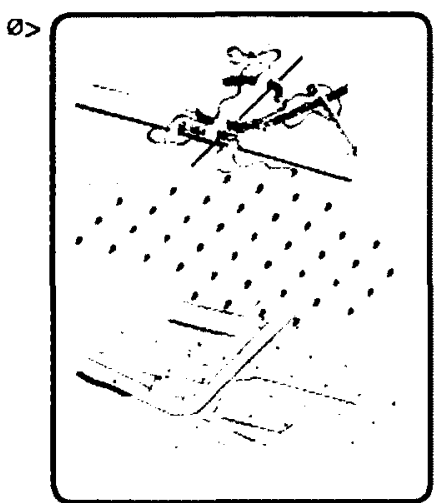

Superimposition of points, lines and surfaces, 1982.

(c)// 26

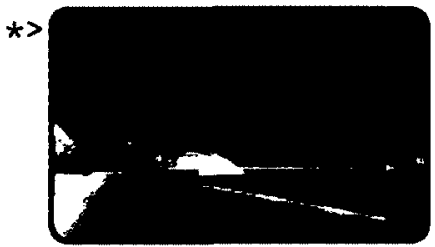

"Ligne D'o, Promenade cinematique et Folie du spectacle", 1984

(c) $/ / 26 \mathrm{~b}$

a park. On the other node, it reflect the complexity of the people's urban life. The architecture and its organization for Parc de la Villette challenges and questions other architects' conventional design strategies referencing the history of the site, its 'typology, origin, or determining signified. ${ }^{37}$ The design system consists of three overlapping layers of point grids, lines and surface through out the site; it was meant to be heterogeneous and mediate conflict between the coexisting context and preexisting history of the site. ø) Each point is a "Folie", claimed to be a programmatic madness of architecture by Tschumi, and held no meaning in order to invigorate a multiplicity of events in the park. $*>$ The fundamental use of heterogeneity in La Villette was to achieve both a separation of the logical systematic connection and strengthen the overlapped composition. This sense of separation and stability in heterogeneity is also apparent in the use of materials and parts composition in adhocism. The collection of parts used for an ad hoc production are intentionally separated by their distinctive individual characteristics while their union makes of them an unexpected, non-generalized, distinctive and recognizable whole. 


\section{Shaken, not stirred}

Now let us move towards Urban Dialysis. Community bond in urban dialysis is engaging the [re]invigoration of the community on at least one of the two levels: the continuous participation of the users in functional events in a constructed space and/or collaboration of the community toward a space. The collaboration in the community is to design, to construct, or to voice their concerns toward the living quality in their neighbourhood; which includes buildings, outdoor spaces, and life on the streets. A common / mutual bond is also created or extended through the participation of the users when a delight of common ground is shared with people through the use of space and the experience in the events. This is the action to put forward activities that are bound to happen in the defined social space; activities that allow positive reinforcement back to the community. Collaboration is an important element of the public intrusion in space because, in the words of 2oth century French sociologist and philosopher Henri Lefebvre, it allows for "grassroots opposition, in the forms of counter-plans and counter-projects designed to thwart strategies, plans and programmes imposed from above." ${ }^{38}$ It should be noted that in developing community bond it is more important for a space to have a continuous interest to the users for a long term community bond than it is to have one-off events of collaboration or participation. This is because it is when a space is occupied with continuous activities that a community is [re] invigorated, or as Lefebvre claimed "... occupied space gives direct expression to the relationships upon which social organization is founded." 39

$38 \quad$ Lefebvre, Henri. The production of space. Trans. Donald Nicholson-Smith Wiley-Blackwell, 1991. p.383

39 Lefebvre, Henri. The production of space. Trans. Donald Nicholson-Smith Wiley-Blackwell, 1991. p.229 


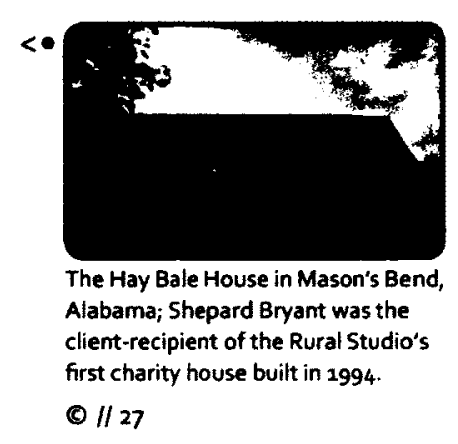

The Hay Bale House in Mason's Bend Alabama; Shepard Bryant was the first charity house built in 1994.

$1 / 27$

\section{Collaborative}

"Samuel Mockbee - architect and expert in community design projects - built his first charity house for $\$ 7000$ in the 90's using donated and salvaged materials and volunteer labor ... <•" 40

The case studies for Urban Dialysis projects are closely related to user participation and more so community-based collaboration. The idea of collecting donated and salvaged materials for a community [re] invigoration ad hoc project should be readily acceptable to members of the community. Community collaboration project can extend the participation model in many aspects of the design process. The case of Samuel Mockbee's design model approach called community design comprised of self-reliance and self-determination that made the self-help model, which combined with technical expertise. ${ }^{41}$ The knowledge gained and proven community efforts for Mockbee's initial charity house became the model for Auburn University's Rural Studio, founded in 1992. Every semester 15 second year undergraduate architecture students undertake the design and construction of a charity house, every year fifth year students design and build a community based project. The studio focuses on architectural practice, education, social welfare, utilizing local salvaged or donated materials, community design and communication. Even a decade after Mockbee's death in 2001 Rural Studio is still designing and building ad hoc collaborative architecture in poor Alabama communities. ${ }^{42}$

4041 Stohr, Kate. "100 Years of Humanitarian Design." Architecture for Humanity. Design like you give a damn: architectural responses to humanitarian crisis. Ed. Architecture for Humanity. Metropolis Books, 2006. 49.

42 Dean, Andrea Oppenheimer. Architectural Record, "Samuel Mockbee: A Life's work". June 2004. 
The practices of collaboration and participation are being used often in our social contexts including media, art, public and private organizations, associations, etc. In an online discussion of participation and collaboration Daniel Mittleman, a DePaul University professor with research interests in Collaborative Engineering, summarized six ideation based engagement strategies commonly referred to by collaborative engineering theorists.

"Generation (going from fewer to more ideas being considered [eg. brainstorming]); Clarification (going from less to more understanding of ideas being considered); Organization (going from less to more understanding of the relationships among ideas [e.g clustering]); Reduction (going from more to less ideas under consideration toward achieving a particular goal [e.g. Voting]); Evaluation (going from less to more understanding of the value of each idea under consideration toward achieving a particular goal [e.g. other kinds of Voting]); Commitment (going from less to more commitment toward acting on an idea toward achieving a particular goal." 43

The International Association for Public Participation (IAP2) has developed foundational tools and techniques to establish ethical,

43 Mittleman, Danny. "Can We Categorize Participation and Collaboration?". Updated 20 Jan 2011. <http://blogs.gartner.com/andrea_dimaio/2010/01/20/different-typesof-participation-and-collaboration/>. Cited Feb 2012. 
effective public participation policies and practices. In IAP 2 processes the public are invited into the entire decision making or problem solving cycle including the organization and evaluation of the ideas generated through participation. The spectrum of participation model from IAP2 references five ascending levels of significance in public participation.4 The first is to INFORM the public with as much assistance as possible to make the objective clear and to assist them in understanding the issues, opportunities and/or solutions; this can be done with different media techniques and social orientation. Second is to CONSULT the public's feedback and concerns regarding the issues. Third is to INVOLVE the public at the start of the process; such as generating dialogues between all stakeholders toward the clarity of the goal. Forth is to fully COLLABORATE with the public in the decision making, development, and alternatives toward the benefit of the goal. Fifth is to EMPOWER the final decision making in the hands of the public before any implementation. 45

In the case of urban dialysis, the idea of collaborative architecture can be understood as a performative framework and non-structural elements as set pieces which when combined will accommodate the users' cooperative adaptation of the spaces. Collaboratively-inspired architects, such as M12studio and 2012Architecten, can provide a framework and mass-customization system for the users, who can then establish a series of collective spaces for different uses.

\footnotetext{
44 International Association for Public Participation, Canada. Updated 2011. <http://iap2canada.ca/>. Cited Feb 2012.

45 IAP2 Spectrum of Public Participation. Updated 2007. <http:/www.iap2.org/ associations $/ 4748 /$ files/IAP2\%20Spectrum_vertical.pdf $>$. Cited Jan 2012.
} 
As we can see these spaces provide initial inputs and accommodations for subsequent ease-of-use adaptations, allowing for unpredictable spatial outcomes to happen. Death and taxes are eternally consistent, architectural use should not be.

There are two core elements of a the collaborative approach in architecture we can examine - designer collaboration and user participation. In the first camp, designers are required to design and/ or utilize architectural and social frameworks to conceive and develop workable contexts that enable the users to actively participate in the system, such as 2012Architecten's mobile modular MSS Station. In the second camp users are actively encouraged to participate in modifications enabled by the architectural framework rather than passively have architectural authorities impose decisions on them [such as the Folie in Parc de la Villette]. In our study of community [re]invigoration - could the pursuit of collaborative systems lead to better architectural experiences and satisfaction? Could it also lead to a greater intermingling of the two camps into a unified whole? How do we create these systems of social and architectural frameworks which support a workable context for community [re] invigoration? A review of other artistic endeavours' user collaborative relationships may provide lessons and suggest suitable forward paths for user collaborative urban dialysis. 


\section{Collaborative [user participation] + Theater}

"All the world's a stage,

And all the men and women merely players;

They have their exits and their entrances;

And one man in his time plays many parts" 46

A theatrical parallel can be seen in audience participation events where the outcome of the story can be different depending on the audience interaction. An acting troupe called iO shape their Broadway musicals on live audience participation. ${ }^{47}$ The themes, story and characters are improvised and different every time in their 30 to 40 minute performances. The organization team devise and perform group number, choreography and other necessities to support the improvised elements. People in the musical profession were impressed with participating audiences singing and how quickly they picked up on their roles. Feedback from an iO organizer was that the participating audiences practice working together with the team and listening better because they are part of the performance. This is true in many collaborative experiences. In the case of collaborative architecture, the architects can be seen as the organization team and the users are members of the participating audiences. The role of the authors and players are blurred and become indistinguishable as the authors come to accept their position as narrators. Thus, social phenomenon can be created from such unpredictable experiences.

46 Shakespeare, William. "As You Like It." Act 2, scene 7, Line 139-142.

47 Chicago's Best Improv Comedy. "Welcome to the iO Theater!". <http:// ioimprov.com/chicago/about $\gg$. Cited Sept 2011. 


\section{Collaborative [user participation] + Social media}

We can examine a theoretical parallel between web page

infrastructure of social media and architecture. The users of individual web pages are controlling the contents as story generators, but the social media organizations are providing the frameworks.

If the frameworks do not adapt to the interests and requirements of their users then they are abandoned for another social media. AOL preceded MySpace, which spawned Facebook, who is now being challenged by an open source distributive framework called Diaspora produced by 4 university students. It is not boredom that drives users away from social media instead it was and is a result of reduction in principles by the companies operating social media websites. These errors of principles include imposing a limited selection of pre-approved design decisions onto their users instead of allowing the users to adapt the framework of the website to showcase their own designs. Not respecting the requirements or requests of their users within a reasonable period, not responding quickly enough to the changes in their user base and not respecting the users right to control of their private information.

A similar concept applies to collaborative architecture, where the users should have control over the use, purpose and adaptation of spaces otherwise they will also abandon their interest in architecture, not out of boredom but because they only have an outsider's voice. 
The architectural structure framework can then be understood as a template for each individual's web page. The social interaction in between the collaborative spaces then becomes the core element for inputs and changes.

\section{Collaborative + Transformable}

Cedric Price is a well respected English architect, writer, and architecture professor whose professional developments, inspiring vision, and knowledgeable criticism made him one of the most influential architects of the late 20 th century. ${ }^{48}$ Fun Palace, a collaborative design organized by Price as well as the subject of half a dozen essays by him, was to utilize improvisational architecture as a break from everyday routine.

"... the users could assemble their own learning and leisure environments, creating an improvisational architecture where they might escape from everyday routine and monotony of serial existence in one-dimensional society, and embark on a journey of creativity and individual fulfilment." 49

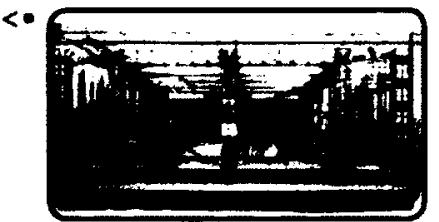

Interior perspective drawing of Fun Palace.

(C) $/ / 28$
A core concept motivating the project $<\bullet$ was time-based urban interventions, in contrast to the static grid structures other parts were considered flexible or adaptable as initiated by user participation. The project is an example of collaborative architecture which was to extend the use of transformable spaces into the everyday routine

48 McDonald, John. Canadian Centre for Architecture. Collection, "Cedric Price: Fun Palace". <http://www.cca.qc.ca/en/collection/283-cedric-price-fun-palace>. Cited Mar 2012.

49 Mathews, Stanley. "Cedric Price as Anti-architect." In Architecture and Authorship. London: Black Dog Publishing, 2007. pp. 142-147 
in order to fulfill the responses of the users and to provide them a regularly changing sense of fun. Improvisation would have be done by moving a few walls, without the use of cranes or other expensive equipment. Mechanical, electrical, hydro and utility wiring was planned to be inside the physical framework therefore allowing many transformations to be freely improvised with little to no cost to the users.

Similar to Fun Palace's designers the role of collaborative architects is to narrate story elements of the physical framework which then offers users the ability to compose different stories through their interpretation and adaptation of the space. Mass-customization systems for multi-family residences, such as RAMTV's proposal, can be used to collectively manage the shared spaces for different daily or seasonal uses. Spatial pockets would provide extra space and enrich both family and community life within the building by going beyond the boundaries of traditional, private household space. For the individual units the system adapts to the changes in family dynamics, as a young single adult less space is required, as a couple with a newborn an extra room becomes useful, as a family with four children the desire for a much larger space grows, as an older couple whose children have left home the need for space lessens and the system accommodates these physical modifications of the space. Price's improvisational architecture and RAMTV's mass-customization 
system creates an understanding of the usefulness of a typology that readily accepts diverse spatial transformation which increases the overall accessibility and effectiveness of each of the space while allowing for adhoc reinterpretations of the current design.

\section{Collaborative + "Negotiate my boundary!"}

"Changing social structure and systems call for new forms of architecture" 50

Negotiate my boundary!: mass-customization and responsive environments is a thesis design research project combining a subsystem of the web-based negotiating for sharing the participants' private space. It is a project by the five person team RAMTV - [their names here], in the AADRL Design Research Lab at the Architectural Association School of Architecture, London. The book is separated into three major sections; research processes, mass-customization, and user scenarios. Section two of Negotiate my boundary! explored three specific levels of the customization process; parametric neighbourhood, spatial envelope, and customizing the boundary.

Their project clearly leads us to the questions:

Can architecture respond to social movements?

Is flexible architecture an acceptable technical solution?

Can it really encourage more social interaction?

$50 \quad$ RAMTV. Negotiate my boundary!: mass-customisation and responsive environments. Ed. Brett Steele. Basel: Birkhauser, 2006. 


\begin{abstract}
A March 2010 published article on deconcrete notes that RAMTV's "social movement of turning one's home into an informal open restaurant for a few hours" has spread all across London and is gaining ground in the US and Cuba, Berlin has started an all day, three meal, differing companions, multi-site version that ends with the entire group congregating at a bar to share the day's experiences. The idea of mixing social interaction with one's hobbies and potentially turning it into extra earnings has becoming popular among the participants. ${ }^{51}$

Will this social movement last, or will people get bored quickly and move on? Is this a sign of people needing more social interaction or a response to economic measures? If architecture is indeed about people and for people, then why not let them participate in telling their story? It is not the architect's story that matters, it is the architect's ability to narrate the diverse stories of the community they are designing for that matters. The example showed that collaborative architecture from both the designers and the users can encouraging positive social interaction as an infectious act of urban and community [re]invigoration.
\end{abstract}

51 deconcrete. "blurring walls." Updated 05 March 2010. <http://www.deconcrete. org/page/7/> Cited 19 April 2011. 


\section{P@}

Case studies for urban community [re]invigoration

The selected projects are examples of ad hoc design methodology, as expressed in urgency, purpose and non-generalization; they consist of small structures and spaces whose design features helped increase the vitality of their existing community. Their developments are varied in design, assembly, purpose and use but share a common property of adhocism. Collectively they embrace common good goals, adapt repurposing unused materials and space, extol the rehabilitation of structures, and acclaim the social importance of community-based collaborative organizations as elements of civic vitality.

These projects are not only a delight to look at, they have helped enliven a community with the activities stimulated in the space. The four projects were designed by two different firms. 2012Architecten based in Rotterdam and M12studio in the States of Colorado.

They took different approach toward the idea of resources [re] appropriation and community [re]invigoration, and their projects have helped inspired the idea of urban dialysis.

M12studio is a collaborative design firm operated by interdisciplinary professionals, while 2012 Architecten is focused on new constructions using [re]purposing waste and excess materials found mostly in local region. Jan Jongert and Cesare Peeren of 2012Architecten initiated Recyclicity [a publication and a community of organization] 
as well as an online community of <Superuse.org>. The web site creates community bond by expanding the interaction poll of people with related interests; it archives, shares methods and research of different recyclable ready-made materials they and other designers have experimented in the past.

(1) Reconfigurable + mobile multifunction envelope

(2) Community-based transformable + mobile music studio

(3) Utilizing composite components for children playground

(4) Social project on a city-owned failing structure

(1) MSS by 2012Architecten - toured around the Netherlands.
(2) M.I.K.E. by M12studio - Sheboygan, Wisconsin at the Kohler Arts Center.
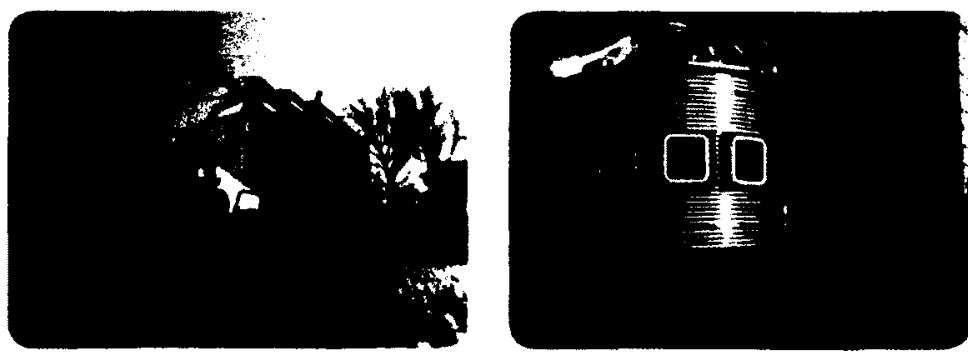

Aug 2006
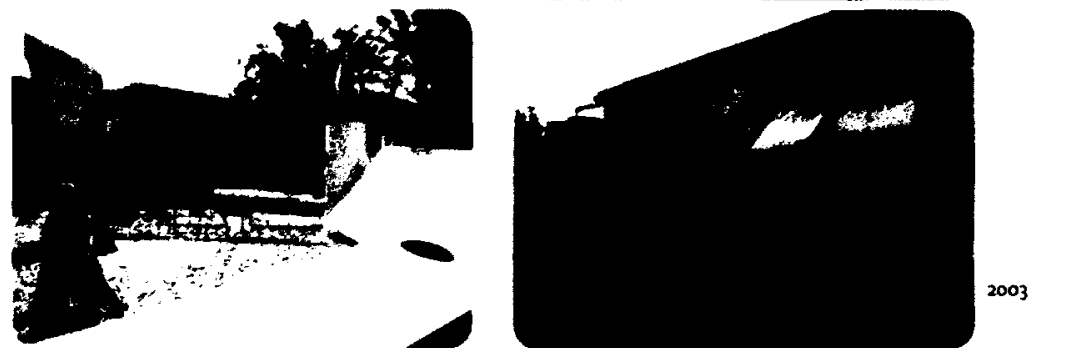

(6) Bicycle Shed by M12studio

(3) WIKADO by 2012 Architecten

- Sheboygan, Wisconsin for the foundation "Kinderparadijs Meidoorn".

e Mi2studio <m12studio.org>. based in Denver and Yuma, Colorado; it is organized and operated by a collective of artists and creative professionals.

2012 Architecten <2012architecten.nl>. Emantspad 53061 CE, Rotterdam 
Case s\{udy \# [

Reconfigurable + mobile multifunction envelope

MSS, Miele Space Station [built in 2003]

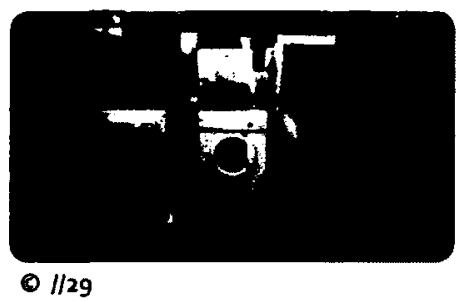

A reconfigurable, multifunctional, cross-programming, mobile, architectural kiosk that has been used as a bar, art vending machine, a concert \& construction site café, a music shop/office/bar, stage setting for a fashion show, a mobile architects' office, and an espresso bar at Delft University school of architecture. Designed by 2012architecten, a Rotterdam based architecture office, whose motto is "A design is not considered as the beginning of a linear process but as a phase in a continuous cycle of creation and recreation, use and reuse." 52

By adding different ad hoc improvised elements in between the modules; such as solar panels, fridge doors, car tires, sails - the MSS could be built and extended in different sizes and configurations. Designed with both Dutch traffic regulations and common Dutch doorway sizes in mind, the height and width of a standard module was intended for travel and use in different places. Ad hoc delight is achieved by the stimulus of material used differently than its initial purpose. MSS bonds the community in user participations in a way of [re]appropriating social and gathering space; as well as its mobile ability to [re]invigorate various places, communities, and social events for the common good - all of these have made it a workable urban dialysis machine. 
Case S[udy \# []

Reconfigurable + mobile multifunction envelope

MSS, Architectural installation

Design Methodology:

Reuse:

, Made Entirely of washing machines

Repurpose:

1 Repurpose waste from common household appliances

Engage:

1. Engages the public in different events with the inspiration of this art and architecture sculpture

Impact:

, Provided practical solution to utilize waste

, Alternative route for other housing possibility

Cross-Program - Multifunctional, it has been used in different events:

espresso bar at the Faculty of architecture in Delft $U$ of Tech.

, art vending machine

- pavementcafe

, music shop/office/bar

, stage setting for a fashion show

, construction shed for Villa Welpeloo

Standard Module:

Separate modules [movable by 2 people]

, $60 \mathrm{~cm}$, standard of washing machine

, roll through standard doors of $210 \times 70 \mathrm{~cm}$

Mobile unit \& Facilitate transportation:

, 5 portions can be assembled on a trailer as a caravan

Reconfiguration:

, segments can be placed in various configurations for different purpose

* 2012architecten. <http://2012architecten.nl/2003/10/ms5-2/>. Cited October 2011.

- Layout Mei Chow 
[Case Stud] \# []

Reconfigurable + mobile multifunction envelope

\section{STUDY -}

MSS [Miele Space Station] Architectural installation

toured around Netherlands
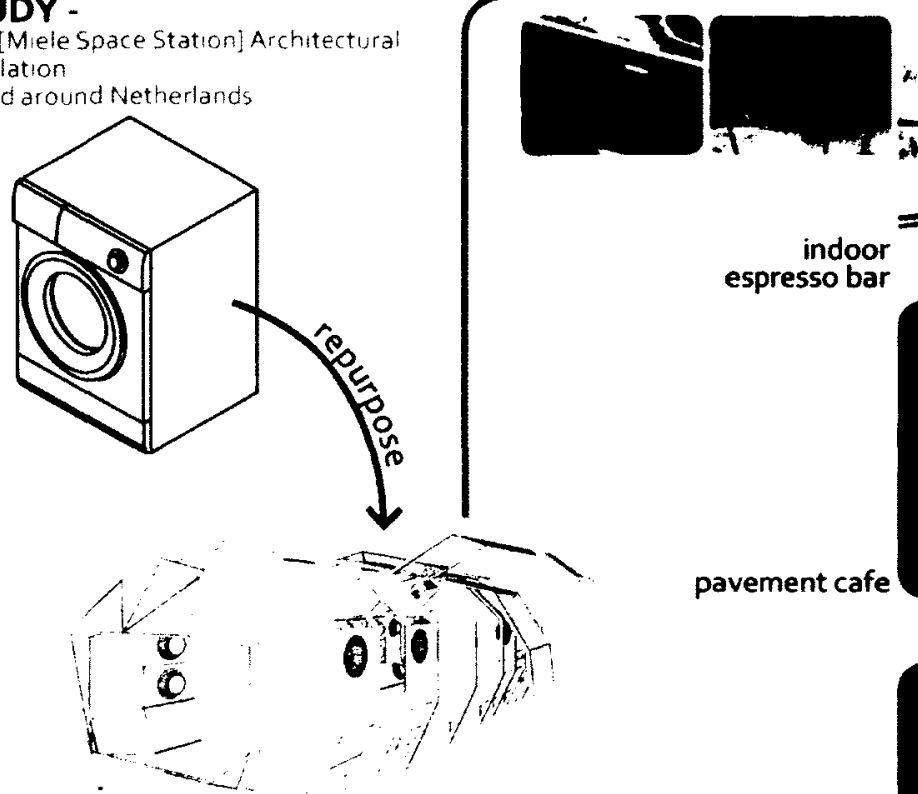

pavement cafe
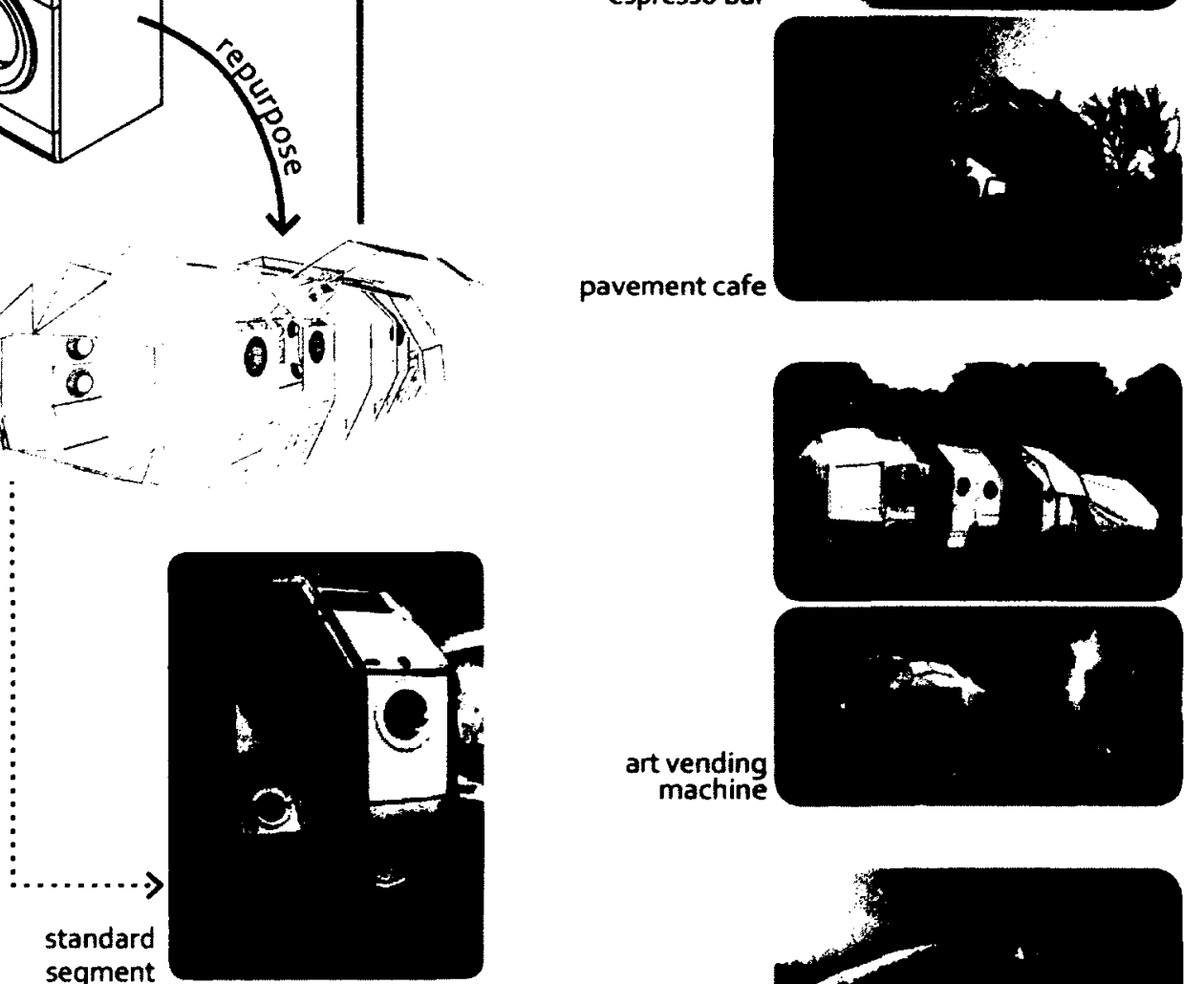

standard segment

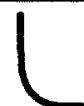

construction

Image source:

2012 architecten. shttp $/ / 2012$ architecten, n/2003/20/mss-2/>2011

Cayout Mei Chow 
Case siudiy \#2

Community-based transformable + mobile music studio

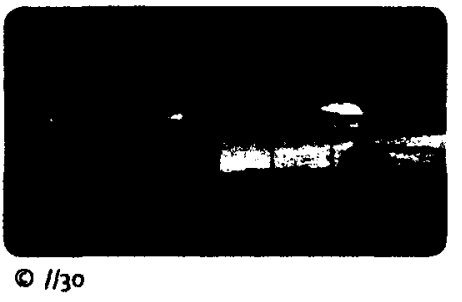

M.I.K.E. - Music Integrated Kiosk Environment [built 2006]

M.I.K.E. is an interdisciplinary architecture with emphasis on engaging public community space through visual and sonic creativity. It was a collaboration involving Richard Saxton [a Colorado-based artist whose work combines art and community practice] of the municipalWORKSHOP subsidiary of M12Studio and Stuart Hyatt of TEAM Records music who were responsible for the design, and 100 community participants who completed the parts assembly. 53 It was a project commissioned for the Connecting Communities Residencies Program in John Michael Kohler Arts Center in Sheboygan, Wisconsin. With different communities and academic partners collaboration for the ongoing residencies program; its aim is to strengthen the region by bring together artists, and [re]connect the teens and young adults to their ancestral cultures, societies, and communities using art as a bridge - M.I.K.E. is one of them. By integrating artists into the community and by inviting the participation of the community public, the residencies program is hoping to bring to the public a greater understanding of the value of the diversity. ${ }^{54}$

(n)

As such, M.I.K.E. is a tool and a process of continuously integrating art, skills and culture into the bonds of a community - an example of urban dialysis machine. By [re]appropriating public space, [re] purposing farming grain bin, camper and truck parts, and through community collaboration; it applied ad hoc approach that not only utilized immediate available materials, but the recognition of the grain bin revealed a piece of cultural history.

53 M12Studio. "M.I.K.E.". <http://m12studio.org/mike>. Cited Oct 2011.

54 John Michael Kohler Art Center. "Residencies". <http://www.jmkac.info/>. Cited Oct 2011. 
Case Squdy \#2

Community-based transformable + mobile music studio

M.I.K.E. [built 2006]

[Music Integrated Kiosk Environment]

, Community based music program

Design Methodology:

- Collaboration project for a community

- Farm Architecture - Assembled from prefabricated ribs that are used for grain bin construction

Reuse:

, Salvaged camper and RV parts

Harvest:

, Skylight is provided for natural light

Repurpose:

- The esthetic from farm architecture - grain bin

Engage:

, engages public space through visual and sonic creativity

, Localat-risk teens and students from a nearby technical

college cut, welded, and glued M.I.K.E. Together

> Stage is set for neighborhood concerts

Impact:

encourage children and young adults to music

Promote collaborative project like this in a community

Distinctive and public positive outcome for the teens efforts

Interdisciplinary - [art + architecture + culture]

, mobile sculpture, architecture $\&$ music

Program - Multifunctional

, interactive sound recording studio

- record various audio experiences such as; music, oral histories, sound art works

, performance stage

Reconfiguration:

, from recording studio to a 3 tier performance stage

* M12studio. <http://m12studio.org/mike >. Cited October 2011.

- Layout Mei Chow 
Case S\{ndy \#2

Community-based transformable + mobile music studio

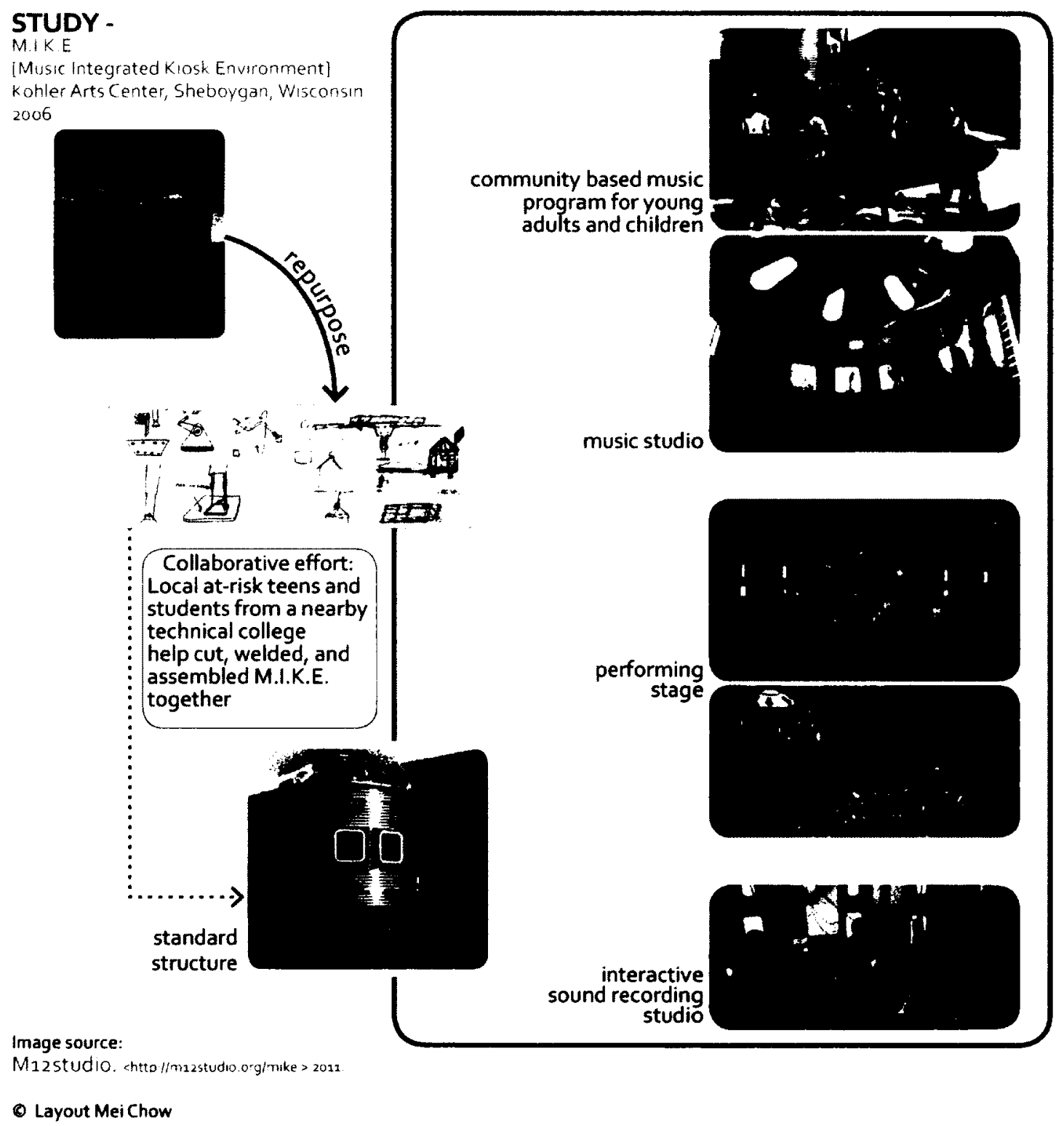




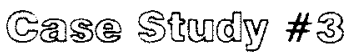

Utilizing composite components for children playground

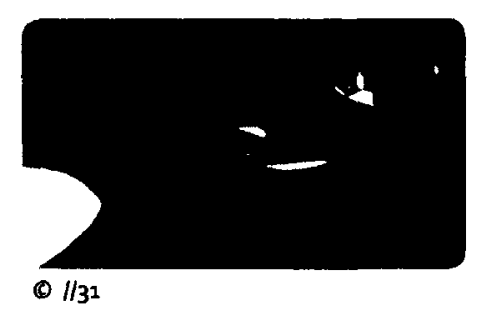

WIKADO - Revamp the old playground condition [built 2008]

This project [re]invigorated the existing $1200 \mathrm{~m} . s q$ children's playground in a problem community. The 40 districts of Vogelaar is a list of 40 Dutch problem neighborhoods identified on 22 March 2007 by Minister Ella Vogelaar of Housing. Each year, in the Netherlands 200 modern wind mill wings are rejected because of because of small unrepairable cracks. At the request of the Kinderparadijs Meidoorn foundation 2012 Architects renovated a failing playground in one of the 40 districts. 55 Elements of the existing park were selected for reuse and utilizing five of the discarded wind mill rotor blades 2012Architects created a maze, slides and tower structures on the existing concrete circle. The maze, arranged with a panna court in the center, is associated with the tradition in Holland of linking the design of children's playgrounds in urban area to the exploration of social and plastic art experimentation. ${ }^{56}$ Four distinctive towers each with their own characteristics support a climbing net, the net also prevents balls from disturbing the neighborhood gardens. ${ }^{57}$

Wikado Park took 2 months to design and was constructed in four months..$^{58}$ It identifies as an urban dialysis machine because of its immediacy in design and construction coupled with the [re] appropriated material and space, it's decidedly public common good as well as it's obvious delight for it's participating users.

55 Wikipedia. "De 40 wijken van Vogelaar". Updated 23 Mar 2012. <http:// nl.wikipedia.org/wiki/De_40_wijken_van_Vogelaar\#De_wijken>. Trans. Cited Mar 2012. 56 "European Environmental Design Award". Best Ed. Ist edition. Ed. Javier Fernandez, Gloria Escribano, Trans. Paloma Gonzalez. 2009: 14-15.

57 2012architecten. "Wikado". <http://2012architecten.nl/2008/10/wikado-2/>. Cited Oct 2011.

$58 \quad$ NG Update, "Wikado playground in Rotterdam". March 2009. 
Gase Study \#

Utilizing composite components for children playground

WIKADO - Revamp the old playground condition

Design Methodology:

Mapped the old situation and made element selection

\section{Reuse:}

1 5 discarded rotor blades to create maze like space

, Reuse the existing concrete circle

\section{Repurpose:}

- Utilization of composite components such as wind turbine rotor blades

Engage:

, Engage the younger generation with alternative play structures

Impact:

1 The opportunity to demonstrate a creative use of disposed material to children and their community

- Put urban waste back in the economic circulatory system instead of land-filling

Interdisciplinary - [art + architecture + culture]

, Sculpture, architecture \& game

Program

, Children's playground as game court and maze

, Urban sculptural fragmentation

* 2012architecten. <http://2012architecten.nl/2003/10/mss-2/>. Cited October 2011.

- Layout Mei Chow 
Case S\{mdy \#3

Utilizing composite components for children playground

\section{STUDY -}

WIKADO [Revamp the old playground] 306. CE, Rotterdam
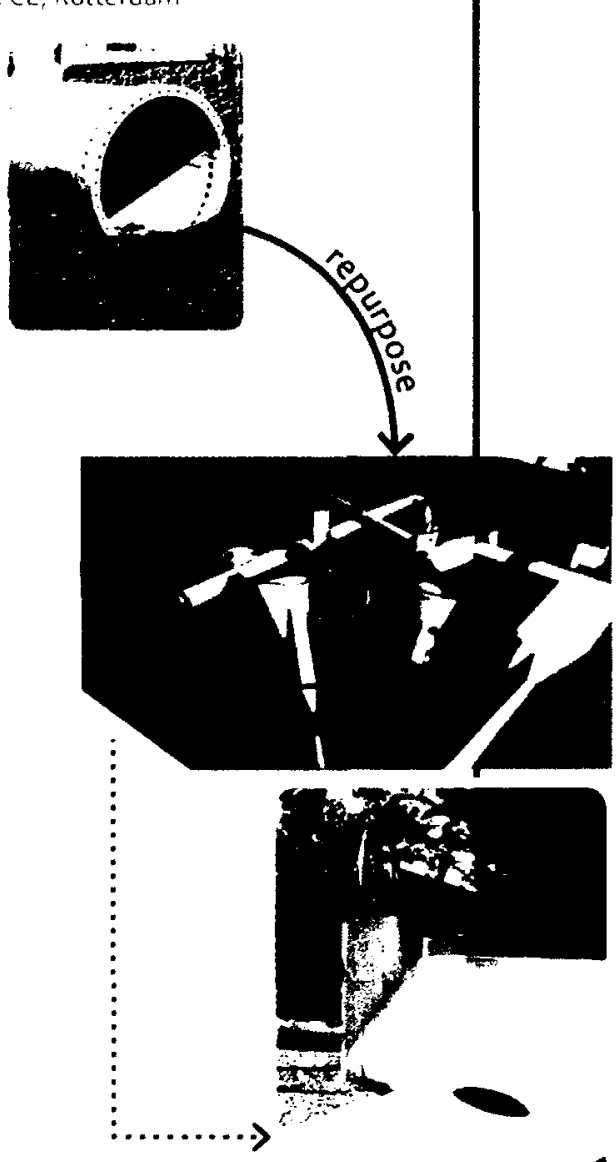

utilized 5 discarded rotor blades to create maze like space

Children playground as game play
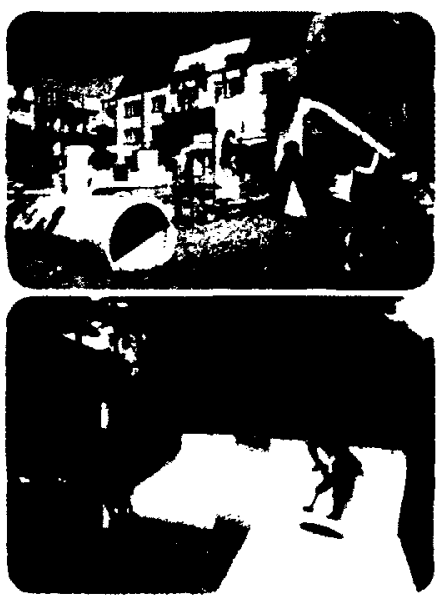

rotor blade fragments

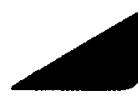

reused the existing

Engage the younger generation an alternative play

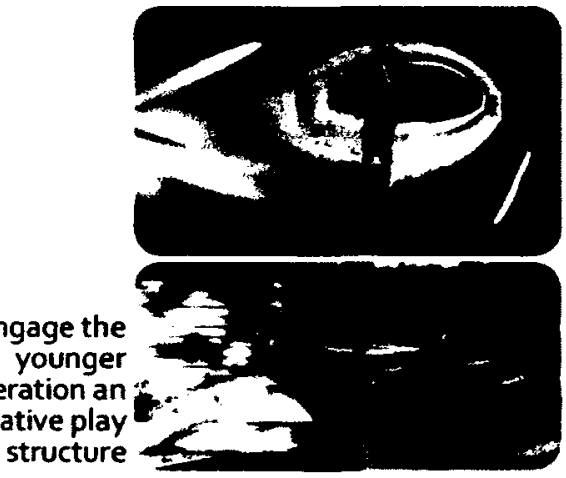

Image source: concrete circle

2012 architecten. <http:/2012architecten. $1 / 2008 / 10 / w 1 k a d o \cdot 21>2011$

- Layout Mei Chow 
Case SEudy \#

Social project on a city-owned failing structure

BICYCLE SHED [built 2003]

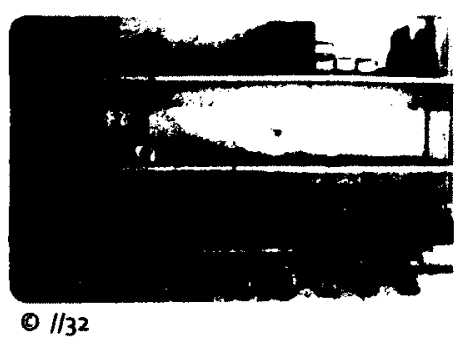

Coleman Center for Arts and Culture, York, Alabama.

Similar to M.I.K.E. the Bicycle Shed was initiated by Richard Saxton under M12studio's municipalWORKSHOP. It was created while Saxton was a resident artist at the Coleman Center for Arts and Culture between 2003 to 2005 . The shed was a [re]appropriation from a city-owned failing and abandoned structure to a bicyclerecycling workshop for young adults, free for those under the age of seventeen. After going through minimal renovation and the addition of some low-tech features for the shed to run regularly with both low maintenance requirements and low cost, the workshop now operates regularly with two volunteers on duties. The ad hoc approach to the low cost restriction included rain water harvesting for basic utilities and recycling used water to feed the plant beds. Energy for the building's water pumps are provided from a solar panel's energy harvesting. ${ }^{59}$ Part of the material improvisation is the structure itself and the easily identified red milk crates filled concrete for the base of the bench. This shed is considered an urban dialysis machine because the [re]appropriation of the space provided initial inputs for subsequent ease-of-use adaptations, allowing for educational purpose for the youth of the community. This rehabilitated structure is becoming a part of community [re]invigoration through the [re] appropriation of the space, and creation of community bond aided in part by the users' participation in skills and education developments.

59 M12studio. "M.I.K.E.". <http://m12studio.org/mike >. Cited October 2011. 


\section{Case sumdy \#4}

Social project on a city-owned failing structure

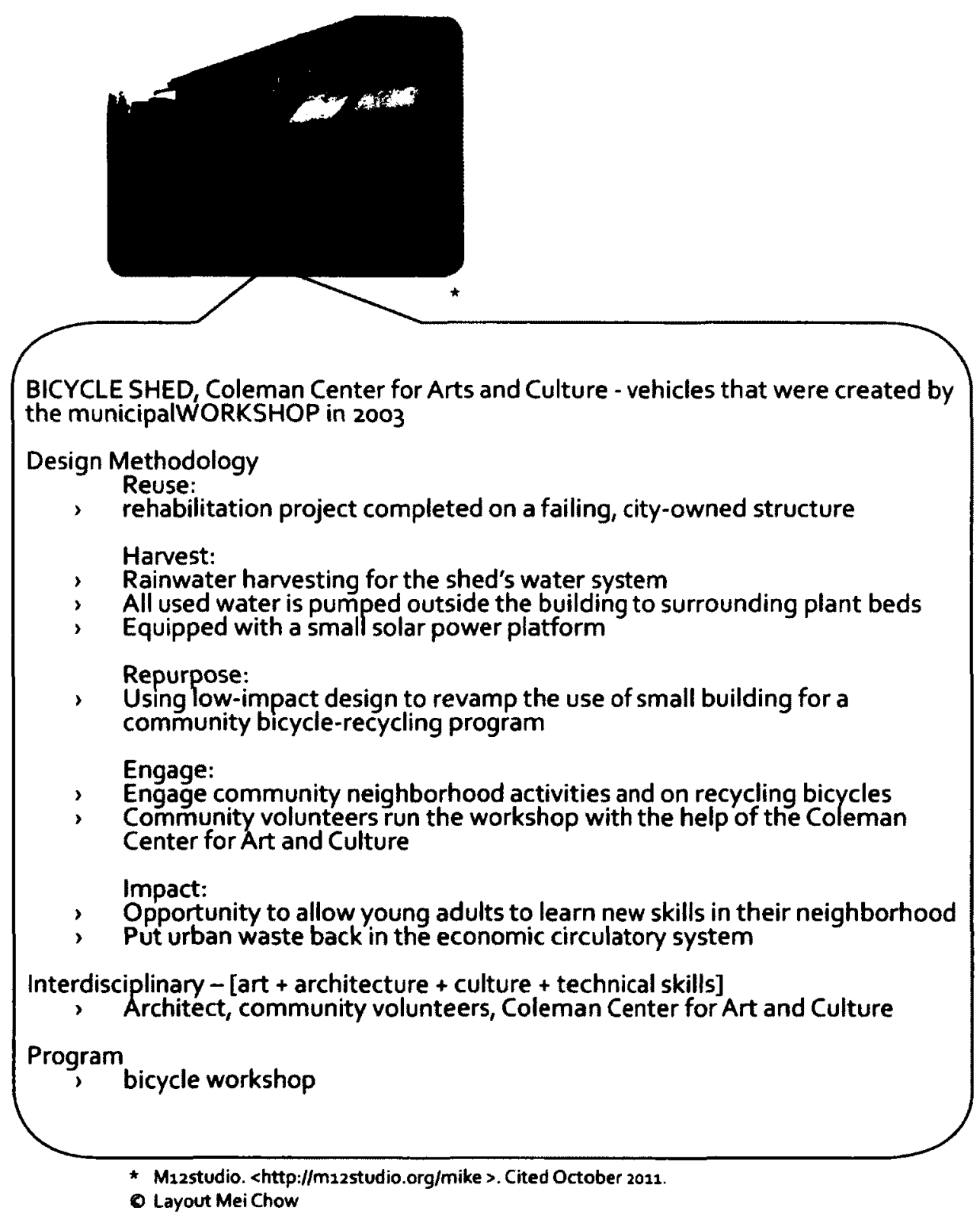


Case Simdy \#4

Social project on a city-owned failing structure

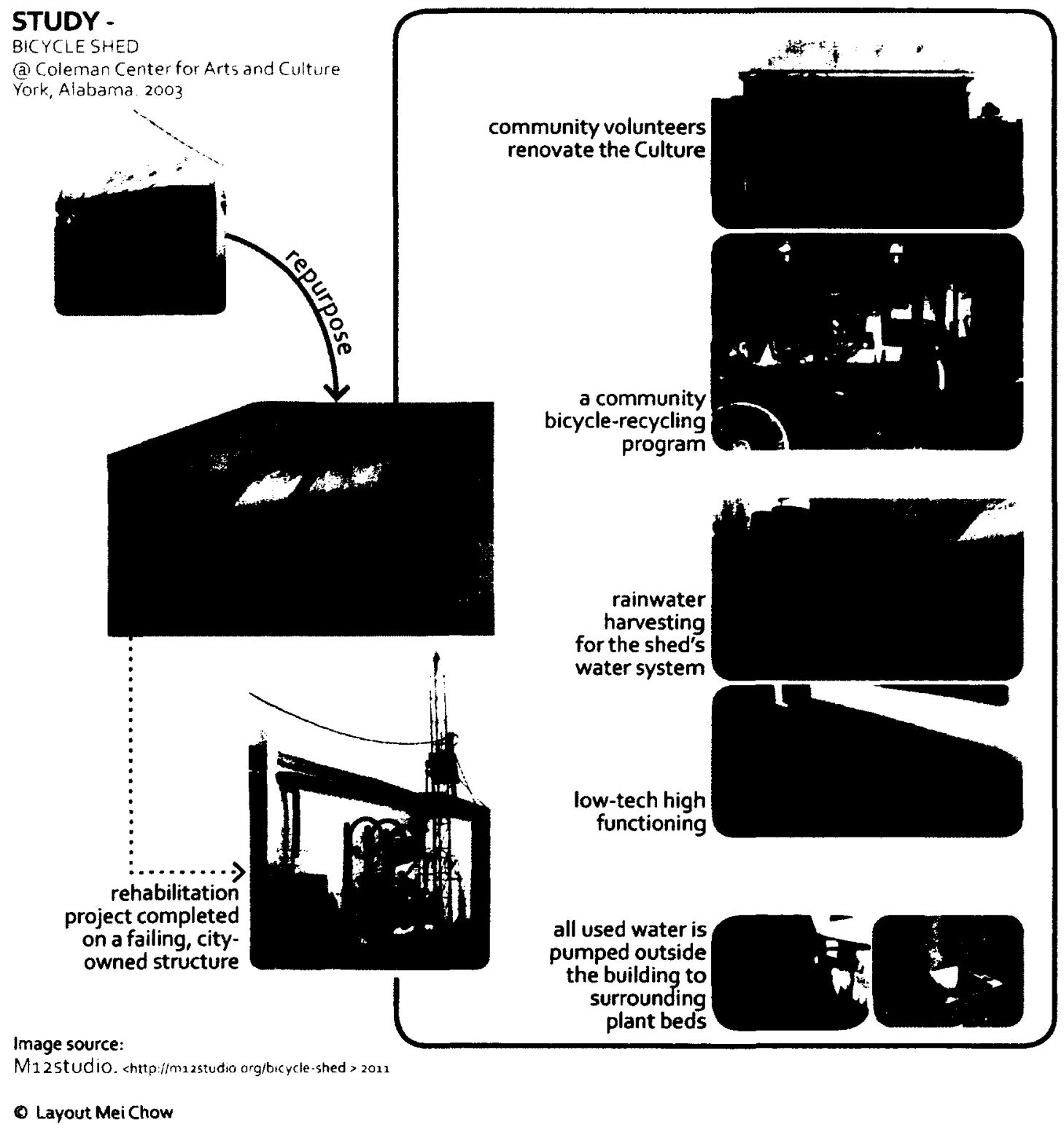




\section{Urban dialysis -}

is a proposed methodology, practice, and process that intends through the utilization of architectural adhocism to improve the quality of life of urban neighbourhoods within cities. Inspiration and evidence was sought from real world practices and projects that demonstrated a combination of community [re]invigoration, based on reported positive user participation, and architectural adhocism.

The four case studies have shown us the challenges presented by time and financial constraints are considerable and consequentially addressing these issues are essential in community [re]invigoration projects. Through the ad hoc utilization of non-standard ready-made parts designers can reduce the time required for implementation. If waste or excess materials are used there is a possible combination of time and cost benefits. Some real world implementations have shown that the cost of utilizing waste and excess materials is balanced out by the increased cost of labour. Urban Dialysis's inclusion of community collaboration, in particular construction volunteers, will have a tremendous impact in short cutting labour expenditures. Furthermore collaborative efforts can also reduce material costs considerably through the use of found, re-used or donated materials and parts. Collaboration of these two types also provide a broader based initial venue for [re]invigorating the social bond in communities. 
Does urban dialysis address affordability, urgency, non-generalization and improvisation in architecture aspects while also ensuring a reinvigorated community vitality through the addition and/ or modification of spaces and structures for socially relevant, imaginative activities? The positive responses we seek to this question can be identified within the ongoing community support for the included case study projects. 


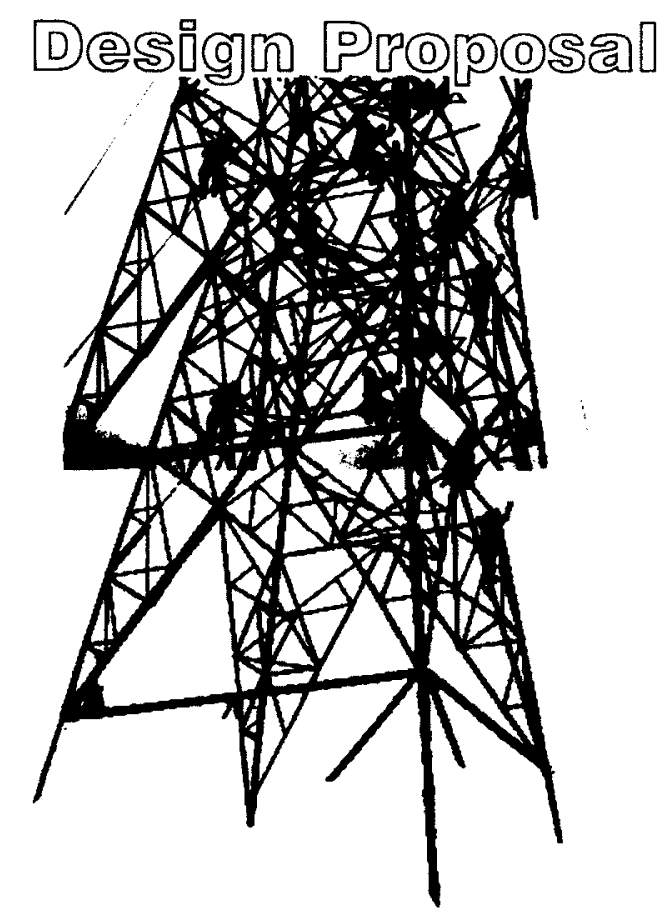




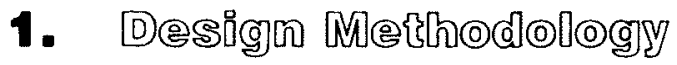

The initial proposal of flexibleX 3 outlined a loose combination of guidelines to aid in incorporating adhocism and community vitality into the process of urban dialysis. Guideline zero - delight for the community [ad hoc delight] is an absolute condition for any and all Urban Dialysis designs. The other condition is that at least two of the remaining four guidelines in any measurable proportion must be included in a combination that results in an urban dialysis design.

flexible $X_{3}$ :: design methodology for urban dialysis:

o) delight for the community [ad hoc delight]<smiles>[AsH2+]</smiles>

1) breaking the rules [ad hoc thinking]

2) community collaborative design and/or construction [wit of ad hoc]

3) materials re-appropriation [ad hoc resources improvisation]

4) providing or [re]appropriating public space for common good

Flexible 3 can be used in these valid possibilities:

$$
\begin{aligned}
& 0+[2+3]->\cup d-1 \\
& 0+[3+4]->\cup d-2 \\
& 0+[1+2]->\cup d-3 \\
& 0+[1+3]->\cup d-4 \\
& 0+[1+4]->\cup d-5 \\
& 0+[2+4]->\text { Ud-6 } \\
& 0+[\text { more than two guidelines] }->\text { Ud } \infty
\end{aligned}
$$

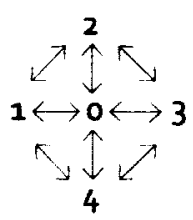




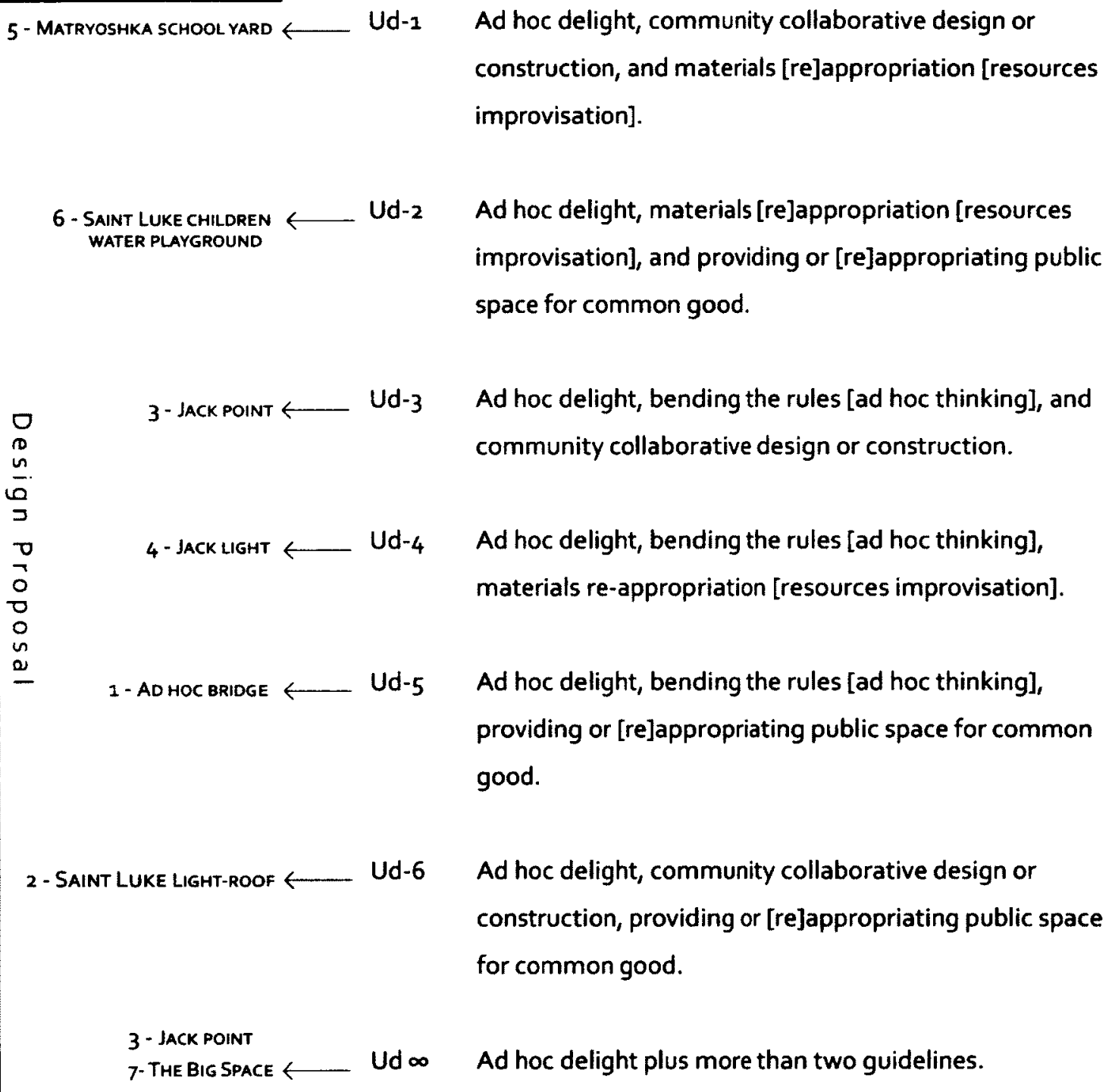




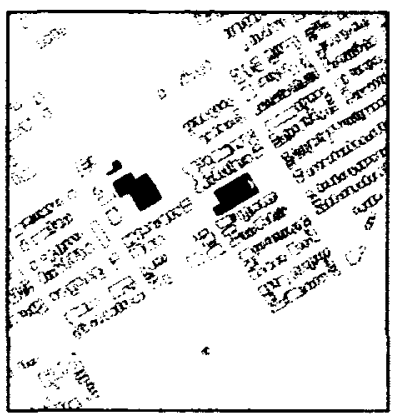

\section{B-G13 :\# Art + Play}

Aims:

$\begin{array}{lll}\text { REDEFINE } & \ldots> & \text { [the space] } \\ \text { REALIGN } & \ldots> & \text { [the community] } \\ \text { REALIZE } & \ldots> & \text { [urban needs] }\end{array}$

Dealing with what is currently important for the people in the community and/or the site. The proposed project explores applications and strategies that can be quickly applied to reinvigorate the vitality of the communities with integration to the existing urban condition.

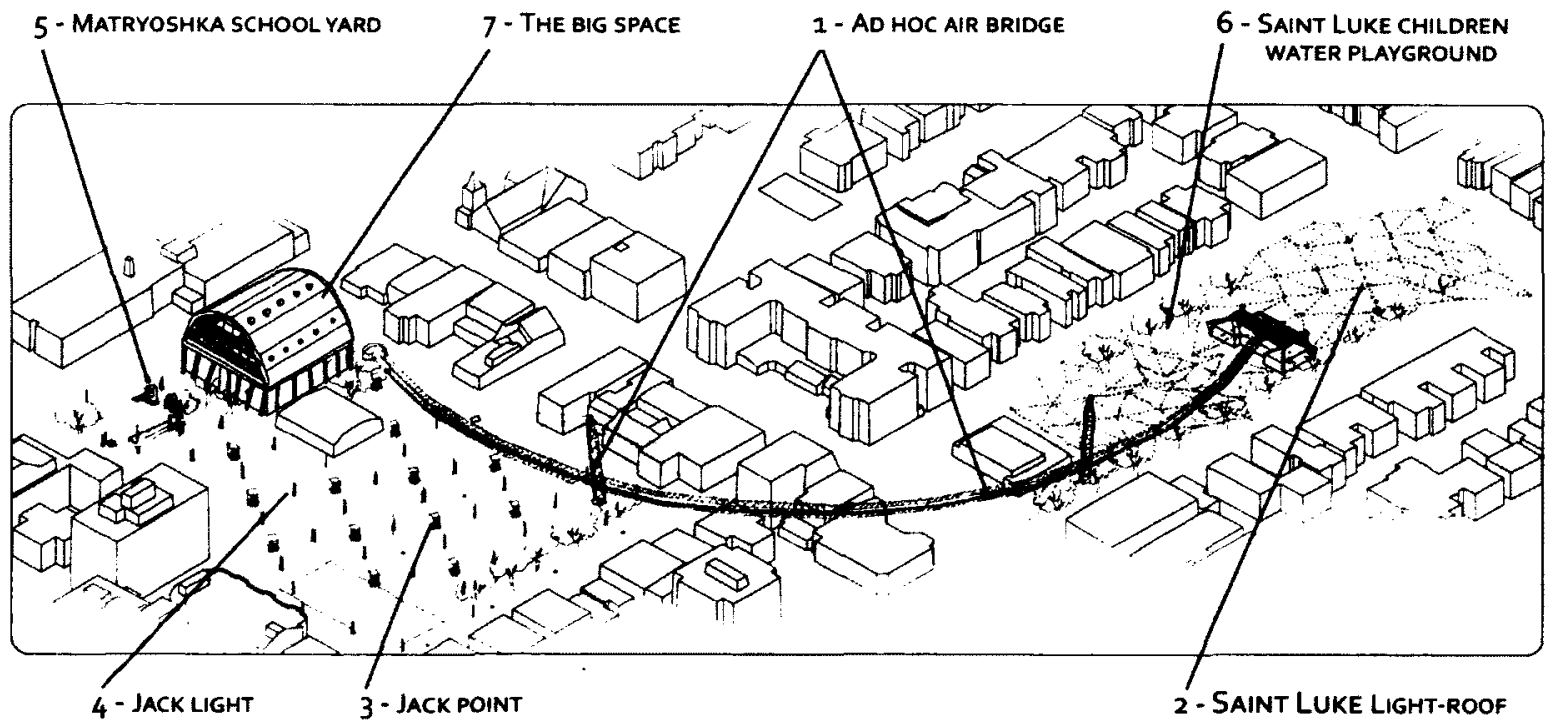




\section{Prologue}

Proposed projects location: Elgin Street Public Schoolyard, Jack Purcell community center, Jack Purcell park, and Saint Luke's park

\section{Why these sites?}

Ottawa's downtown growing population, spurred on by multiple condominium developments, is straining the present public space uses in the Golden Triangle. This situation sets the stage for an ad hoc architecture experiment. In referring to included site analysis of recent developments, there have been at the minimum seventeen recent residential developments in and around the Golden Triangle neighbourhood. The research showed ten residential towers were built between 2005 to 2012, seven towers are currently under construction and at least one more tower has not yet broken ground but is currently under going a selling process to the general public. Despite this change in Ottawa's urban core ecology, little has changed in the community center and the city parks to increase long-term Current condition of the Jack Purcell Park

- //MeiChow

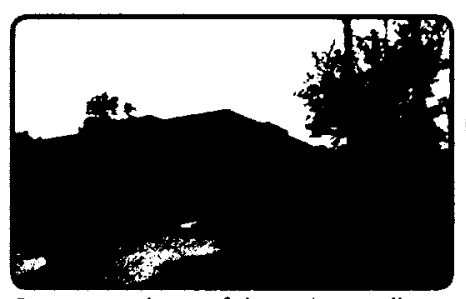

Current condition of the Jack Purcell Community Center community vitality to accommodate the rapid growth of population.

Current condition :: Long before the new residential developments, the community knew that their activity spaces needed major improvements after all their local community centre was built in a 1974 for a much smaller population. The residents priorities being Elgin Street Public Schoolyard and Centretown's largest off-leash dog park; interestingly both direct primary user groups of the spaces are the dependents (children and dogs) of the initiators - those pushing the changes are the secondary users (the parents and owners). 


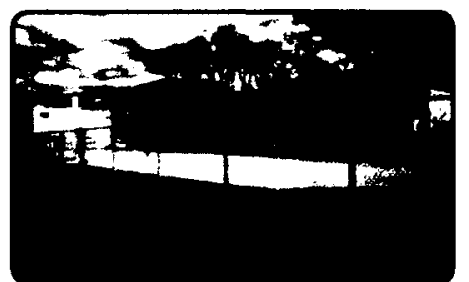

lack Purcell off-leash dog park and its new renovation.

(1/Meichow

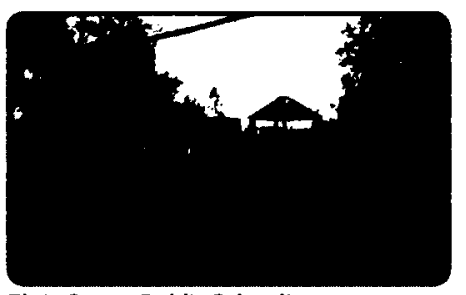

Elgin Street Public School's new playground structure.

- /lMei Chow
According to past and present community members, it took the school parents and dog owners almost a decade to negotiate with the city to upgrade the playgrounds and to construct an off-leash dog area that was safely separated away from the school children. Last summer, the off-leash area was fenced off, paved with decomposed granite aggregate surface to minimize odor and bacteria from dog urine and ringed with woodchipped spacers to keep the dogs on the loose stone and dirt surface. In the Elgin Street Public Schoolyards there are two separate playground structures located about five meters apart from each other. One of them was replaced last year with a much larger structure that can accommodate more children, more activities and provide an accessible structure for physically challenged children and parents. The new playground structure was paid using funds raised by both the parents and community members of the Jack Purcell Recreation Association (JPRA). These two examples provide concrete evidence of a strong community bond in this neighbourhood, which is a fundamental positive force for longterm community [re]invigoration.

\section{My background with Jack Purcell Community Center}

My experience with the Golden Triangle neighbourhood began when I was an undergraduate at Carleton University, having lived in the area for total of five years with my final year as a dog owner and a regular user of the Jack Purcell off leash dog park. During my five years I also assisted in various programs held by Jack Purcell Recreation Association; such as annual craft sale and community 
garden sales. The project proposal for the site is derived from multiple perspectives; myself being a user and observer of the site, and insightful information from the president and other members of JPRA.

\section{Working with Jack Purcell Recreation Association (JPRA)} JPRA ( a not-for-profit organization) is run by a volunteer Board of Directors and represents the residents of the community in maintaining and improving the quality of life in the Golden Triangle neighbourhood through child care, recreation, sport and leisure activity programs all within their city agreed upon spaces: Jack Purcell Community Center, Elgin Street Public schoolyard and gymnasium Jack Purcell park, and Saint Luke's park. Eleanor Sawyer, president of JPRA, provided insight of the current conditions in these areas and the communities plans and hopes for the near future, she asked that some future plans be kept as a private discussion between myself and Miss Sawyer until public consultation begins. One of her biggest mentionable concerns for the community center is the lack of space to accommodate different on-going and new activities that are in demand by the community. Miss Sawyer stressed the urgency and importance of a full-sized gymnasium for the community as well as lack of land for such a structure, and stated that until the city has sufficient finances to purchase more land for expansion the only way for the community center to grow is to work inside the boundaries they currently have. 


\section{Informal conversation excerpt with Eleanor Sawyer}

MC: Mei Chow | ES: Eleanor Sawyer - president of the Jack Purcell Recreation Association (JPRA)

April.19.2012 Thursday

MC, I am proposing my thesis project within the Jack Purcell neighbourhood, between the two parks monitored by JPCC (Jack Purcell Community (entre) and the school yard at the Elgin Street Public School.

ES, Oh, that's good but what we really need is to expand our community centre because we've run out of space in the centre.

MC, I can add a level of spaces above the existing structure. I will try to use ad hoc ready-made parts for the proposal.

ES, Okay. We need our own full-sized gymnasium. The one we currently use is just not big enough and it's owned by the Elgin Street Public School.

A few days later, I presented the finished digital model to Miss Sawyer who provided some feedback; in particular, she was interested to see the project explorations in the parks but was also interested in the elevated flexible-program space and gymnasium. In fact, she said she would like to have me present the model to the JPRA board and Councillor Diane Holmes after my thesis defence. She was concerned over the limited budget the City of Ottawa has for expanding the community centre. However, she thinks an ad hoc approach of reusing ready-made parts is a good idea. This level of endorsement in using ad hoc architecture as a proposal to reinvigorate community spaces for daily social events and activities shows a public interest in the project and I am very excited to show my efforts to the JPRA Board. 


\section{Recent residential developments}

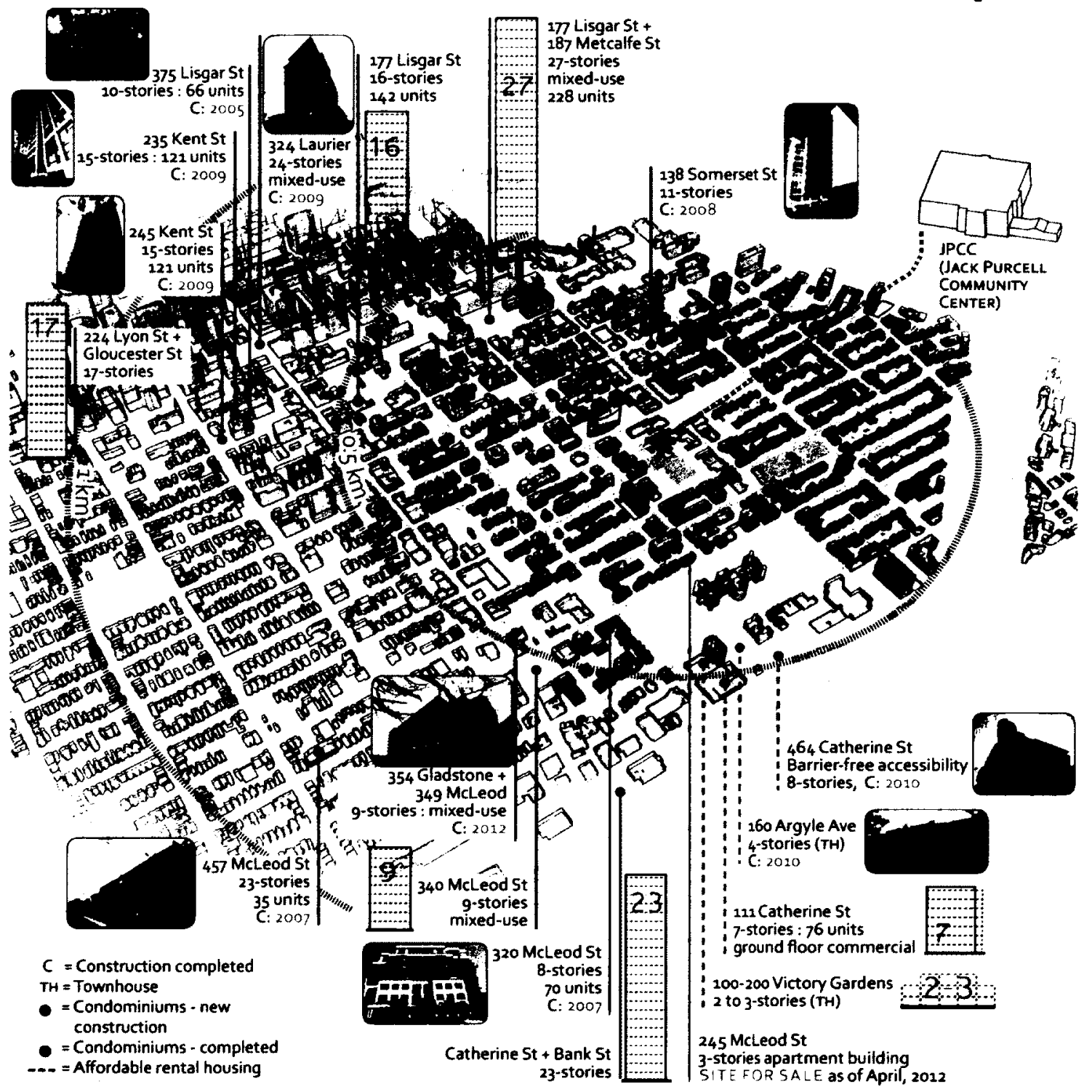


Site taxonomy

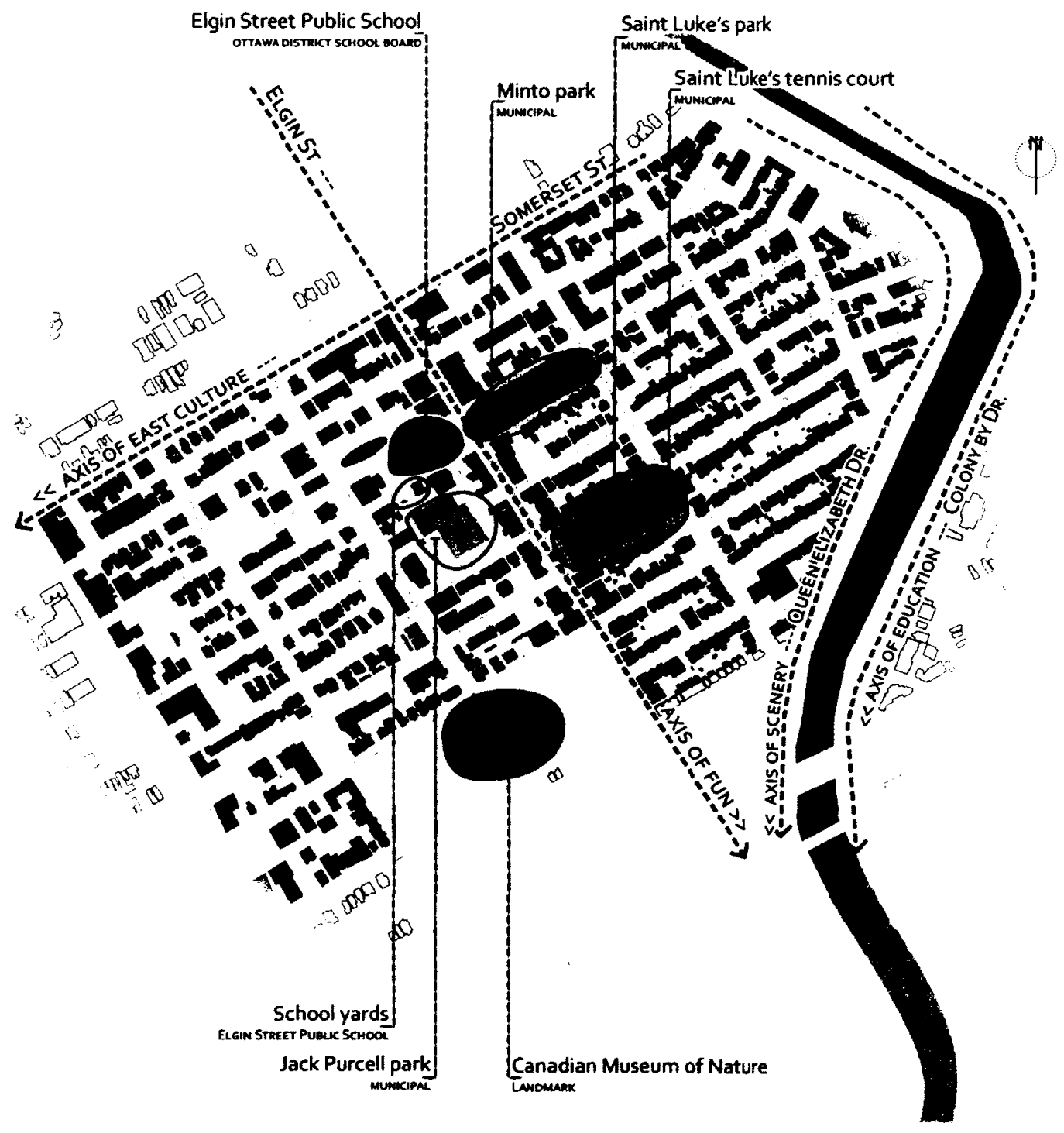




\section{Site taxonomy}

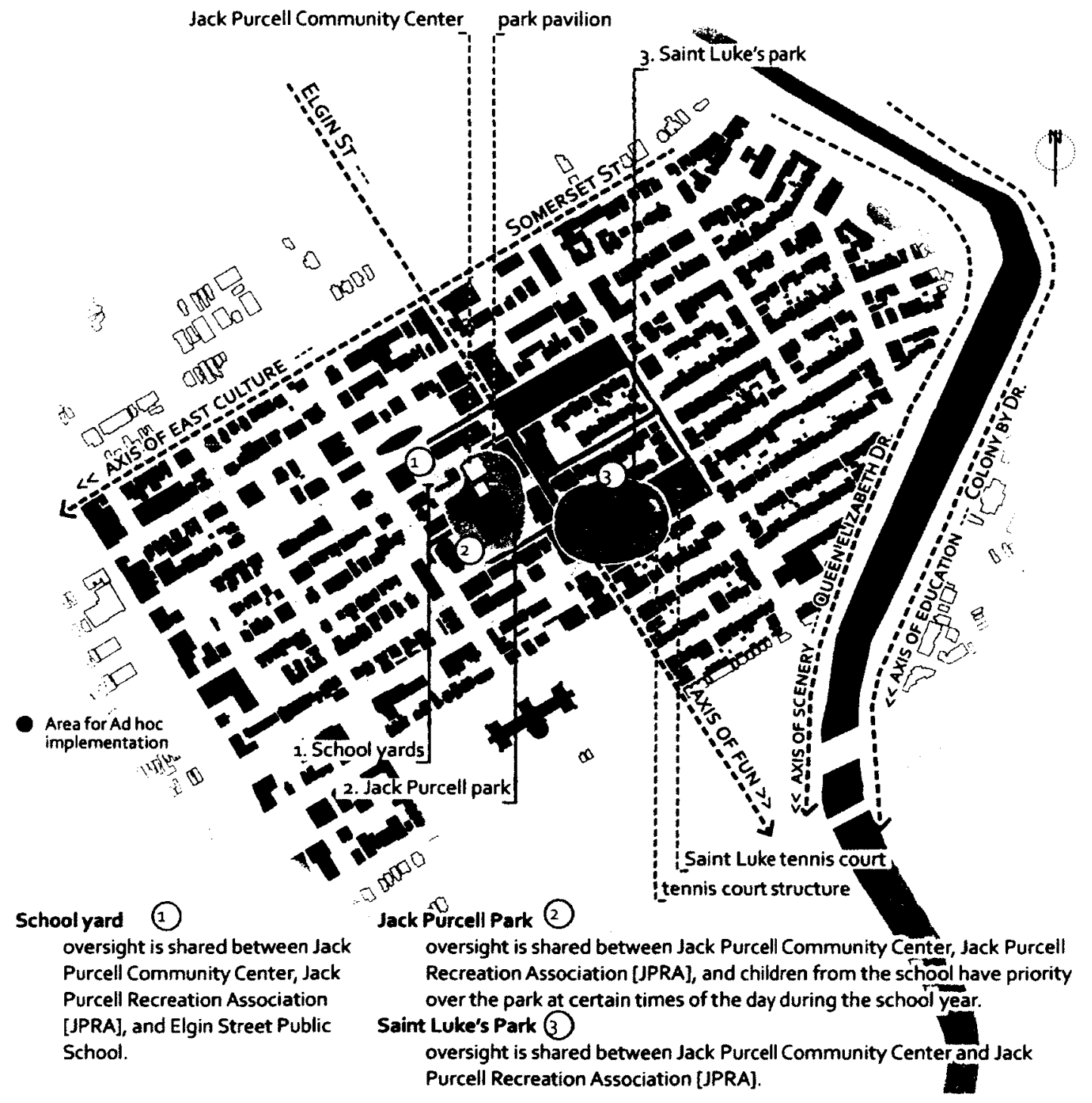


Site taxonomy

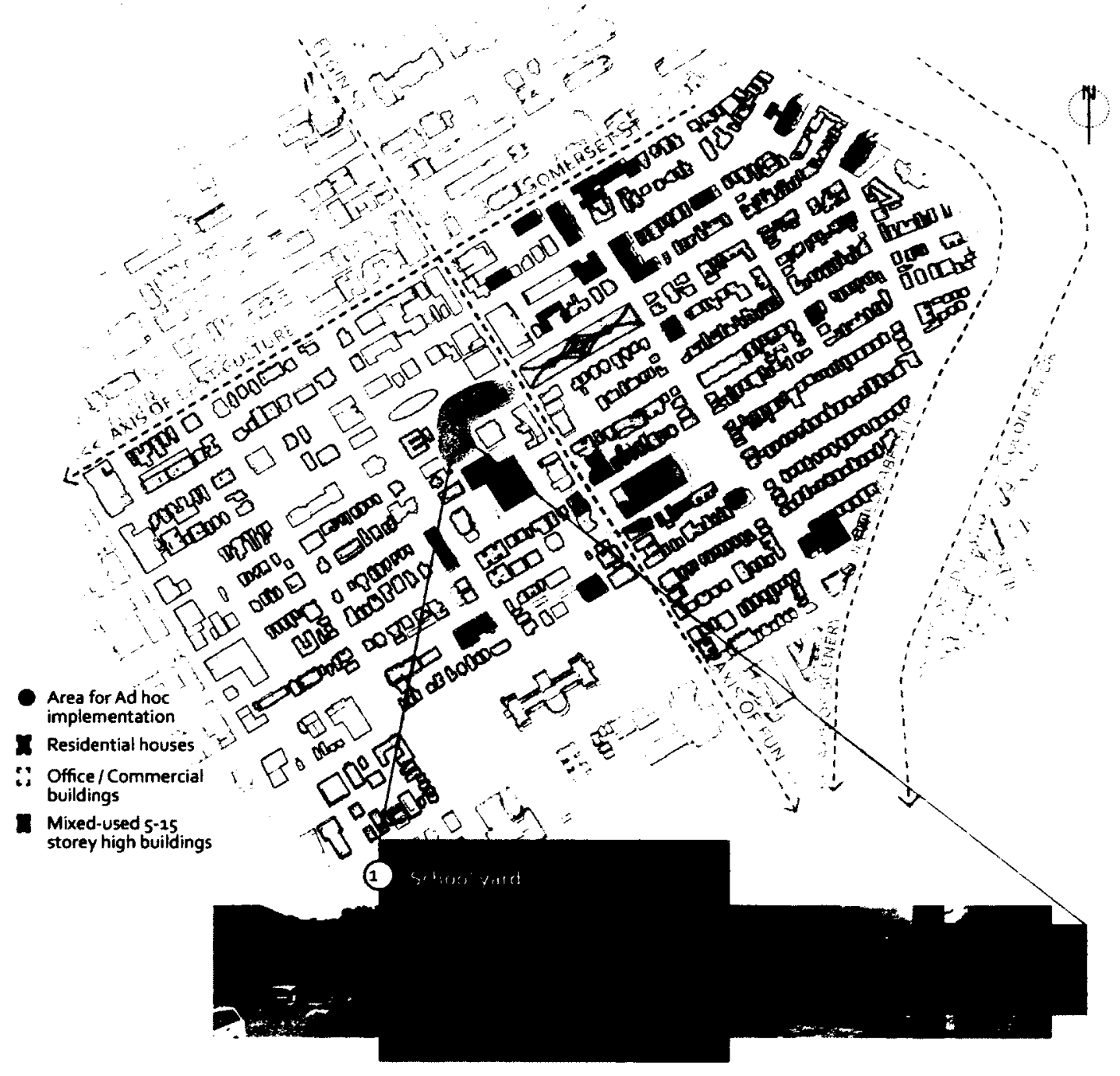




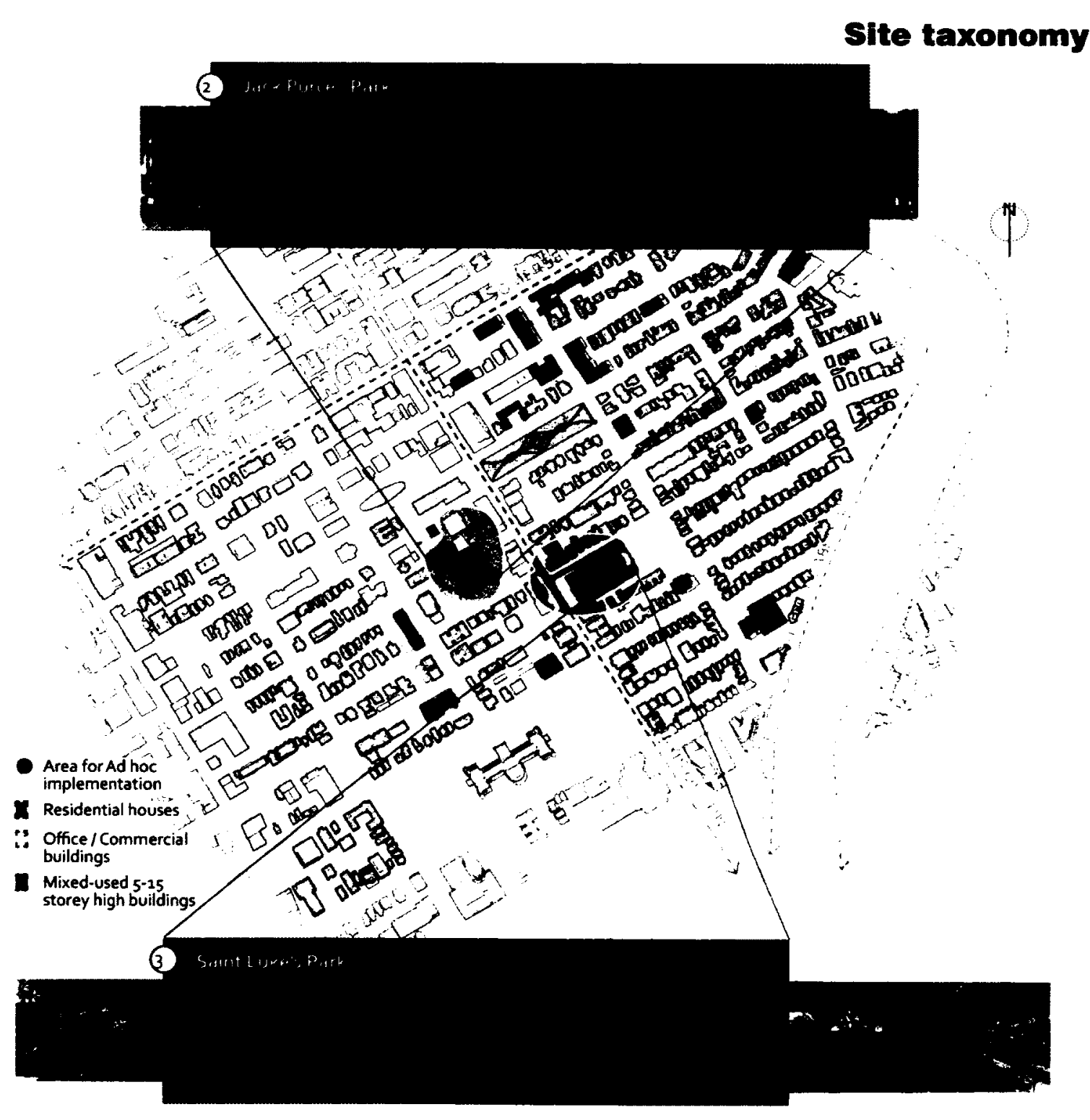




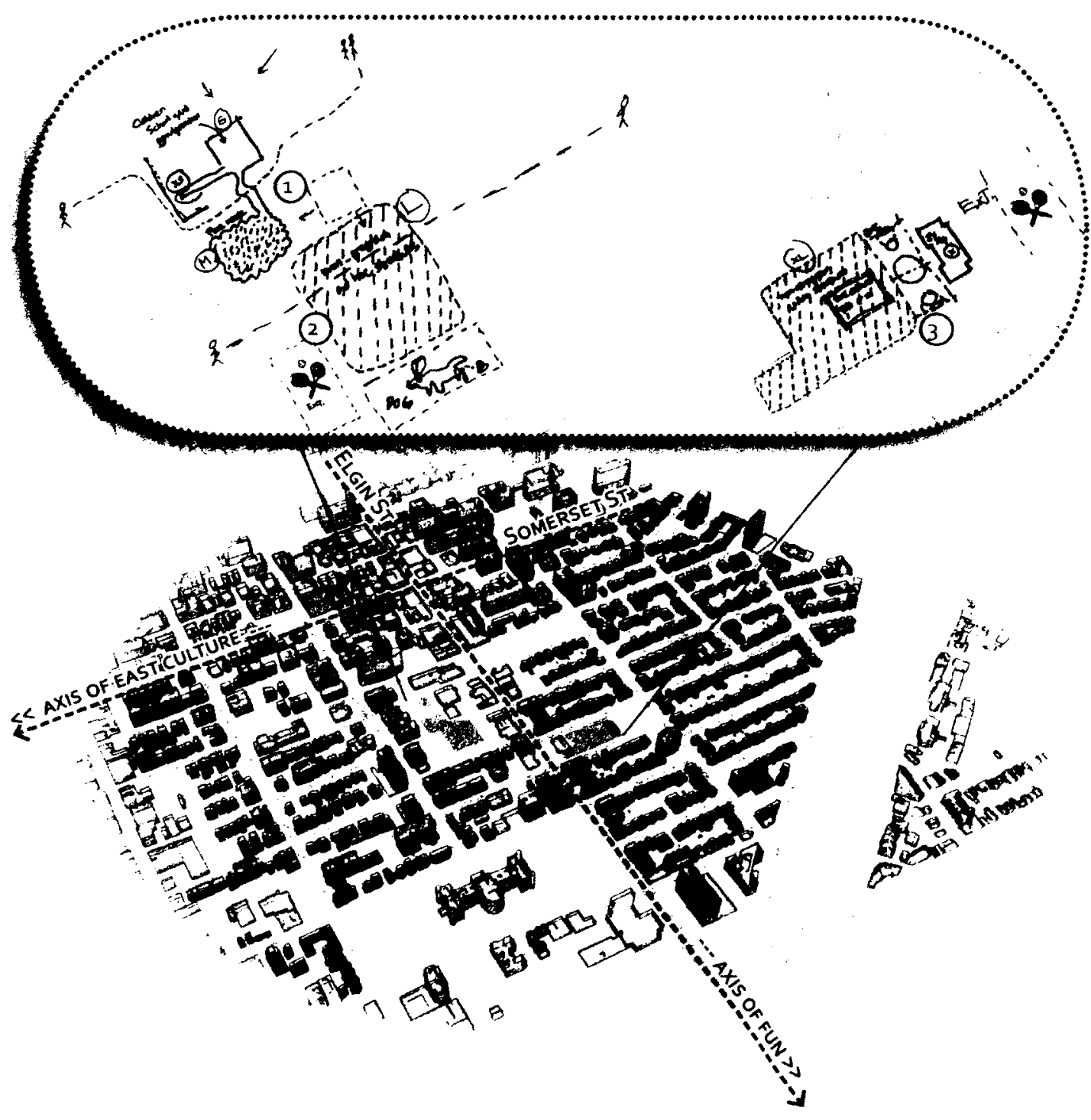




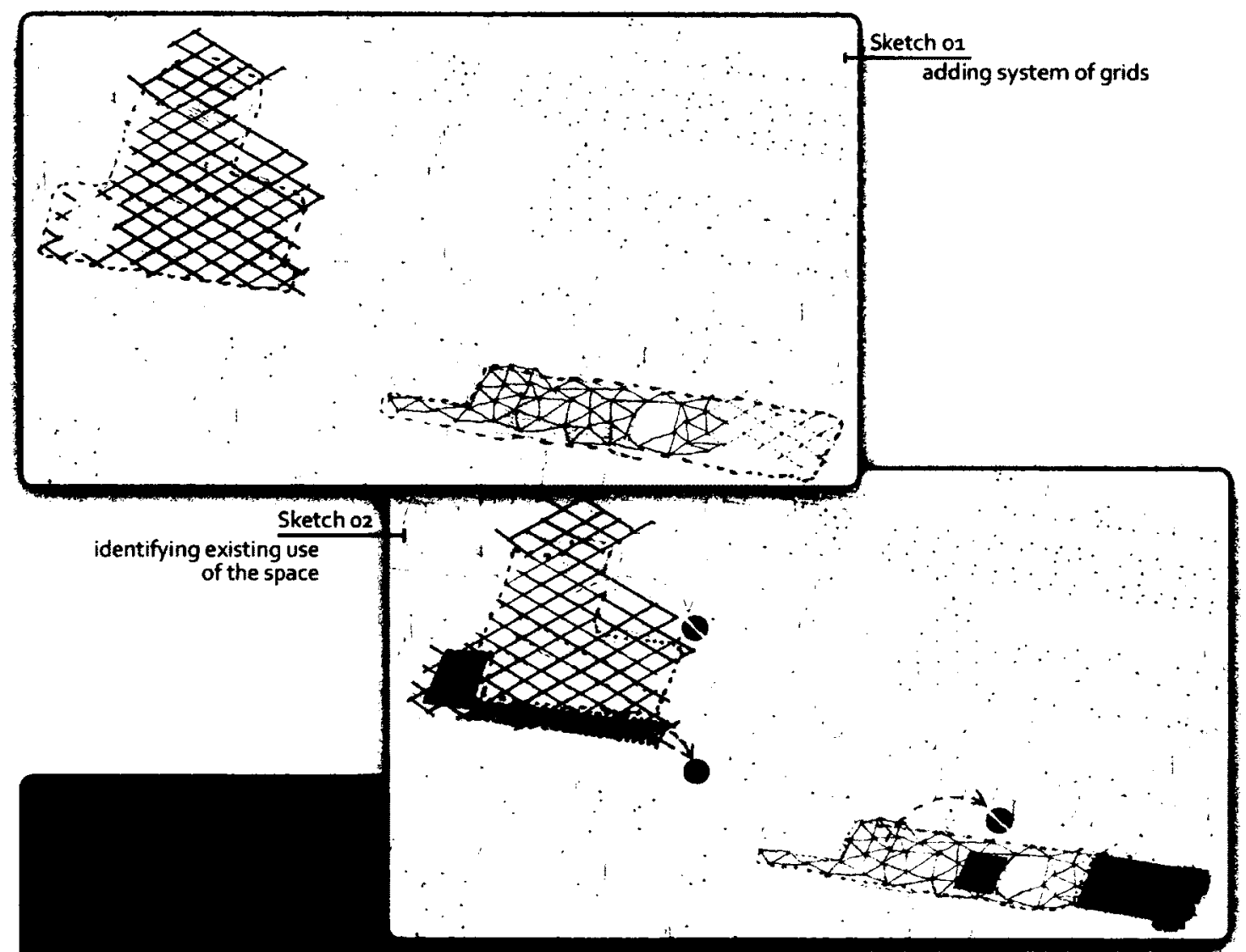

Sketch 03

adding points to the grids 


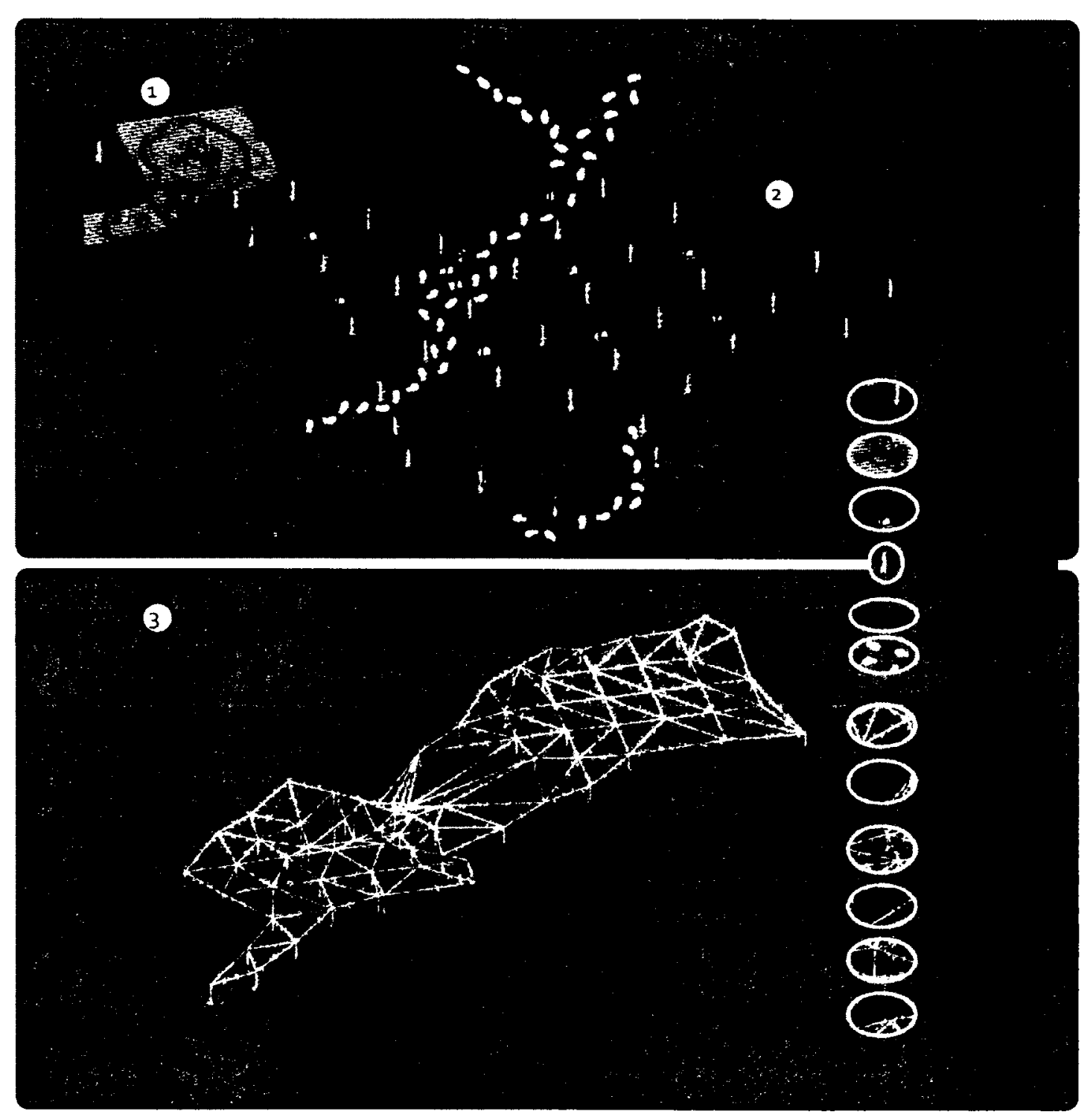




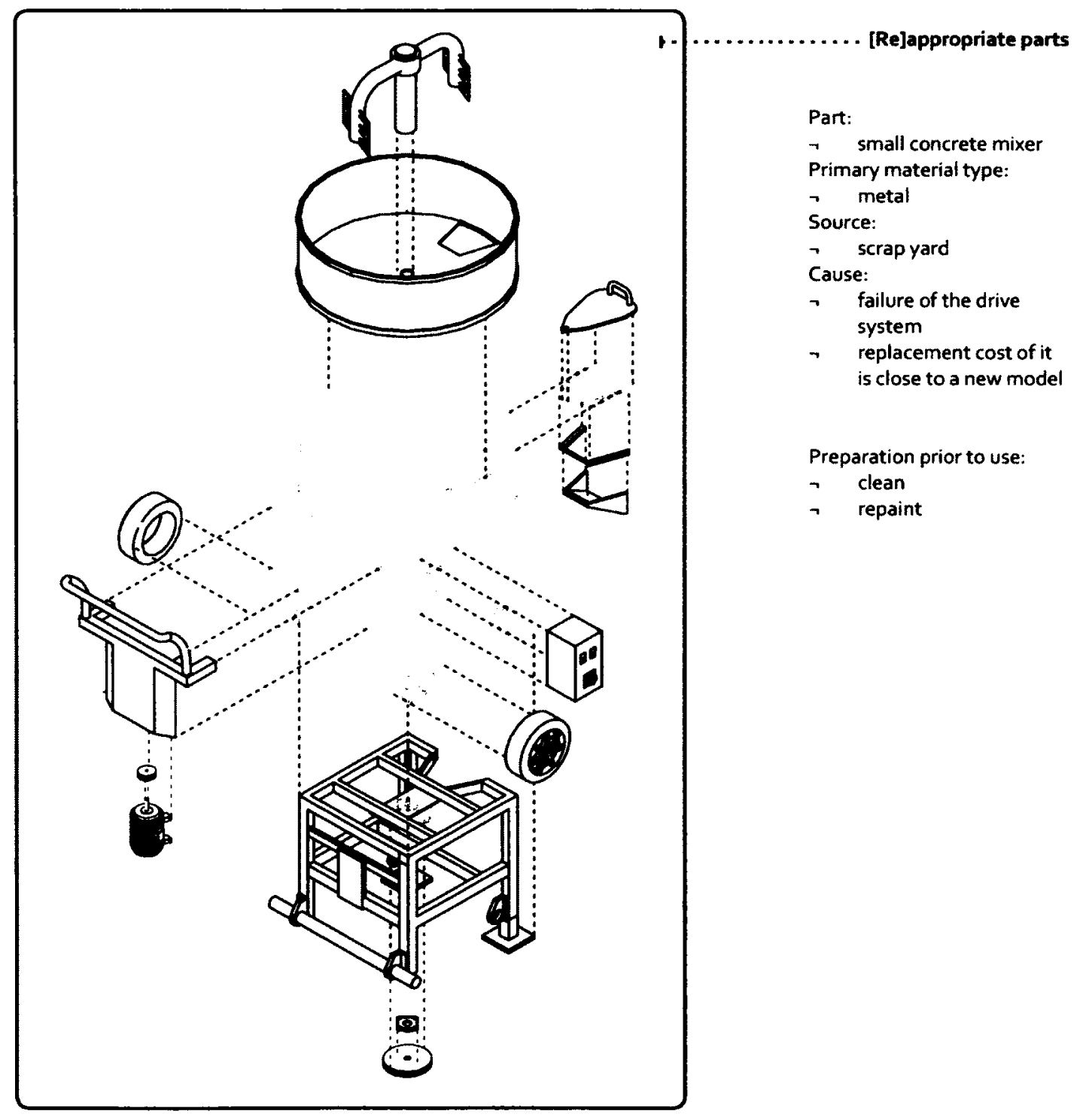




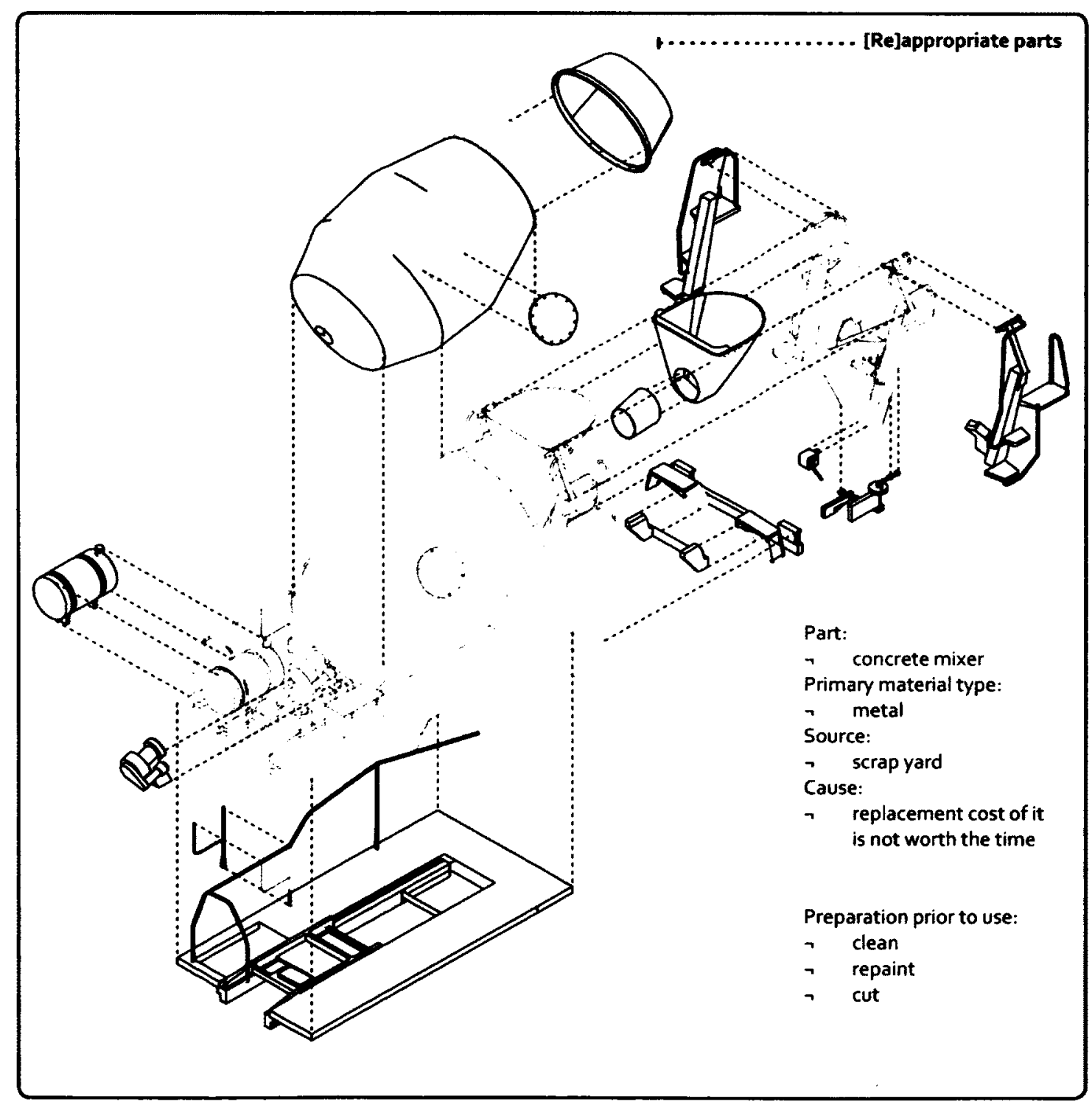




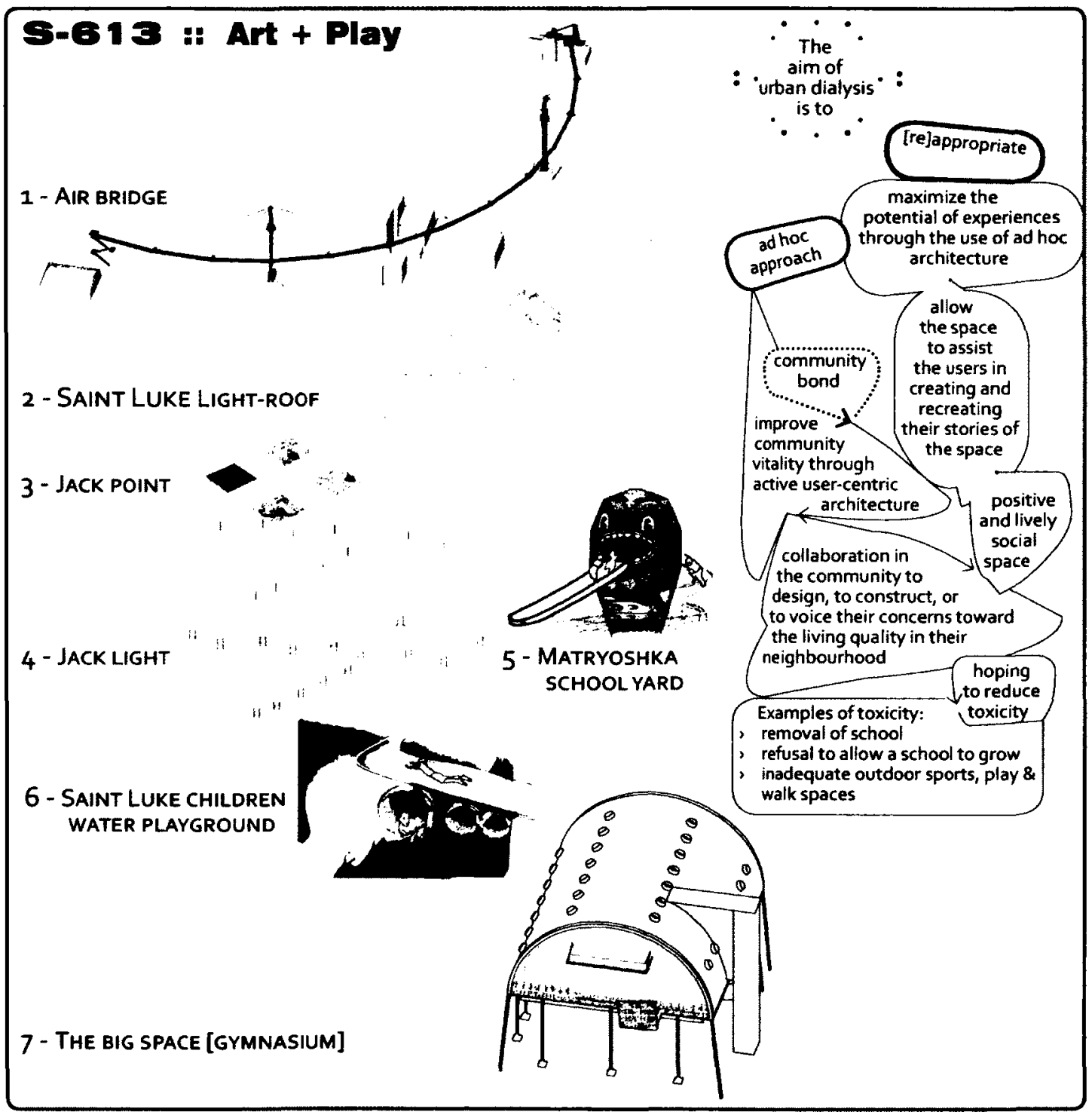




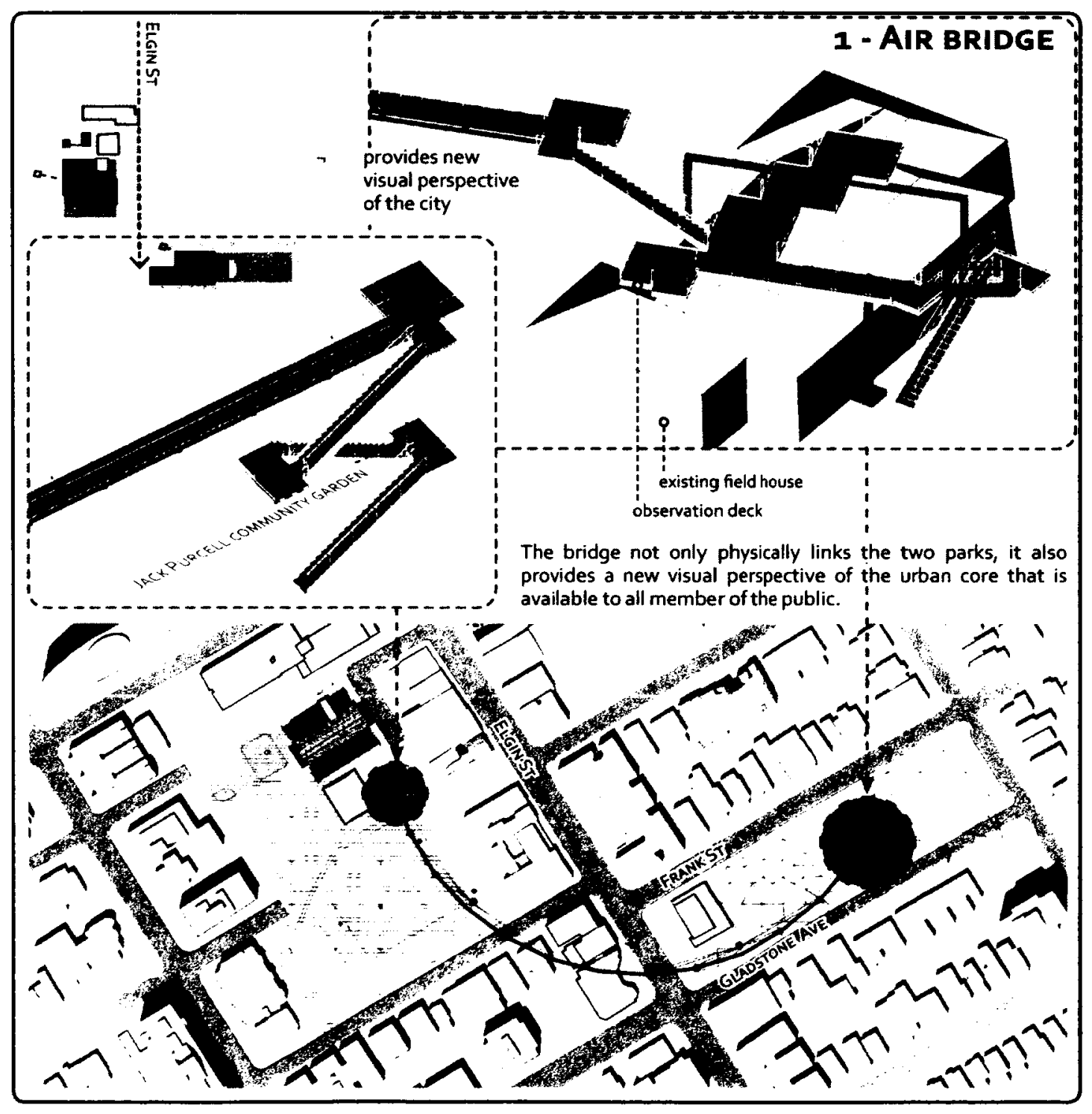




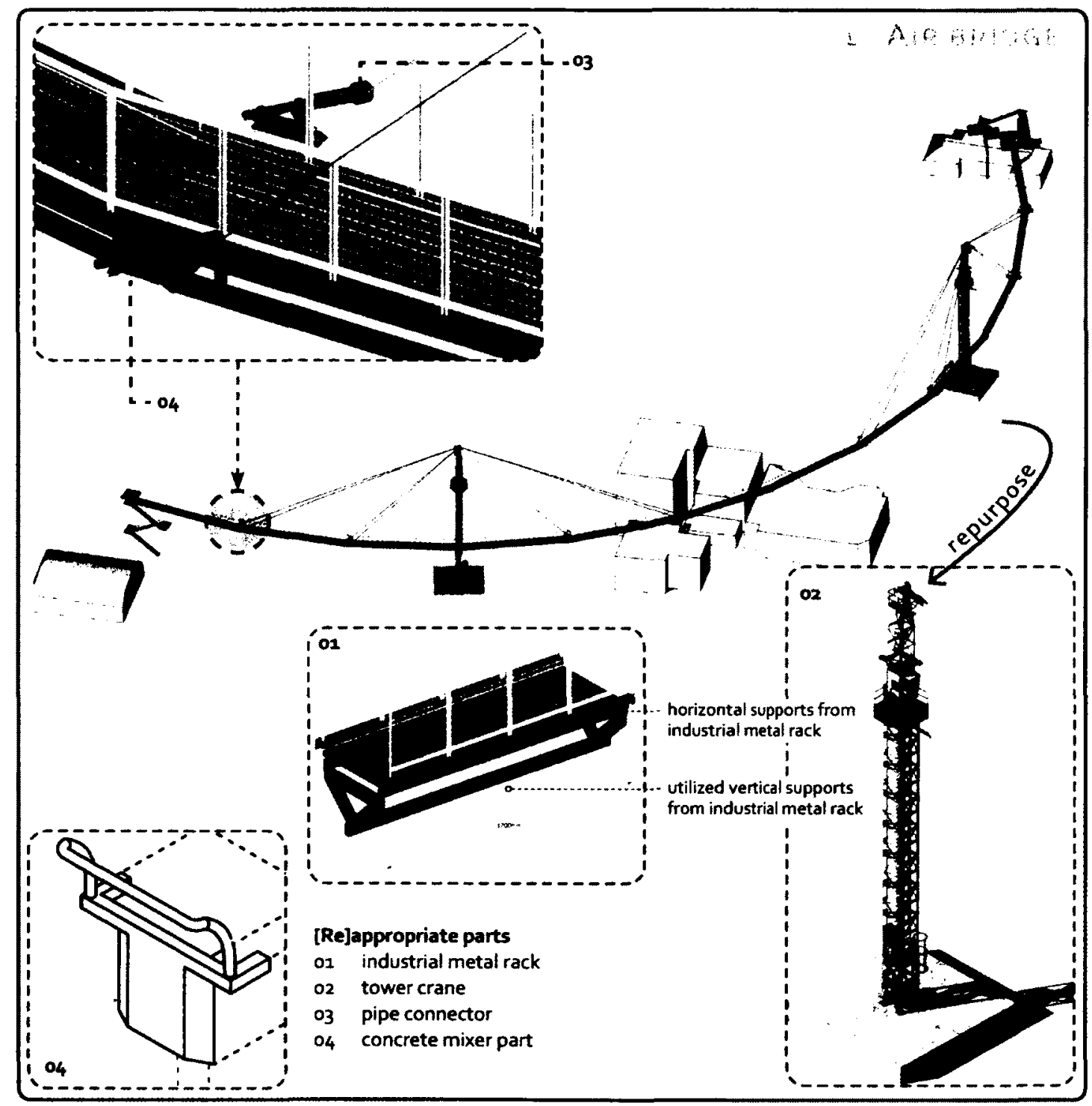




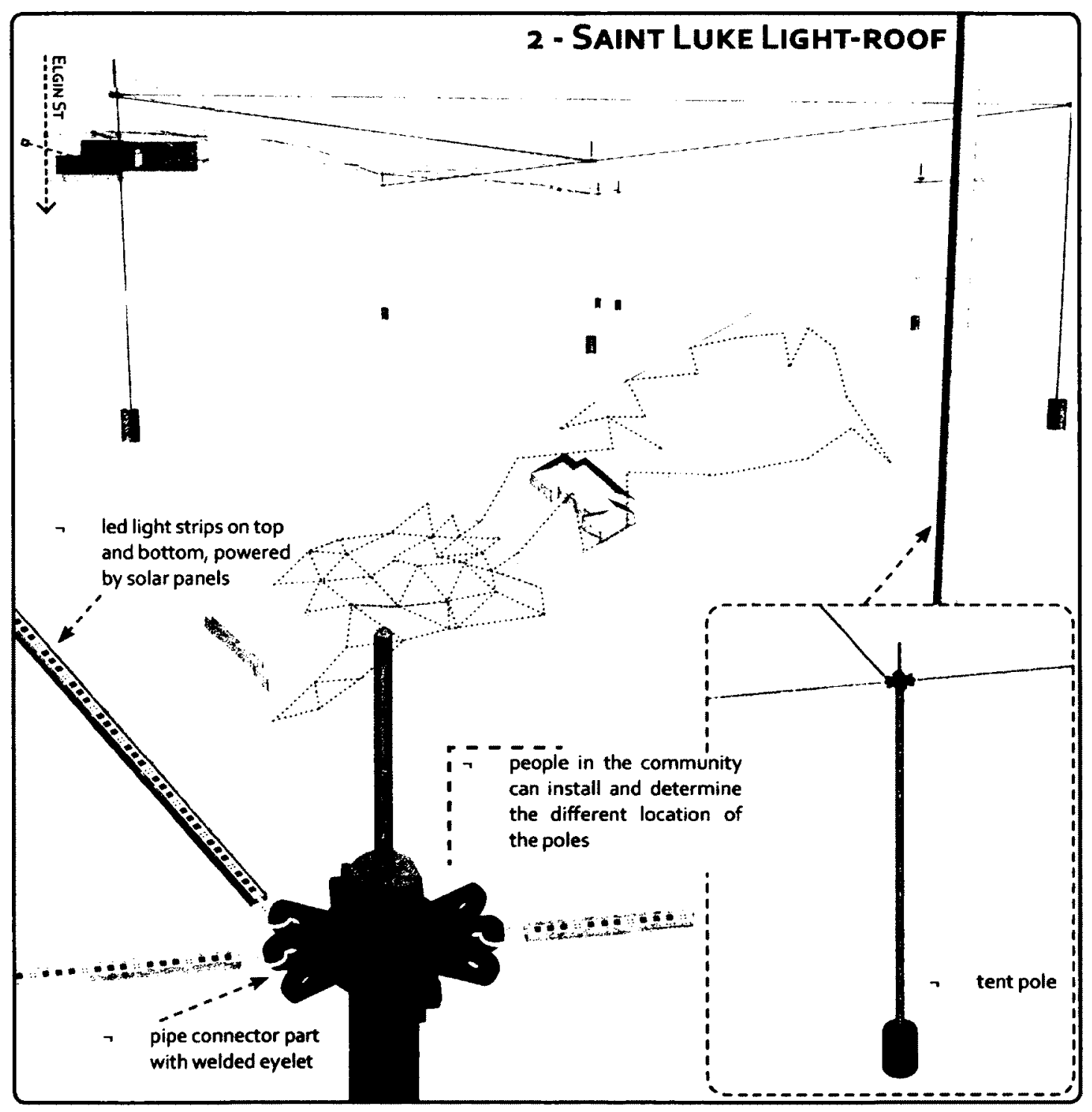




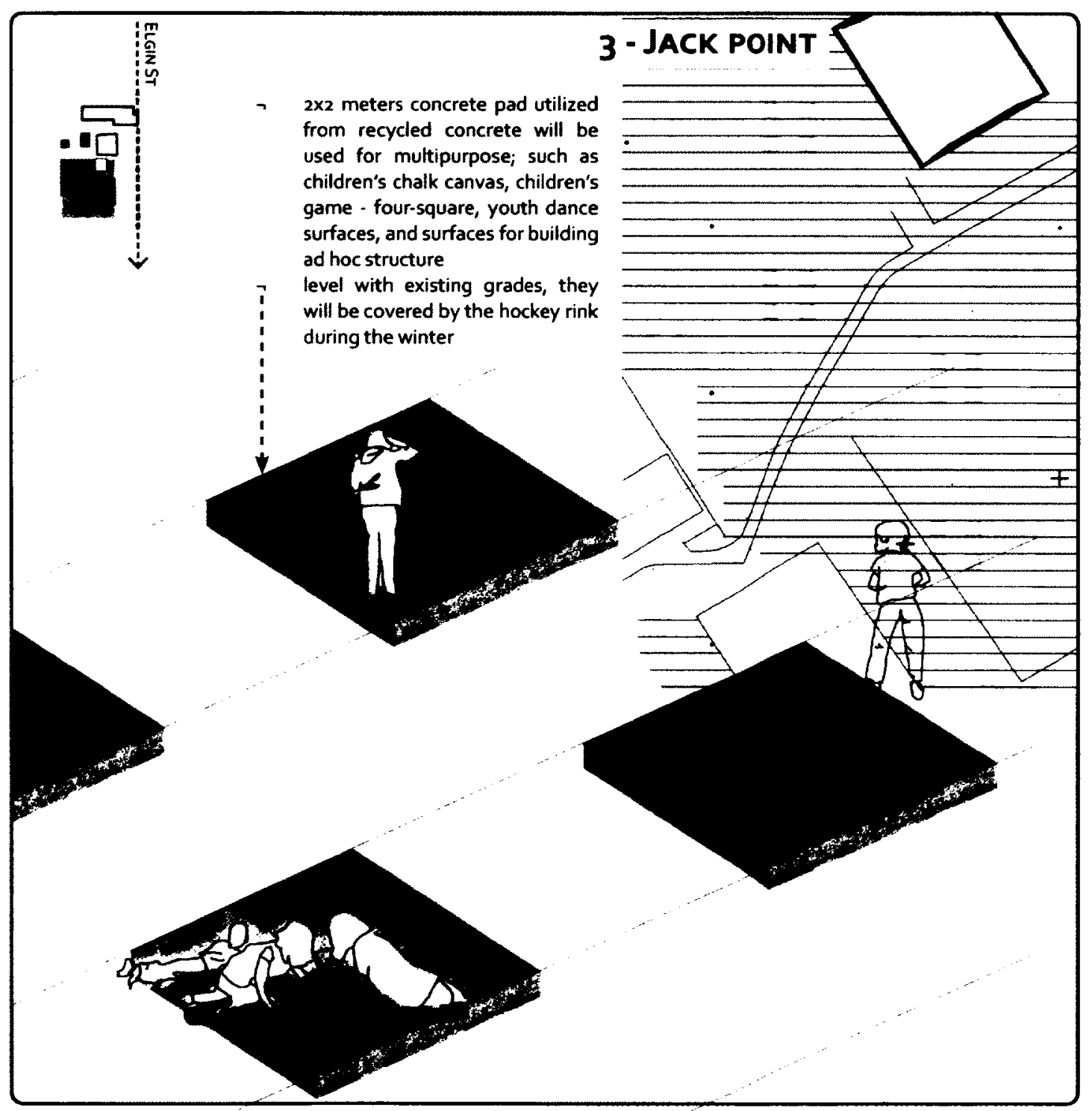




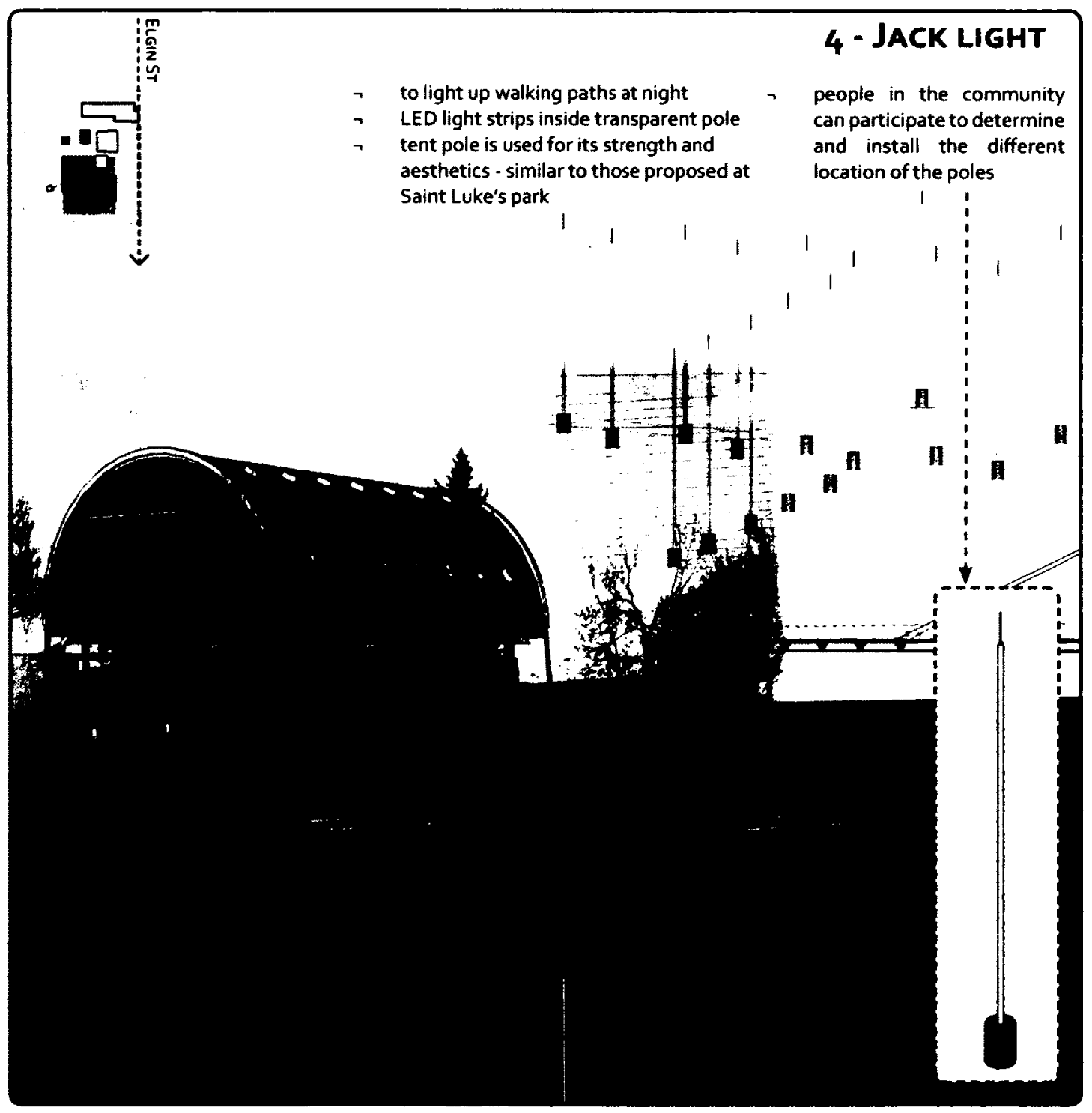




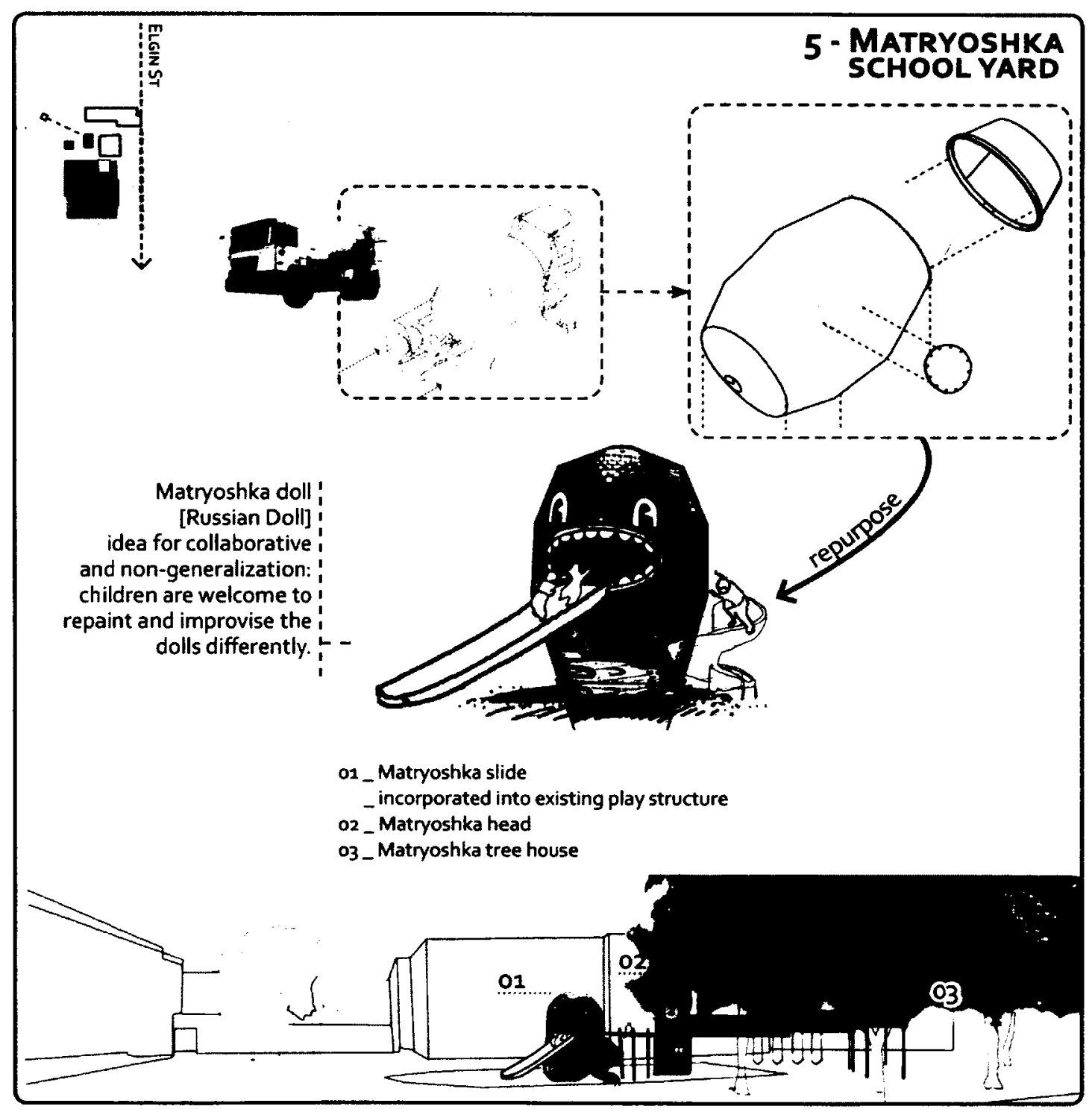




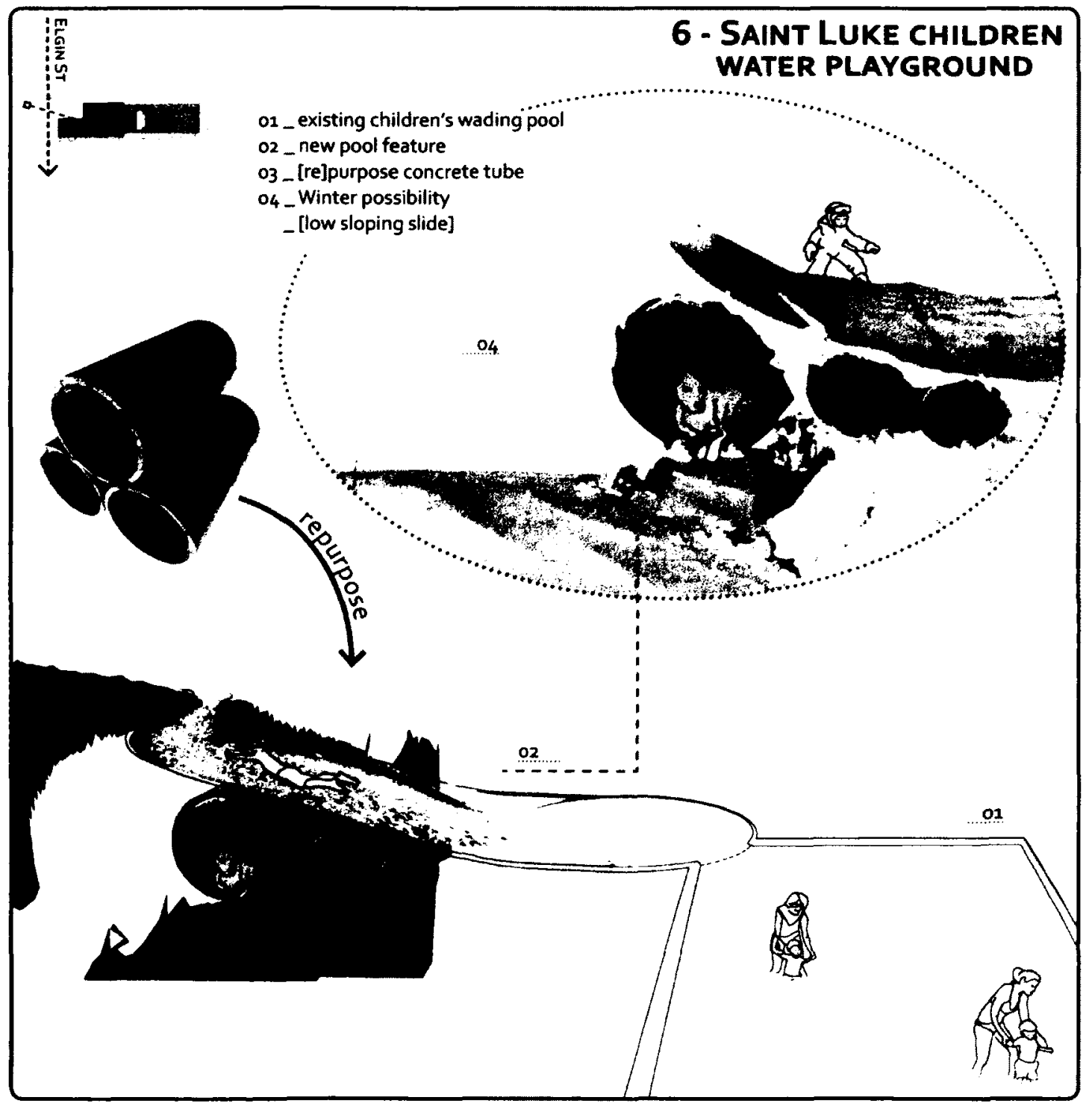




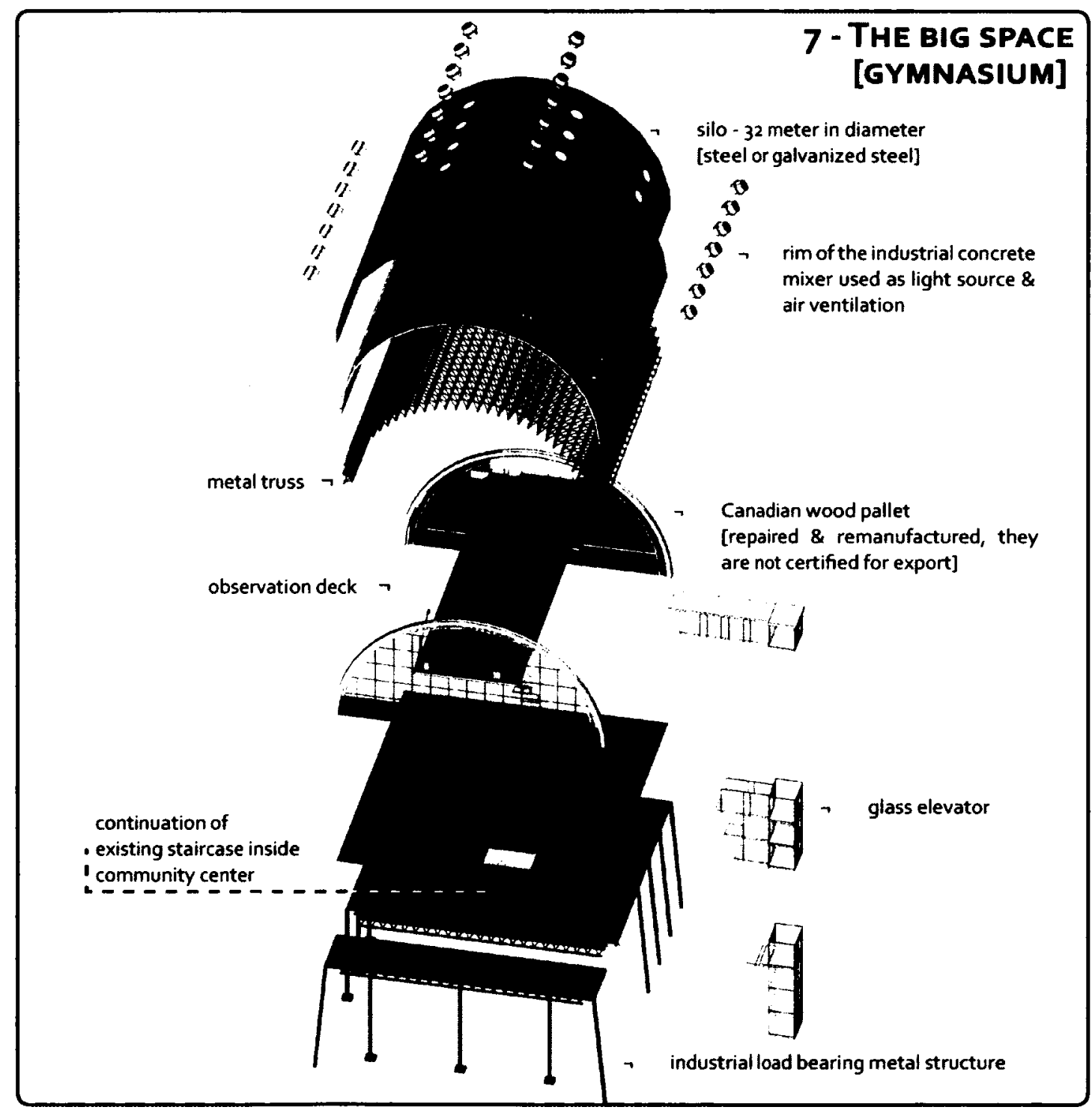




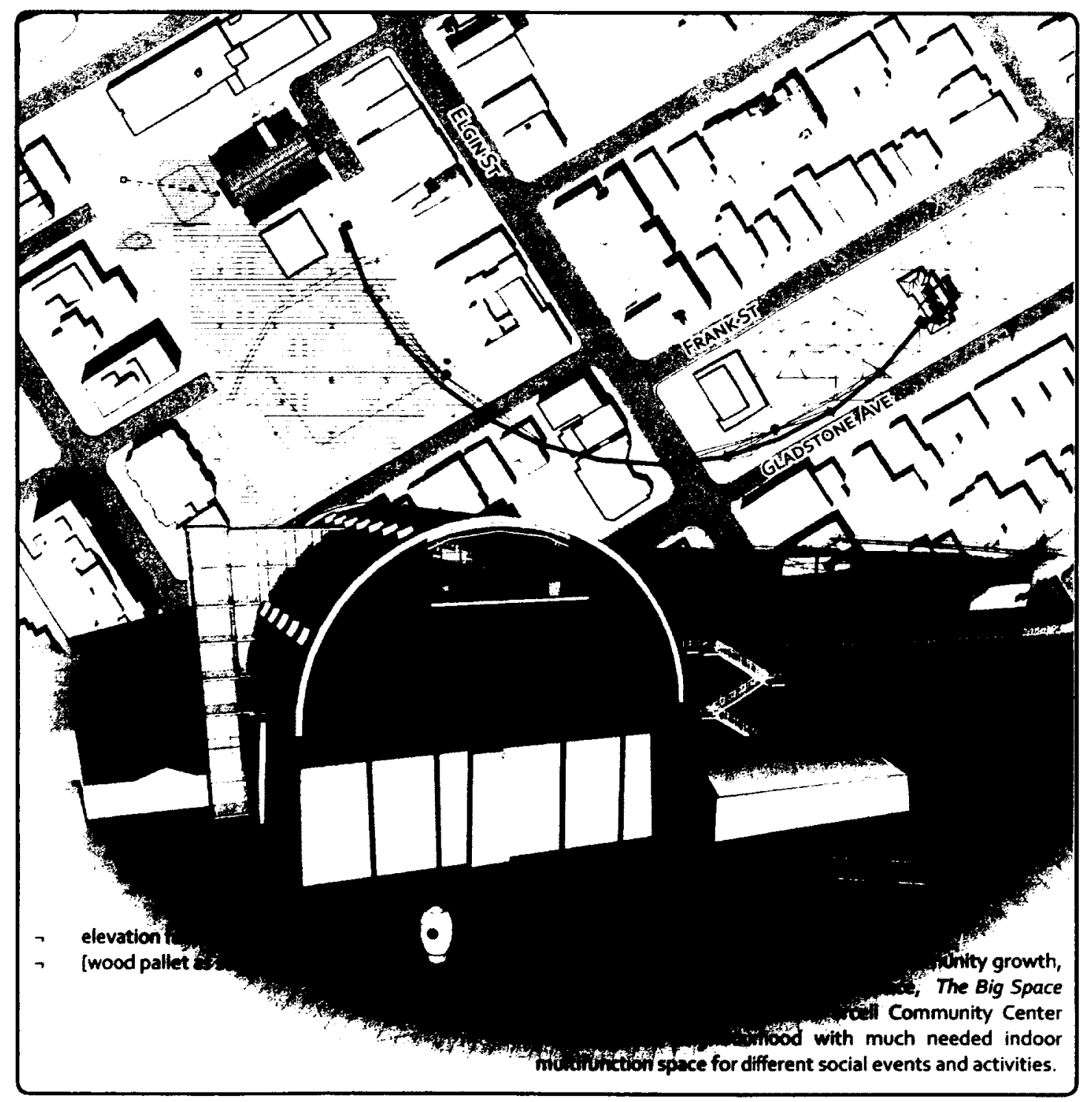




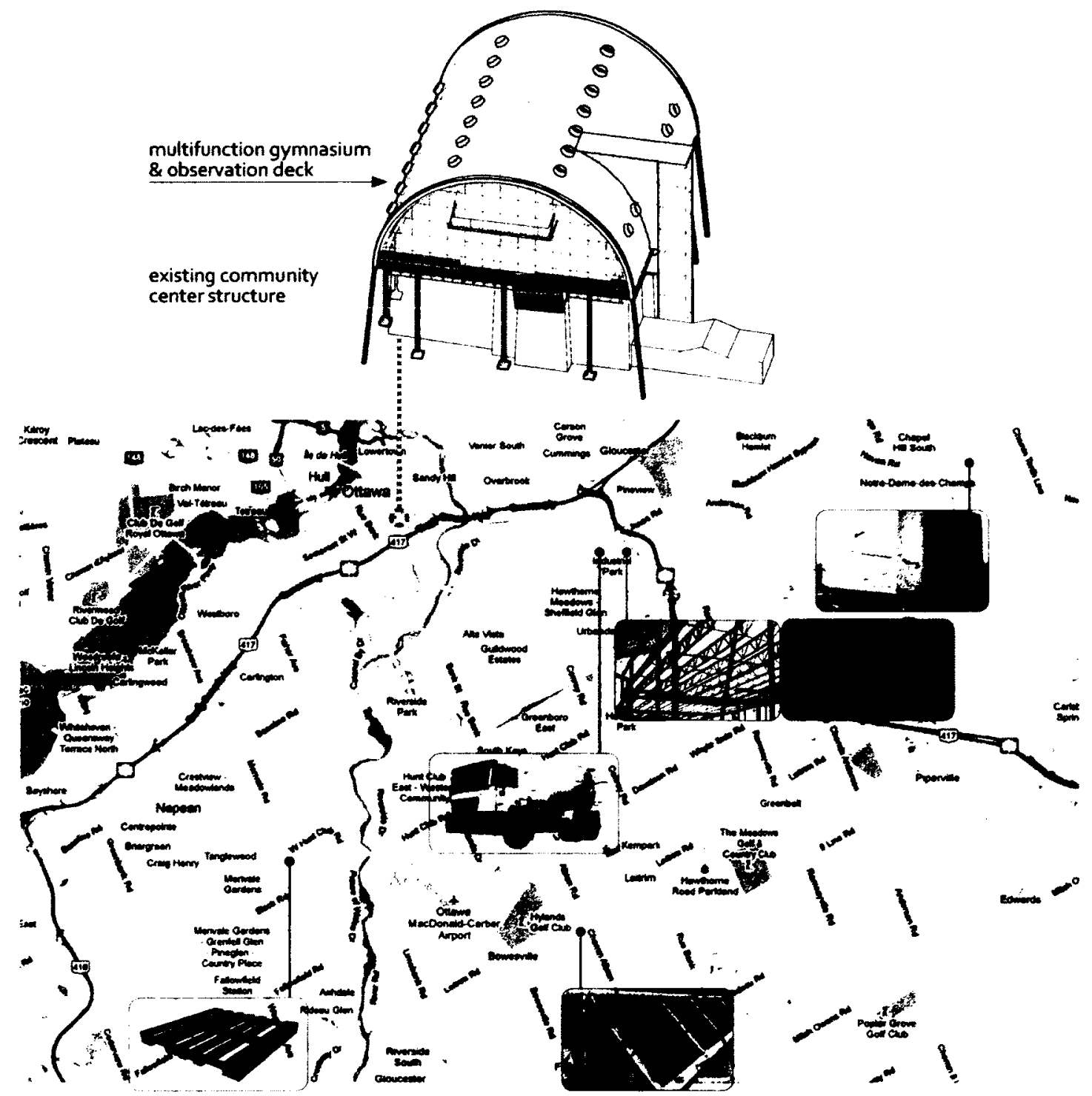




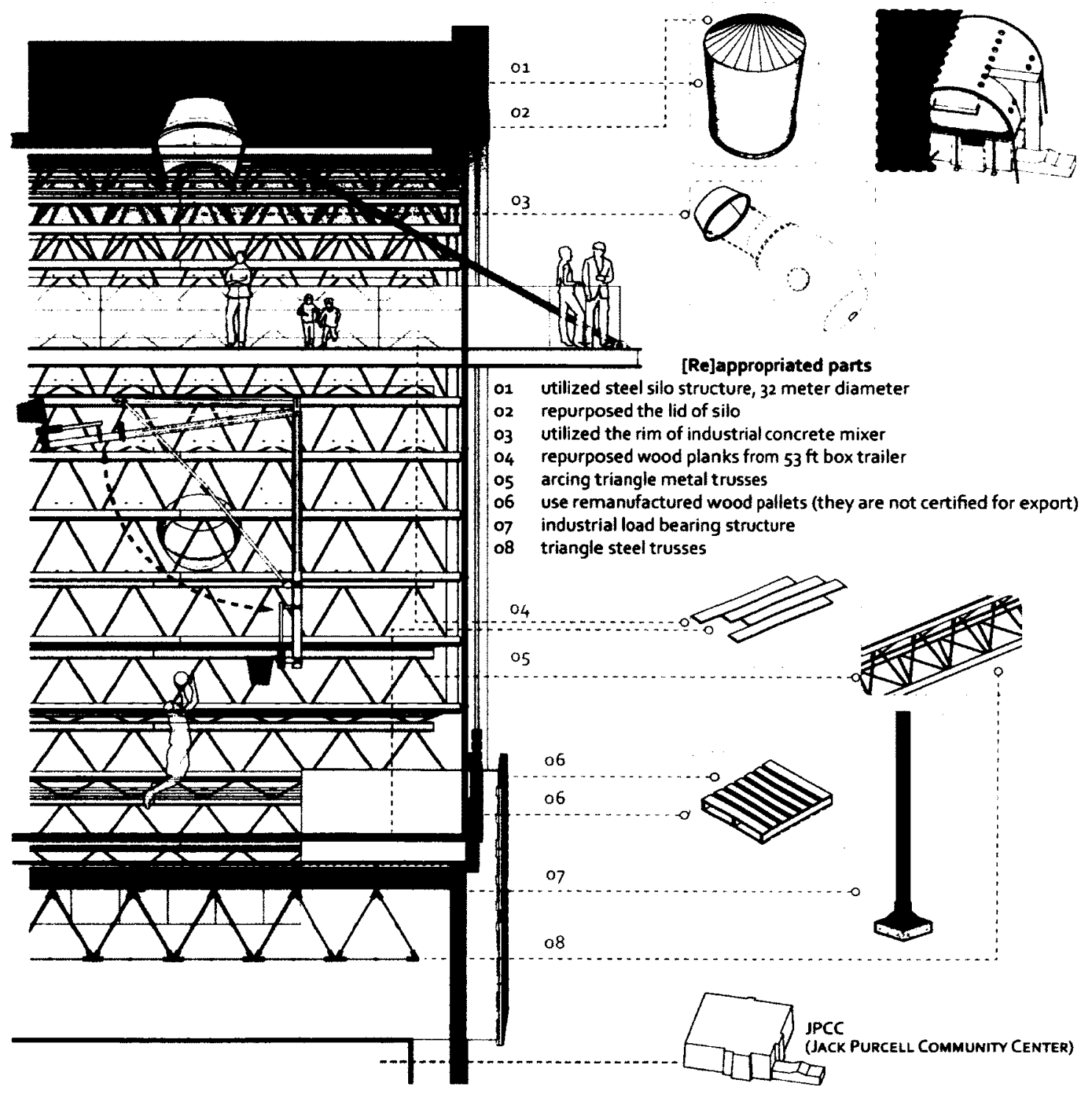




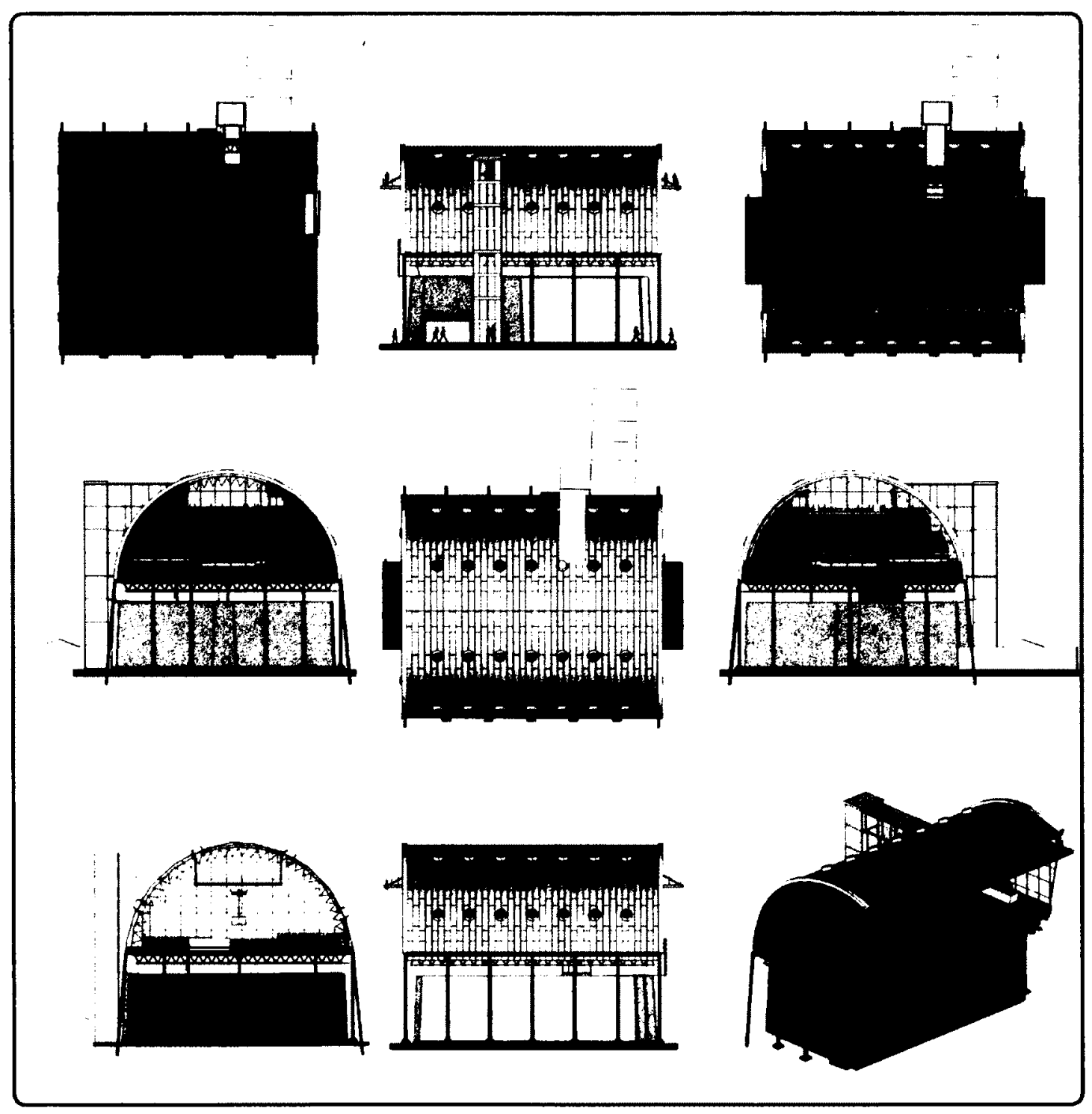




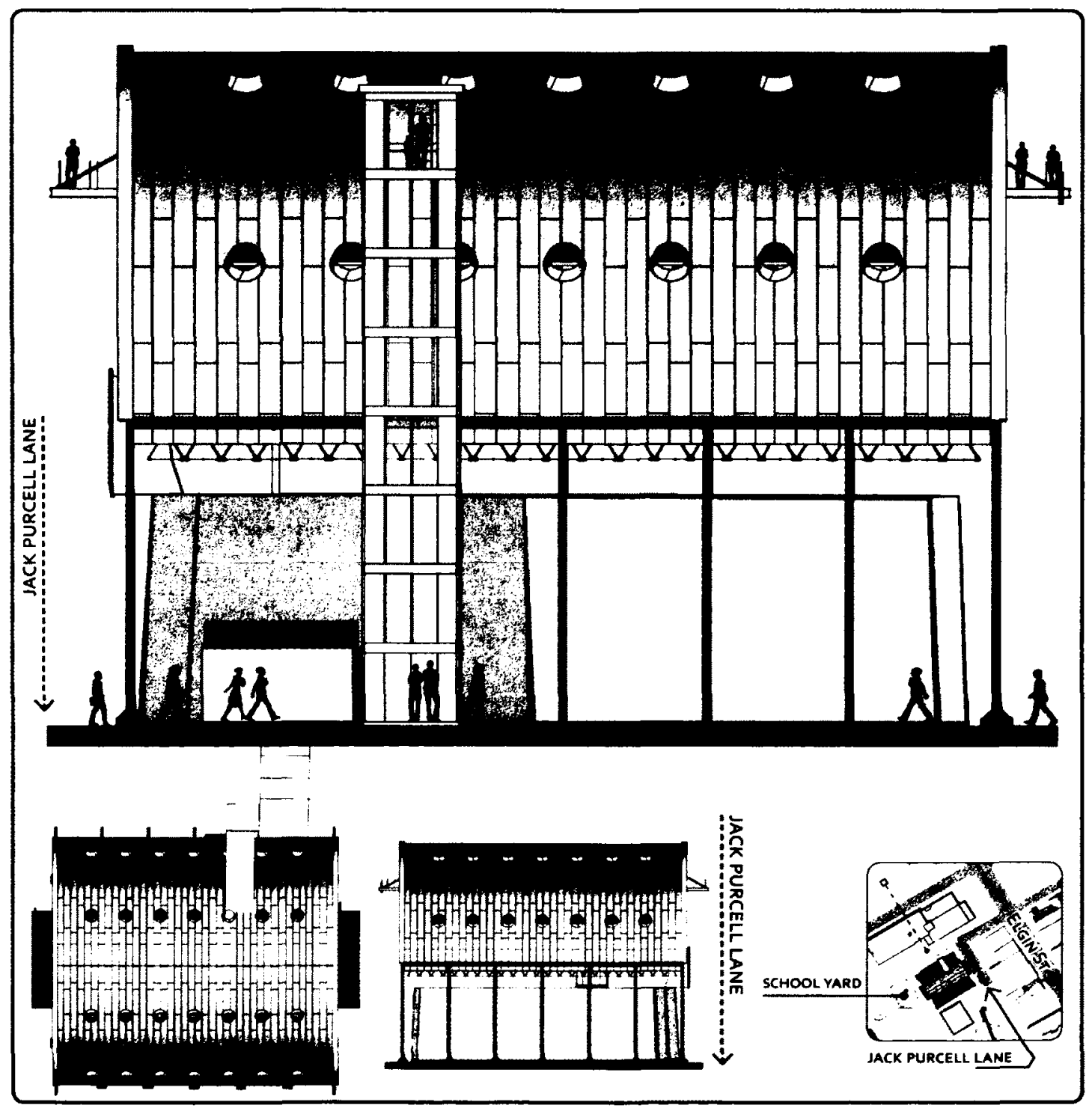




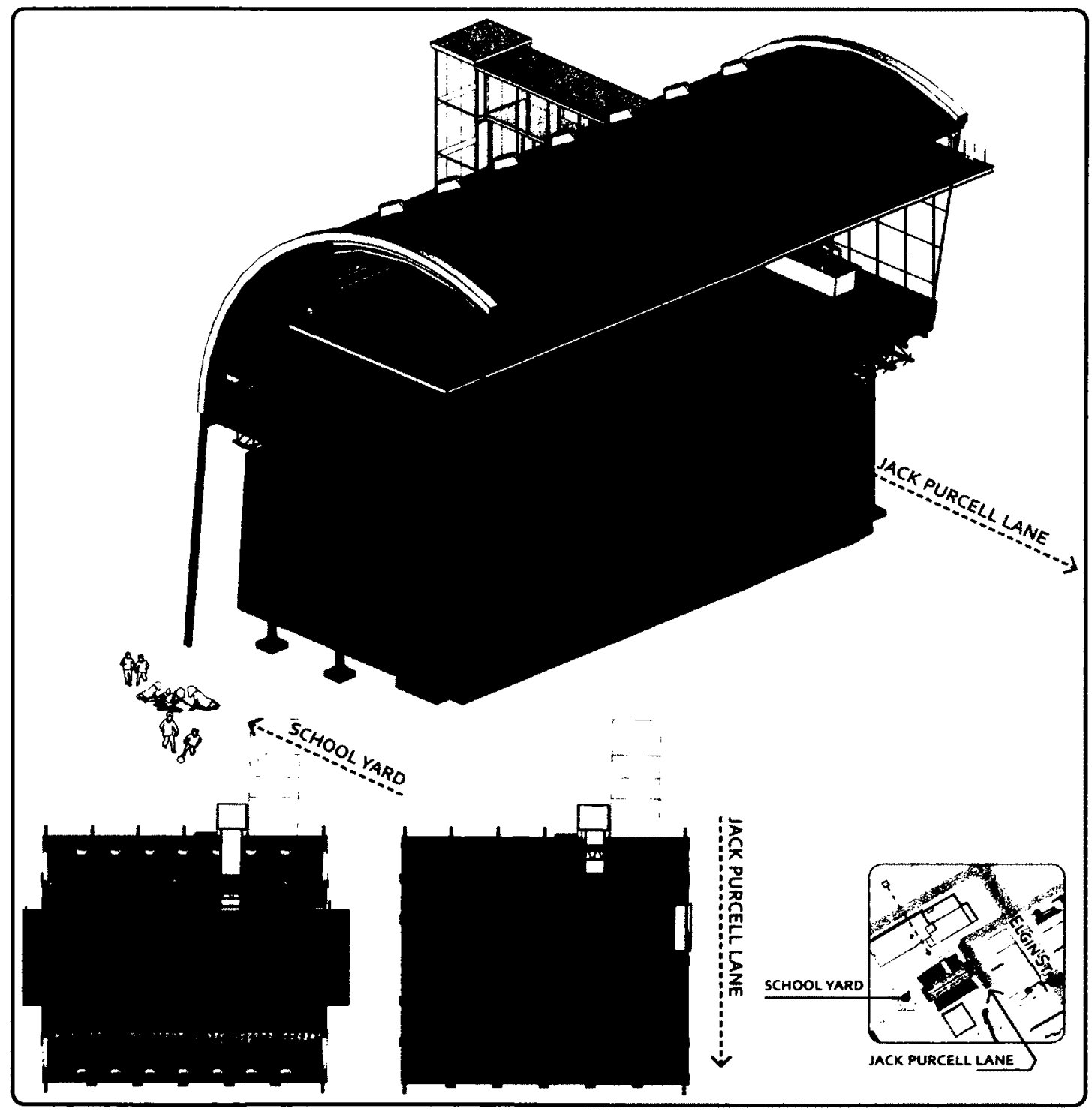




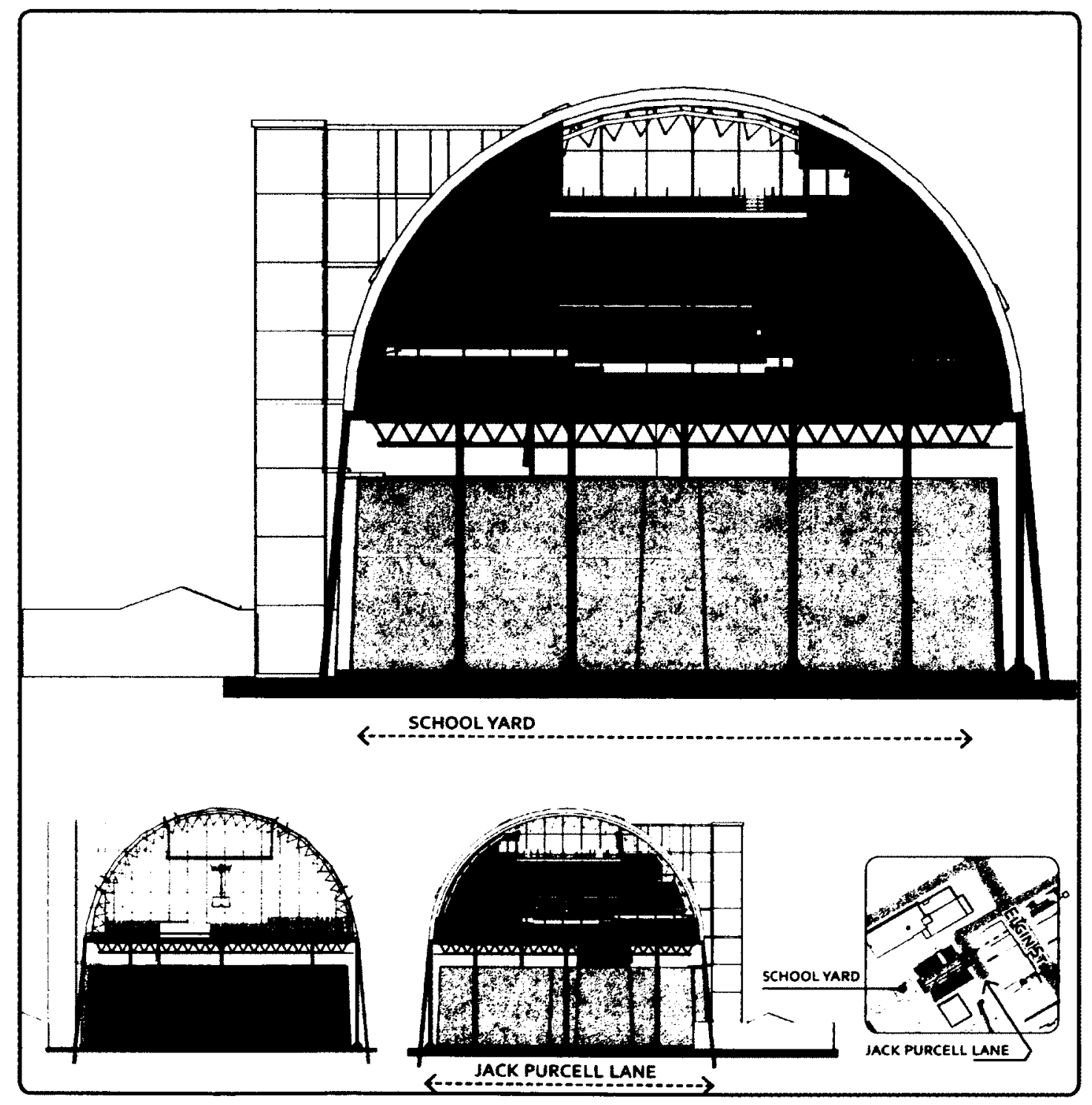




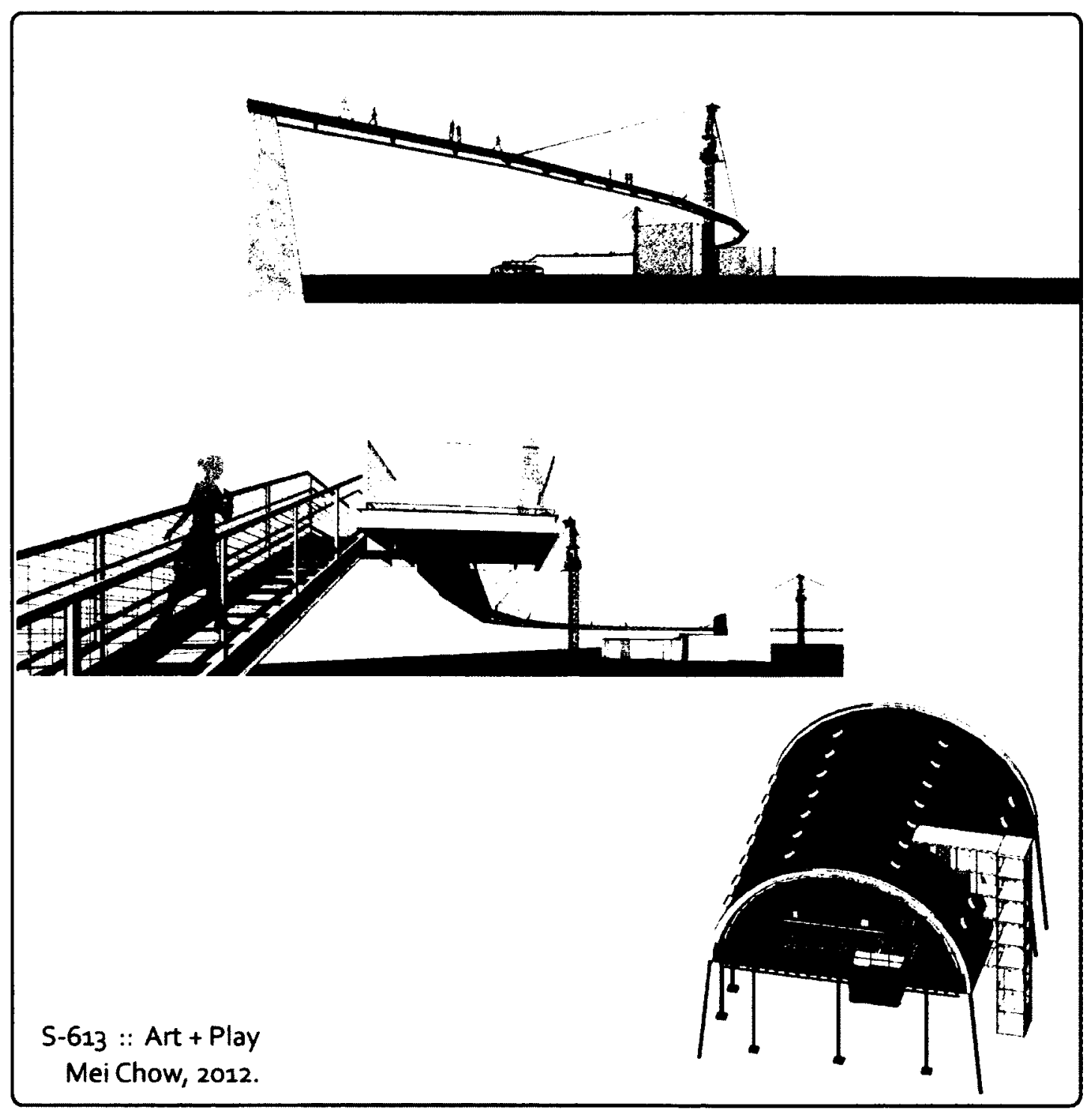




\section{Bibliography}

Chan, Chi Kau. Community Development and Management of Private Sector Housing Estates in Hong Kong. Diss. University of Hong Kong, 1995-74-88.

Claude Levi-Strauss, The Savage Mind: The nature of human seciety. Oxford University Press, 1996. 16-19.

Findley, Lisa. Building Change. Routledge. Routledge, 2005.

Jacobs, Jane. The death and life of great American cities. Vintage Books, 1992.

Jencks, Charles \& Silver, Nathan. Adhocism: the case for improvisation. New York: Doubleday \& Co., 1972.

Kossak, Florian (eds). Agency: Working with Uncertain Architectures. Taylor \& Francis, 2010. Lambot, lan. City of Darkness: Life In Kowloon Walled City. Watermark, 1993.

Lefebvre, Henri. The production of space. Wiley-Blackwell, 1991.

Mathews, Stanley. "Cedric Price as Anti-architect." In Architecture and Authorship. London: Black Dog Publishing, 2007. 142-147.

Maturana, Humberto R., Varela, Francisco J. Autopoiesis and cognition: the realization of the living. Boston: D. Reidel Pub, 1980. 78, 89.

Mauss, Marcel. The Gift: forms and functions of exchange in archaic societies. Taylor \& Francis, 1970.

McEwan, Indra Kagis. Vitruvius: Writing the Body of Architecture. MIT press, 2003.

Porter, Tom. Archispeak: an illustrated guide te architectural terms. Routledge, 2004

Sadler, Simon. Archigram: Architecture withoutArchitecture. MIT Press, 2005. 17-18.

Steele, Brett. RAMTV (eds). Negotiate my boundary!: mass-customisation and responsive environments. Basel: Birkhauser, 2006. 
Stohr, Kate. "100 Years of Humanitarian Design." In Architecture for Humanity. Design like you give a damn: architectural responses to humanitarian crisis. Ed. Architecture for Humanity. Metropolis Books, 2006. 33-53.

Till, Jeremy. Architecture depends. MIT press, 2009.

Tschumi, Bernard. Architecture and disjunction. MIT Press, 1996.

Yu, Pui Kwan. A Study on Quasi-public Space in Large Scale Private Residential Development case in Hong Kong. Diss. University of Hong Kong, 2007. 27-65. 
Journals:

"Buildings and Climate Change: Summary for Decision-Makers." United Nations Environment Program. 2009.

deconcrete. "blurring walls." Updated 05 March 2010. <http:/www.deconcrete.org/page/7/> Cited 19 April 2011.

Dimberg, U., Thunberg, M., Elmehed, K. "Unconscious Facial Reactions to Emotional Facial Expressions."

Psychological Science. 2000. <http://apsychoserver.psych.arizona.edu/JJBAReprints/PSYC501A/Readings/

Dimberg_Thunberg_Elmehed_2000_Psych_Science.pdf >

Perez-Gomez, Alberto, "Hermeneutics as Discourse in Design", Design Issues, Vol. 15 No. 2, Design Research

(Summer, 1999): 71-79.

Hess, U. \& Blairy, S. "Facial Mimicry and Emotional Contagion to Dynamic Emotional Facial Expressions and

Their Influence on Decoding Accuracy". International Journal of Psychophysiology. 2001. <http://psych. colorado.edu/ tito/sp03/7536/Hess\%26Blairy_2001.pds $\$$.

\section{Periodicals:}

Dean, Andrea Oppenheimer. Architectural Record, "Samuel Mockbee: A Life's work". June 2004.

"European Environmental Design Award". Best Ed. 1st edition. Ed. Javier Fernandez, Gloria Escribano, Trans.

Paloma Gonzalez. 2009: 14-15.

Inchingolo, Margherita Caldi. "Where recycling meet design: Essays by Saggi." Materia 2009: 56-60.

NG Update, "Wikado playground in Rotterdam". March 2009.

\section{Electronic Sources:}

2012architecten. <http://2012architecten.nl/>. Cited Nov 2011.

Chicago's Best Improv Comedy. "Weicome to the iO Theater!". <http://ioimprov.com/chicago/about>. Cited Sept 2011.

Ferino-Pagden, Sylvia. Museum, Vienna: National Gallery of Art . <http:/www.nga.gov/exhibitions/2010/ arcimboldo/arcimboldo_brochure.pdf $>.2010$.

International Association for Public Participation (IAP2). "Spectrum of Public Participation”. Updated 2007. $<$ http://www.iap2.org/associations/4748/files/LAP2\%20Spectrum_vertical.pdf >. Cited Jan 2012.

International Association for Public Participation (Canada). Updated 2011. <http://iap2canada.ca/>. Cited Nov 2011.

John Michael Kohler Art Center. "Residencies". <http://www.jmkac.info/>. Cited Oct 2011. 
Lowry, Glenn. MoMA Highlights: 325 works from The Museum of Modern Art. New York: The Museum of Modern Art, revised 2004, p. 76.

M12studio <m12studio.org $>$. Cited Oct 2011.

Project for Public Spaces. "Hall of Shame". <http:/www.pps.org/great_public_spaces/one?public_place_id=369>. Cited Feb 2012.

Quinion, Michael. "World Wide Words". Updated 2012. < http:/www.worldwidewords.org/weirdwords/ww-baf1. htm> Cited January 2012.

Smith, Riley. Celsias. Updated 14 December 2011. <http:/www.celsias.com/article/wikis-are-normally-onlinewikilane-streets-literal/>. Cited Feb 2012.

Statistics Canada, "Population of census metropolitan areas", <http://www40.statcan.gc.ca/101/cst01/>. Cited Jan 2012.

Vitruvius, Pollio. The Ten Books on Architecture. Trans. Morris Hicky Morgan. Cambridge: Harvard University Press. Press. 1914. < http://www.perseus.tufts.edu> cited November 2011.

Webster, George. CNN, "Road to Rio: Green activists paint guerrilla cycle land." Updated 01 Dec $2011<$ http:// www.cnn.com/2011/12/01/world/americas/wikilane-mexico-city/index.html>. Cited Feb 2012.

Webster's Revised Unabridged Dictionary (1913). Updated 03 February 1998. <http://www.websters-onlinedictionary.org>. Cited Oct 2011 to April 2012.

Wikipedia. "De 40 wijken van Vogelaar". Updated 23 Mar 2012. <http://nl.wikipedia.org/wiki/De_40_wijken van_Vogelaar\#De_wijken>. Trans. Cited Mar 2012. 
P35」/18 27th century boat builders. (Jencks, Charles \& Silver, Nathan. Adhocism: the case for improvisation. New York: Doubleday \& Co., 1972). 16.

P36」/19 Arcimboldo, Giuseppe. Winter, 1563. Museum, Vienna. National Gallery of Art.

P37」/20 Picasso, Pablo. Bull's head, 1942. Reunion des Musees Nationaux/Art Resource, NY.

P37 J/21 Silver, Nathan. Dining Chair, 1968. book cover. (Jencks, Charles \& Silver, Nathan. Adhocism: the case for improvisation. New York: Doubleday \& Co., 1972).

P40_//22 Chow, Mei. Ad hoc fruit stand, HengKong, 2011.

P41」/23 Gris, Juan. Breakfast, 1914. MoMA PS1. The collection. <http://www.moma.org/collection/ object.php?object_id=35572>. Cited Jan 2012.

p41_/24 Cook, Peter. Archigram. Entertainments Tower Project. Archigram. <http://archigram. westminster.ac.uk/project.php?id=52>. Cited Jan 2012.

p42_/25 Tschumi, Bernard. Sequences cinematiques, 1986. (Tschumi, Cinegramme). 13.

P42_/26 Tschumi, Bernard. Superimposition of points, lines and surfaces, 1982. (Tschumi, Cinegramme).3

p43ـ/26b Tschumi, Bernard. Ligne D'o, Promenade cinematique et Folie du spectacle, 1984. (Tschumi, Cinegramme). 15 .

p45_//27 Joynt, Tom. The Hay Bale House. Architectural Record, "Samuel Mockbee: A Life's work". June 2004 .

p52 J/28 Price, Cedric. Fun Palace, Interior perspective drawing. Canadian Centre for Architecture. Collection. <http://www.cca.qc.ca/en/collection/283-cedric-price-fun-palace>. Cited Mar 2012.

P56_//292012architecten. MSS, Miele Space Station. 2012architecten. <http://2012architecten. nl/2003/10/mss-2/>. Cited October 2011.

p59_/30 M.lK.E. - Music Integrated KioskEnvironment. M12studio. <http://m12studio.org/mike >. Cited October 2011.

p62_/31 WIKADO - Revamp the old playground condition. 2012architecten. <http://2012architecten. nl/2003/10/mss-2/>. Cited October 2011.

p65_/132 BICYCLESHED. M12studio. <http://m12studio.org/mike >. Cited October 2011. 



\section{Image source}

p12 $\lrcorner / 1$ M12studio. M.I.K.E. John Michael KohlerArts Center, Wisconsin. <http://m12studio.org/mike>. Cited Oct 2012.

p12_/12 Kowloon Walled City, 1993. HK Public Library, Hong Kong.

p13_/3 Terasawa, Kazumi 寺攞一美. Walled city section. (Large lllustrated Kowloon City 大図解 九龍 城. Japan: Iwanami Shoten 岩波輻店, 1997).

p16 $\lrcorner / 4$ Webster, George. Wikicarril, a bike lane campaign. CNN, "Road to Rio: Green activists paint guerrilla cycle land." Updated 01 Dec 2011. <http://www.cnn.com/2011/12/01/world/americas/ wikilane-mexico-cityfindex.html>. Cited Mar 2012.

P3oJ/5 Case study house \#8. (Smith, Elizabeth. Case study houses. Taschen: Mul edition, 2009). p28」/6 MMS, Miele Space Station. <http://2012architecten.nl/2003/10/mss-2/>. Cited Oct 2011.

p19_Jl7 Bicycle Shed, Coleman Center for the Arts and Culture. <http://m12studio.org/bicycle-shed>. Cited Oct 2011.

p23_J/8 Tschumi, Bernard. Superimposition montage diagrams. (Architecture and disjunction. MIT Press, 1996). 202.

P24_/19 Tschumi, Bernard. Parc de la villette vue aerienne (aerial view) diagram. (Cinegramme folie: le Parc de La Villette, Paris, dixneuvieme arrondissement. France: Champ Vallon, 1987). 10-11.

p25_/10 Tschumi, Bernard. La Case Vide, 1985. (Tschumi, Cinegramme). 25.

p27 J/11 Mei foo private housing estate, 2003. University of Hong Kong.

p28」/12 Map of LaiChi Kok park, MeiFoo estate, and Kwai Chung Road. Map. Openstreetmap. <http:// www.openstreetmap.org/>. Cited Mar 2012.

p28」/13 Chow, Mei. LaiChi Kokpark, Hong Kong. 2011.

p29J/14 Chow, Dickson. Ad hoc space in Norman Foster's HongKong \& Shanghai Bank, 2011.

p29.J14b Kathy. "The Robot Building". Updated 23 Mar 2012. <http://kathysnotesfromhongkong. blogspot.ca/>. Cited 31 Mar 2012.

P30 J/15 Superuse beok cover. (Hinte, Ed van. Peeren, Cesare. Jongert, Jan. Superuse: constructing new architecture by shortcutting material flows. 010 Publishers, 2007).

p32 J/16 Bicycle shed workshop interior, Coleman Center for the Arts and Culture. <http://m12studio. org/bicycle-sheds. Cited Oct 2011.

p32 J/17 Bicycle shed workshop exterior, Coleman Center for the Arts and Culture. <http://m12studio. org/bicycle-shed>. Cited Oct 2011. 